\title{
ANÁLISIS DEL PROGRAMA DE SANEAMIENTO FISCAL Y FINANCIERO DEL HOSPITAL DE BOSA II NIVEL - ESE, DESDE SU VIABILIDAD E IMPACTO \\ FRENTE A LAS OBLIGACIONES CONVENCIONALES Y CARGAS LABORALES
}

CLAUDIA LILIANA MORENO RAMIREZ

YANSY VIVIANA HERNANDEZ BETANCOURT

UNIVERSIDAD SANTO TOMAS DE AQUINO

MAESTRÍA EN PROTECCIÓN SOCIAL

BOGOTÁ, D.C.

2016 


\title{
ANÁLISIS DEL PROGRAMA DE SANEAMIENTO FISCAL Y FINANCIERO DEL HOSPITAL DE BOSA II NIVEL - ESE, DESDE SU VIABILIDAD E IMPACTO \\ FRENTE A LAS OBLIGACIONES CONVENCIONALES Y CARGAS LABORALES
}

\author{
CLAUDIA LILIANA MORENO RAMIREZ \\ YANSY VIVIANA HERNANDEZ BETANCOURT
}

Trabajo de grado para optar al título de Magister en Protección Social

ASESOR

EMILCE GARZÓN PEÑA

\author{
UNIVERSIDAD SANTO TOMAS DE AQUINO \\ MAESTRÍA EN PROTECCIÓN SOCIAL \\ BOGOTÁ, D.C. \\ 2016
}


Nota de aceptación

Firma del presidente del jurado

Firma del jurado

Firma del jurado

Bogotá, 4 de febrero de 2016 


\section{DEDICATORIA}

Este trabajo está dedicado a nuestros hijos Mariana y Nicolás, quienes son el motor de nuestras vidas. Nuestra inmensa gratitud a ellos por el tiempo cedido. 


\section{AGRADECIMIENTOS}

Muchas personas apoyaron la idea de realizar esta investigación, a todos ellos muchas gracias. Sin embargo, es imprescindible agradecer al Hospital Bosa II Nivel ESE y a sus trabajadores, quienes con sus vivencias y condiciones especiales, sumadas a la situación crítica de la salud en el país, nos sensibilizaron en la encrucijada de la "salud con compromiso social" "frente a el carácter financiero de las ESE de Colombia.

\footnotetext{
${ }^{1}$ Lema Hospital Bosa II Nivel ESE. $2012-2016$.
} 


\section{CONTENIDO}

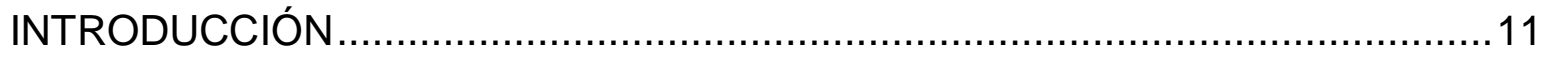

CAPITULO 1. EL MODELO DE SOSTENIBILIDAD FINANCIERA EN EL SECTOR SALUD COLOMBIANO: PROGRAMAS DE SANEAMIENTO FISCAL Y

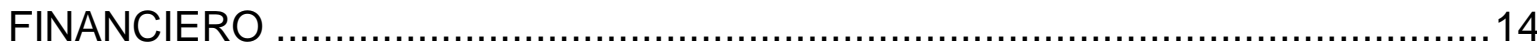

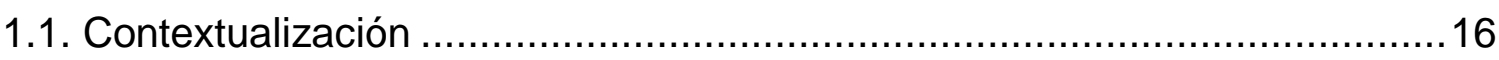

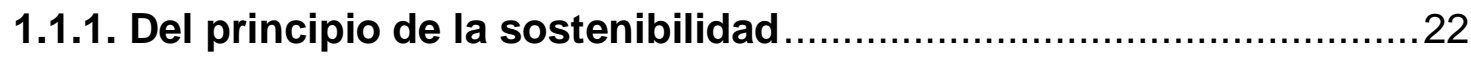

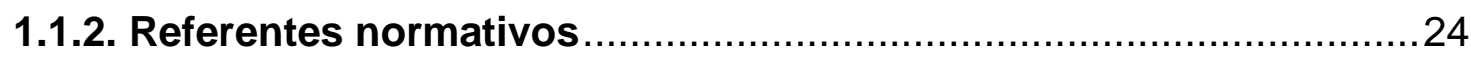

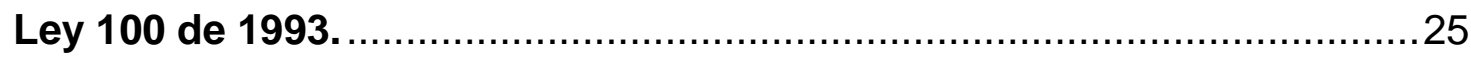

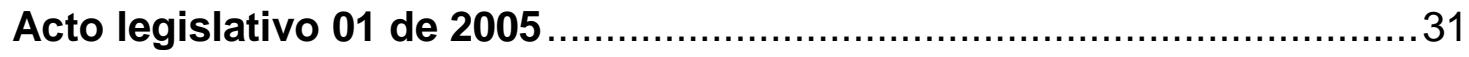

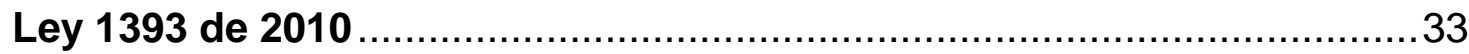

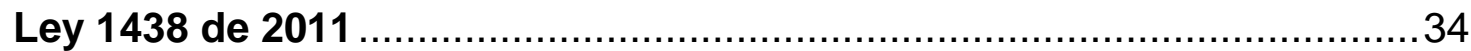

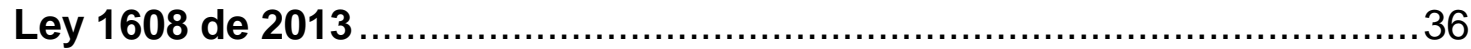

1.1.3. Rentabilidad fiscal y Financiera vs. Rentabilidad social ................37

1.2. Conceptualización de los Programas de saneamiento fiscal y financiero ...40 CAPITULO 2. PROGRAMAS DE SANEAMIENTO FISCAL Y FINANCIERO EN HOSPITALES DE II NIVEL - ESE - BOGOTA. COMPARACIÓN DE MODELOS

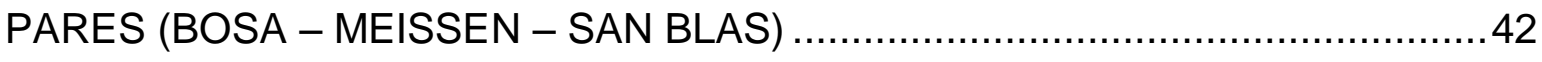

2.1. Modelos pares. Caracterización de los Programas y medidas de saneamiento fiscal y financiero de Empresas Sociales del Estado - ESE, en riesgo medio y alto .51

2.1.1 Caracterización del PSFF hospital de Meissen II nivel ESE ............51

2.1.2 Caracterización del PSFF hospital de San Blas II nivel ESE ............64 
2.1.3 Caracterización del PSFF hospital de Bosa II nivel ESE

CAPITULO 3. PROGRAMA DE SANEAMIENTO FISCAL Y FINANCIERO DEL HOSPITAL DE BOSA II NIVEL - ESE: DESDE SU VIABILIDAD E IMPACTO FRENTE A LAS OBLIGACIONES CONVENCIONALES Y CARGAS LABORALES

3.1. Programa de Saneamiento Fiscal y Financiero 2013-2017 - Hospital de Bosa II Nivel ESE .88

3.2. Los trabajadores Oficiales en el Programa de Saneamiento del Hospital de Bosa II Nivel - ESE.... 100

CONCLUSIONES 113

BIBLIOGRAFÍA. 117 


\section{LISTA DE TABLAS}

Tabla 1. Estado de deudas conforme el Minsalud ..............................................30

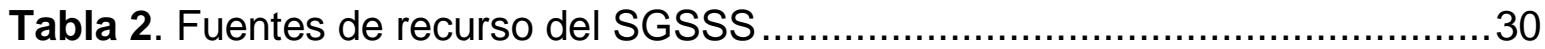

Tabla 3. Consolidado de categorización del riesgo de las ESE en Bogotá 20122015 48

Tabla 4 Portafolio de servicios prestados Hospital de Meissen II Nivel ESE .51

Tabla 5. Planta de Personal Hospital de Meissen II Nivel Ese..............................53

Tabla 6. Costos de personal vigencia 2008-2012 ..........................................63

Tabla 7. Servicios prestados por el Hospital San Blas II Nivel ESE ......................65

Tabla 8. Planta de personal del Hospital de San Blas II Nivel ESE ......................65

Tabla 9. Proyección de Vacantes 2014-2017. Hospital San Blas II Nivel ESE......72

Tabla 10. Oferta de servicios Hospital de Bosa II Nivel ESE .............................80

Tabla 12. Medidas planteadas en el programa de saneamiento fiscal y financiero

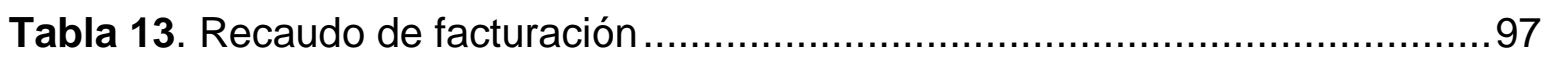

Tabla 14. Plan cargos 2015. Hospital Bosa II Nivel - ESE ................................105

Tabla 15 Déficit histórico generado en la operación corriente (en millones de pesos). 


\section{LISTA DE GRÁFICAS}

Gráfica 1. Diagrama Funcional. Sistema General de Seguridad Social Integral ...20

Gráfica 2. Flujo de recursos del sistema de salud. 21

Gráfica 3. SGSSS - Ley 100 de 1993. 26

Gráfica 4. Categorización de ESE de Bogotá, en riesgo medio y alto, vigencia 2012-2013 46

Gráfica 5 Variación de los costos totales de funcionamiento Hospital de Meissen periodo 2008-2012

Gráfica 6 Variación de los costos de funcionamiento Hospital de Meissen periodo 2008-2012. .62

Gráfica 7 Ingresos por facturación Hospital de Meissen 2008-2012...................64 Gráfica 8 Composición de gastos Hospital San Blas 2008-2013 Fuente (Hospital San Blas II Nlvel, 2013) .75

Gráfica 9 Costos generados por servicios Hospital San Blas periodo 2008-2013 76 Gráfica 10 Valores mensuales de los costos de personal Hospital San Blas .77 Gráfica 11 Variación en los gastos de personal Hospital San Blas periodo 20102012.

Gráfica 12 Ingresos por facturación Hospital de Meissen periodo 2008-2013 ......78 Gráfica 13. Población atendida por el Hospital de Bosa II Nivel ESE. 2008-2012 81 


\section{RESUMEN}

En la ejecución del servicio público de la salud en Colombia, la implementación de los Programas de Saneamiento Fiscal y Financiero - PSFF-, se convierten en procesos complejos donde convergen elementos de tipo económico, social, político y técnico de gran relevancia, los cuales exigen análisis de fondo, en aras de comprender los alcances, impactos y consecuencias del desarrollo del principio de sostenibilidad.

Es desde esta perspectiva que en la presente investigación se retoma el caso del Hospital de Bosa II Nivel ESE, con el fin de corroborar el proceso de implementación del PSFF, frente a los temas de viabilidad e impacto en torno a las obligaciones convencionales y cargas laborales pactadas entre el Estado (empleador) y los trabajadores oficiales de la Red Pública de Hospitales, visibilizando las contradicciones entre los postulados económicos y los compromisos de derecho y responsabilidad social. 


\section{INTRODUCCIÓN}

La Ley 1438 de 2011, estableció el proceso de adopción de los Programas de Saneamiento Fiscal y Financiero - PSFF- para las Empresas Sociales del Estado ESE. Conforme la normativa, se parte de la "determinación del riesgo" desde parámetros de mercado, equilibrio y viabilidad a partir de indicadores financieros, con el fin de procurar una verificación de la situación económica de las entidades, para categorizarlas en niveles de riesgo alto, medio o bajo, lo que implica la obligación de "someterse a un programa de saneamiento." (Ley 1438, 2011)

En el año 2013, el Ministerio de Salud y Protección Social mediante la Resolución 1877, dió a conocer la categorización del riesgo de las ESE a nivel territorial, asignando al Hospital de Bosa - II Nivel, la categoría de "en riesgo medio", razón por la cual la entidad se vió en la necesidad de asumir nuevas medidas para mejorar su liquidez y el uso de algunos recursos del sector salud. (Resolución 1877, 2013)

La entidad hospitalaria conforme la Ley 1608 de 2013, procedió a adoptar un PSFF bajo las condiciones emitidas por el gobierno nacional, tomando como base los criterios de: a) Reorganización administrativa, b) Racionalización del gasto, c) Restructuración de la deuda, d) Saneamiento de pasivos y e) Fortalecimiento de los ingresos, todo en aras de permitir una adecuada operación, con miras a garantizar el acceso, oportunidad, continuidad y calidad en la prestación de los servicios de salud de la población usuaria. (Ley 1608, 2013)

Sin embargo, al momento de proceder a la implementación del PFSS, se evidencia una serie de limitaciones para el cumplimiento de las medidas, en particular en lo tocante a la "Racionalización del Gasto" y el "Fortalecimiento de ingresos", esto en 
razón a los acuerdos y pactos suscritos entre el Hospital de Bosa y sus trabajadores oficiales, contenidos en la Convención Colectiva vigente, donde se fortalecen las garantías salariales y prestacionales de este tipo de trabajadores de la Red Pública de hospitales del Distrito Capital. (ESE - SINTRASALUD - AGRECONDUCTORES - SINDISTRITALES, 1995 - 2016)

Esta situación llevó a plantear la siguiente pregunta de investigación ¿Pueden las ESE lograr la implementación de los Programas de Saneamiento Fiscal y Financiero y soportar al mismo tiempo las cargas impuestas por los mandatos normativos laborales y por la Convención Colectiva vigente?

Bajo esta óptica, la investigación se centró en el análisis del PSFF propuesto para el Hospital de Bosa II Nivel ESE, haciendo énfasis en las medidas dirigidas a racionalizar el gasto y fortalecer los ingresos, con el objetivo de visibilizar los impactos y consecuencias que trae la incorporación de medidas de orden económico, en una entidad centrada en el servicio social de la salud. De esta forma, se revisa de forma particular la contradicción que se suscita al pretender establecer un modelo de hospital rentable, frente a las obligaciones económicas contraídas por la entidad en la Convención Colectiva vigente, suscrita entre las ESE adscritas a la Secretaria Distrital de Salud y el sector de los Trabajadores Oficiales.

El trabajo investigativo se circunscribe a un proceso teórico - documental, basado en herramientas cualitativas y cuantitativas, que permitan obtener como resultado un análisis pertinente del PSFF del Hospital de Bosa II Nivel - ESE, desde aspectos basados en la viabilidad e impacto sociolaboral, en aras de comprender las limitaciones y posibles alternativas para una efectiva ejecución y cumplimiento del plan. 
De esta forma el presente documento se estructura en tres apartados. En el primero, se revisan los aspectos fundamentales del modelo de sostenibilidad financiera, desde su estructura teórica, jurídica y administrativa, con el fin de desentrañar la propuesta de solidez económica y financiera en el servicio público de salud, a partir de la implementación de los PSFF, para las ESE catalogadas en riesgo alto y medio.

En un segundo momento, Se describe el PSFF del Hospital de Bosa II Nivel - ESE, en correlación con los Programas de los Hospitales pares (catalogados en riesgo medio/alto de la Red Pública del Distrito Capital) de Meissen y San Blas, en aras de visibilizar sus estrategias de mejora a nivel económico y financiero.

En el tercer acápite, se analiza de forma particular el caso del Hospital de Bosa II Nivel - ESE, haciendo énfasis en las estrategias proyectadas en el plan de: i)Racionalización del Gasto y ii) Fortalecimiento de ingresos, partiendo de la medida de "financiamiento parcial del gasto generado por la operación de los Trabajadores Oficiales con recursos del PSFF", situación que implica estudiar a fondo las condiciones de protección de los Trabajadores Oficiales convencionados y sus garantías protegidas a través de la Convención Colectiva Vigente, todo ello con miras a visibilizar las posibles alternativas jurídicas, técnicas, económicas y políticas para lograr la implementación del PSFF desde postulados de equilibrio social, pero a la vez económico. 


\section{CAPITULO 1. EL MODELO DE SOSTENIBILIDAD FINANCIERA EN EL SECTOR SALUD COLOMBIANO: PROGRAMAS DE SANEAMIENTO FISCAL Y FINANCIERO}

El actual Sistema de Seguridad Social Integral en Colombia -SSSI, establecido a partir de la reforma incorporada por la ley 100 de 1993, buscó estructurar el conjunto de instituciones, normas y procedimientos, de que disponen la persona y la comunidad, para garantizar sus derechos irrenunciables en pro de obtener la calidad de vida acorde con la dignidad humana, mediante la protección de las contingencias que la afecten. (Legis, 2013, pág. 19) Así, se articularon el Sistema General de Pensiones, el Sistema General de Seguridad Social en Salud - SGSSS, el Sistema General de Riesgos Laborales y los Servicios Sociales Complementarios. La Seguridad Social se consolidó de esta forma, como un servicio público obligatorio, cuya dirección, coordinación y control se mantuvo en cabeza del Estado colombiano, pero con la innovación de permitir que fuera prestado por entidades públicas o instituciones privadas, con lo que se modificaba el anterior esquema de un sistema netamente gubernamental.

EI SSSI se solidificó a partir de seis principios fundamentales, eficiencia, universalidad, solidaridad, integralidad, unidad y participación, como ejes de esta nueva organización que desde un esquema de vinculación de diferentes actores e instituciones propendió por:

1. Garantizar las prestaciones económicas y de salud a quienes tienen una relación laboral o capacidad económica suficiente para afiliarse al sistema.

2. Garantizar la prestación de los servicios sociales complementarios establecidos por la ley. 
3. Garantizar la ampliación de cobertura hasta lograr que toda la población acceda al sistema. (Legis, 2013, pág. 20)

De esta forma, el SSSI se convirtió en una organización de actores, instituciones, recursos e infraestructura de gran envergadura, que si bien trajo avances en cuanto a cobertura del aseguramiento, acceso a los servicios, equidad y protección financiera, aun presenta serios limitantes en cuanto al flujo y a la transparencia de recursos públicos destinados específicamente al sector salud y a la legitimidad del sistema. (Banco Interamericano de Desarrollo, 2015, pág. 2) Esto ha traído serias crisis y fuertes reparos, los cuales han dado origen a variadas propuestas en pro de una verdadera reforma que propenda por cristalizar el cumplimiento de los principios base de los subsistemas y el sostenimiento de los mismos.

La amplitud del tema, hace que resulte prudente para el abordaje analítico partir de un fraccionamiento del sistema a partir de sus subsistemas, en aras de lograr la comprensión de los mismos, desde sus propias complejidades. Desde esta perspectiva, la presente investigación se centra en el subsistema de la Seguridad Social en Salud, revisando específicamente el proceso de sostenibilidad financiera del mismo, desde el análisis de los Programa de Saneamiento Fiscal y Financiero dirigido a las Empresas Sociales del Estado -ESE -, como estrategia de restablecimiento de la "solidez económica y financiera de estas Empresas, con el propósito de asegurar la continuidad en la prestación del servicio público de salud." (Ley 1608, 2013, pág. 6)

Es así, como en el presente apartado se presenta de forma general la organización del SISSS, en aras de especificar sus características básicas, enfocando el objeto de estudio de la investigación que se centra en las categorías de Sostenibilidad 
Financiera y Programas de Saneamiento Fiscal y Financiero - PSFF, como punto de partida para el abordaje especifico del caso del Hospital de Bosa II Nivel ESE, en su calidad de Empresa Social del Estado adscrita a la Secretaría Distrital de Salud, quien en la actualidad desarrolla su PSFF, bajo una dinámica de racionalización del gasto y fortalecimiento de ingresos.

\subsection{Contextualización}

Sistema General de Seguridad Social en Salud - SGSSS, está constituido por el conjunto de entidades públicas y privadas, la normatividad y procedimientos correspondientes a garantizar el servicio público esencial de la salud a toda la población colombiana. Su objetivo principal consiste en regular el servicio y crear las condiciones de acceso a la población en todos los niveles de atención. (Legis, 2013, pág. 131)

EI SGSSS se compone de dos regímenes que coexisten articuladamente, ellos son:

1. El Contributivo. Al cual debe estar afiliada la población laboral del país.

2. El Subsidiado. Donde está afiliada la población que no puede sufragar el costo total o la parte del costo del servicio.

Todos los afiliados al sistema tienen como mínimo un plan integral de protección de la salud, el cual ha sido denominado Plan Obligatorio de Salud - POS-, que se compone de:

1. Atención preventiva

2. Médico - quirúrgica

3. Medicamentos esenciales 
La estructura del SGSSS está basada en 21 principios, los cuales dan fundamentación conforme a la lógica de un servicio público esencial. Ellos son:

1. Universalidad. Cubrimiento a toda la población residente en el país en todas las etapas de la vida.

2. Solidaridad. Apoyo y garantía de acceso y sostenibilidad.

3. Igualdad. Garantía sin discriminación.

4. Obligatoriedad. Afiliación obligatoria.

5. Prevalencia de derechos. Protección a la maternidad y a los derechos de la infancia y la adolescencia.

6. Enfoque diferencial. Reconocimiento de poblaciones con características particulares.

7. Equidad. Entre el acceso al plan de beneficios y las prestaciones individuales, sin poner en riesgo los recursos necesarios para la atención de toda la población.

8. Calidad. Atención integral, segura, oportuna y humanizada.

9. Eficiencia. Optima relación entre los recursos disponibles para obtener los mejores resultados.

10.Participación social. Intervención de la comunidad en: organización, control, gestión y fiscalización. 
11. Progresividad. Gradualidad en la actualización de las prestaciones incluidas en el plan de beneficios.

12. Libre escogencia. Entre las promotoras de salud y los prestadores de servicios dentro de su red.

13. Sostenibilidad. Las prestaciones que reconoce el sistema se financiaran con los recursos destinados por la ley para tal fin, los cuales deberán tener un flujo ágil y expedito. Las decisiones que se adopten en el marco del sistema deben consultar criterios de sostenibilidad fiscal. La administración de los fondos no podrá afectar el flujo de recursos del mismo.

14. Transparencia. Condiciones públicas, claras y visibles.

15. Descentralización administrativa. Organización descentralizada compuesta por direcciones territoriales.

16. Complementariedad y concurrencia. Los actores del sistema desde sus distintos niveles territoriales se complementan en acciones y recursos.

17. Corresponsabilidad. Autocuidado. Fomento a los deberes de solidaridad, participación y colaboración.

18. Irrenunciabilidad. No se puede renunciar a este derecho ni total ni parcialmente.

19. Intersectorialidad. Acción conjunta y coordinada de los diferentes sectores y organizaciones. 
20. Prevención. Enfoque de precaución en: gestión del riesgo, evaluación de procedimientos y prestación de servicios.

21. Continuidad. Vocación de permanencia y no se debe en principio ser separado del mismo cuando esté en peligro la calidad de vida e integridad. (Legis, 2013)

Es desde esta disposición de principios, instituciones, actores y recursos que se consolida un sistema complejo en pro de dar atención adecuada del servicio público de salud en el país.

A continuación se presenta un breve diagrama funcional del sistema: 


\section{SISTEMA DE SEGURIDAD SOCIAL INTEGRAL - SSSI}

\begin{tabular}{|l|}
\hline Sector \\
Privado: \\
EPS \\
IPS \\
\hline
\end{tabular}

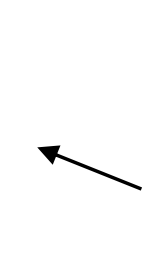

\section{Sector}

público:

Direcciones

Seccionales

Distritales

Locales

IPS Públicas

EPS

ESE (Decreto

1876 de 1994)

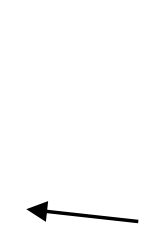

SISTEMA GENERAL DE SEGURIDAD SOCIAL EN SALUD - SGSSS
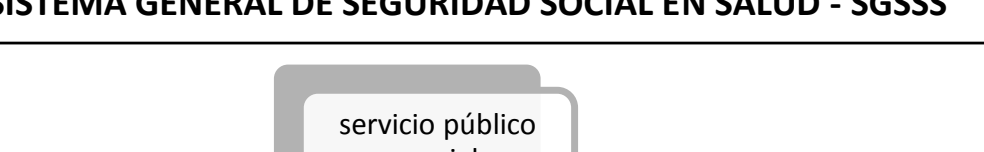

esencial y

obligatorio de

salud
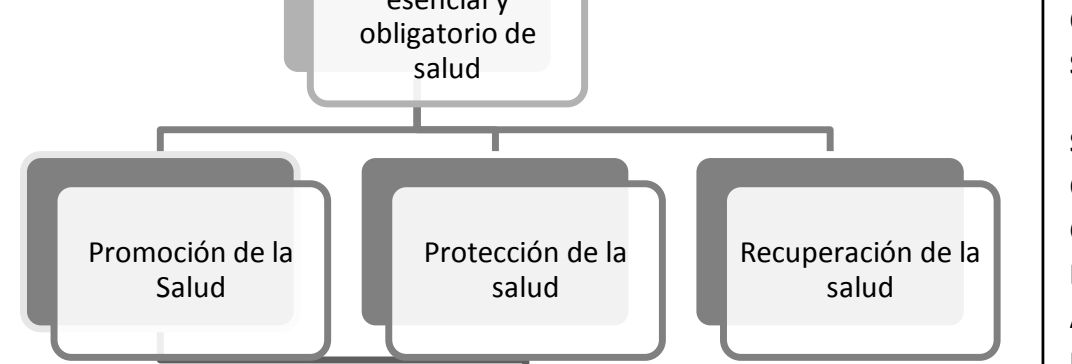

Organización descentralizada. (Direcciones seccionales / distritales / locales

Régimen contributivo. Vinculación a través del pago de una cotización individual o familiar o un aporte económico financiado.

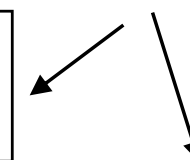

Régimen

subsidiado.

Vinculación a través del pago total o parcial de una

Fondo de solidaridad y garantía en salud - FOSYGA

Cuenta adscrita al Ministerio de Salud que tiene por objeto garantizar que la solidaridad del sistema funcione y llegue a todos los niveles de la población.

\section{SISTEMA GENERAL DE RIESGOS LABORALES} unidad de pago por capitación subsidiada con recursos fiscales o de solidaridad.

\begin{tabular}{|l|} 
S \\
E \\
R \\
V \\
I \\
C \\
I \\
O \\
S \\
S \\
O \\
C \\
I \\
A \\
L \\
E \\
S \\
C \\
O \\
M \\
P \\
L \\
E \\
M \\
E \\
N \\
T \\
A \\
R \\
I \\
O \\
S \\
\hline
\end{tabular}

Fuente: (Garzón, 2014).

Cada sistema articula instituciones, actores, acciones, recursos y principios, en pro de generar un régimen integral que corresponda con el cumplimiento constitucional 
de la Seguridad Social para todos. En el caso del subsistema de salud, el funcionamiento articulado del modelo contributivo y subsidiado, desde la participación pública y privada, se solidifica bajo una postura financiera, donde prima la idea de un servicio sostenible ligada al tema de mercado.

De allí, que el tema del funcionamiento y gestión de recursos resulte fundamental dentro de la presentación general del subsistema.

\section{Gráfica 2. Flujo de recursos del sistema de salud}

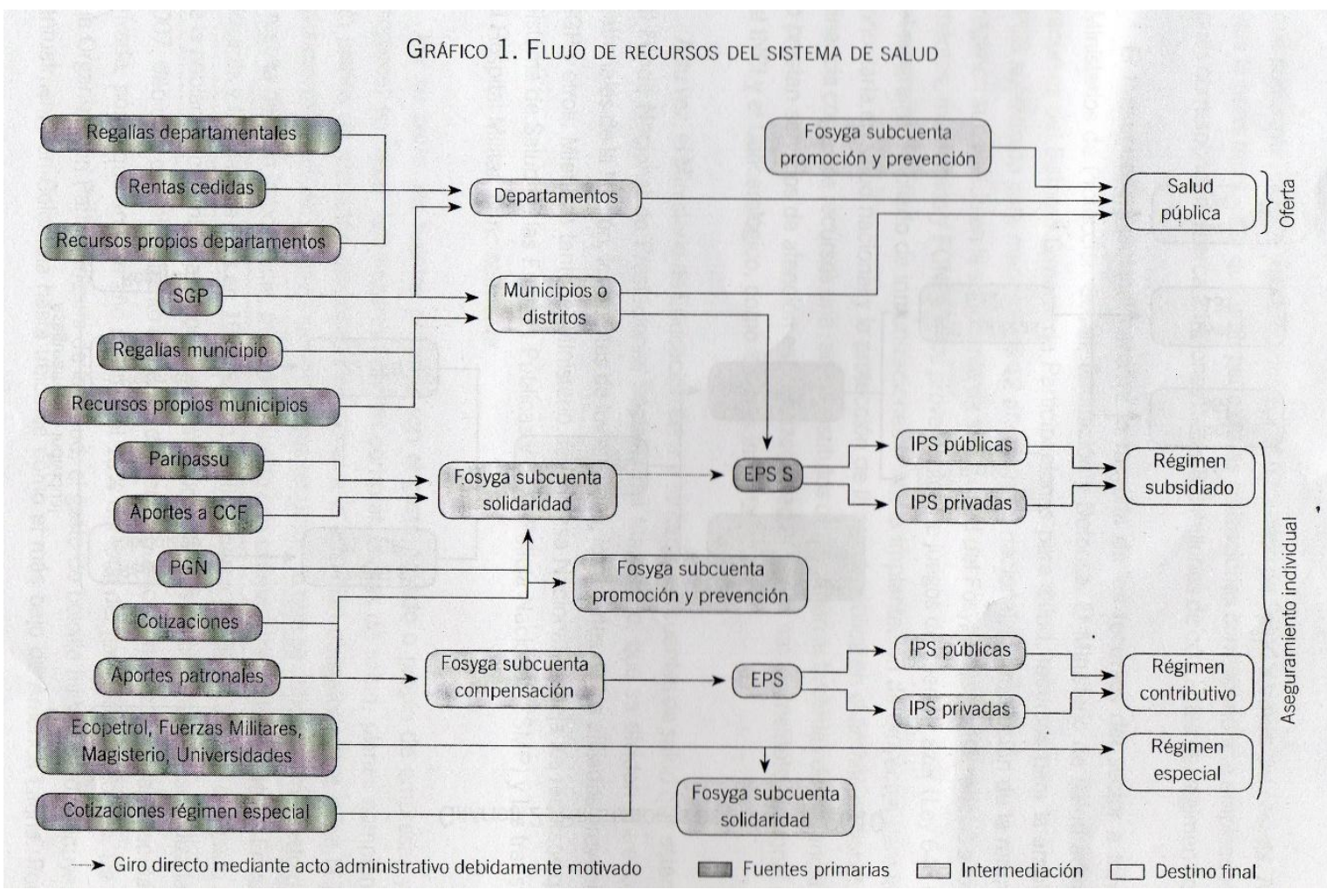

Fuente: (Núñez, Zapata, Castañeda, Fonseca , \& Ramírez, 2012, pág. 15) 
A partir de esta descripción básica del sistema, se procede a analizar el principio de sostenibilidad, en consideración a que es desde allí que se articulan los Programas de Saneamiento Fiscal y Financiero como estrategias de ajuste del sistema, que se convierte en el punto central de abordaje de la investigación.

\subsubsection{Del principio de la sostenibilidad}

A partir de la década de 1990 el sector de la salud en Colombia sufrió una transformación radical, que rompió con la visión de "oferta de la salud", para insertarse en un nuevo enfoque que estaría basado en los procesos de "demanda". Es así, que se procede a la creación de nuevas entidades promotoras de salud (EPS) y se modifican los hospitales públicos y privados en instituciones prestadoras de salud (IPS), todo bajo la figura del aseguramiento y la participación activa de los privados en el manejo de recursos, bajo postulados de mejorar la gestión y de forma particular, de aumentar la cobertura, punto principal de lo que fuera la reforma en su momento.

Hoy por hoy, los resultados muestran algunos logros en cuanto a cobertura, pero la calidad, cumplimiento y eficacia han quedado entre dicho frente a la real garantía del derecho a la salud en el país. Esto ha generado una crisis muy aguda, planteándose en la actualidad la necesidad de una nueva reforma que cumpla con la protección de la salud de los colombianos. Instituciones tan importantes como la Asociación Colombiana para la Exigibilidad del Derecho a la Salud y la Seguridad Social - SALUD AL DERECHO-, exponen que,

"Si las cifras oficiales en cuanto al aumento en cobertura en aseguramiento fueran ciertas, podríamos decir que esto es un logro. 
Desafortunadamente, aseguramiento no significa que el derecho a la salud se esté garantizando, en cuanto sólo cubre determinados riesgos. El modelo actual es INVIABLE porque se soporta económicamente en los aportes derivados del empleo formal, pero el contexto económico colombiano es el desempleo y de incremento de la informalidad del trabajo. En otras palabras, no hay posibilidad de aumentar significativamente el aseguramiento individual." (Salud al Derecho, 2007, pág. 11)

Así mismo, se reprende el papel de las aseguradoras del régimen contributivo y subsidiado en la prestación del servicio, en cuanto a su actividad como intermediarios, el manejo de los recursos, la prioridad latente por una alta rentabilidad y la falta de un sistema de información y base de datos unificado, que permita una real verificación de cuentas, vigilancia y control.

De esta forma se ha puesto en entredicho el subsistema y a su vez, su sostenibilidad financiera, que si bien se puede concebir como un principio fundamental dentro del modelo de aseguramiento, en razón a su contenido como elemento dirigido a los recursos destinados por la ley, bajo la óptica de un flujo ágil y expedito, desde criterios de sostenibilidad fiscal, ha entrado en contradicción con el cumplimiento del derecho a la salud, en un enfrentamiento entre los postulados económicos y los sociales. Tal es así que desde análisis gubernamentales se ha afirmado que:

"Hay problemas estructurales del sistema de salud que han avanzado y no han sido atendidos oportunamente, lo que ha generado un impacto creciente que hoy amenaza la viabilidad financiera del SGSSS; quizás el más importante esta no actualización periódica, oportuna y adecuada 
del Plan Obligatorio de Salud (POS). Por tal razón, se ha dado un crecimiento progresivo y desmedido de las prestaciones y servicios No POS que han sido asumidas por las EPS -principalmente las del régimen contributivo- y recobradas parcialmente al Fosyga. En otras palabras, el POS se congeló pero la demanda por servicio siguió creciendo sin que las autoridades lo advirtieran. Hay que recordar que en el 2010 el valor de las prestaciones y servicios No POS de las EPS del régimen contributivo superó los $\$ 2,4$ billones, cerca de 120 veces más que ocho años atrás. Este es un factor crítico que contribuye en gran parte a la grave crisis financiera y que ha puesto en dude la sostenibilidad financiera de las EPS del contributivo desde el año 2009 en adelante." (Núñez, Zapata, Castañeda, Fonseca , \& Ramírez, 2012, págs. 8-9)

Se reconoce desde la institucionalidad, que el problema se ha concentrado en "ajustar el actual modelo de aseguramiento, pues el país carece de opciones serias o modelos alternos diferentes a asumir directamente el aseguramiento de toda la población colombiana (...) lo cual no proporcionaría ventajas sobre el modelo actual." Estas premisas han llevado al gobierno nacional a plantear formas alternas de solución al problema de la sostenibilidad, incentivando herramientas jurídicas de manejo y gestión del recurso, tal como se plantea en las leyes 1438 de 2011 y 1608 de 2013.

\subsubsection{Referentes normativos}

Para reconocer y comprender la figura de la sostenibilidad financiera en el sector de la salud, resulta necesario remontarse a las pautas establecidas en la Ley 100 de 
1993, para luego, comprender su desarrollo desde los postulados del Acto Legislativo 01 de 2005, en correspondencia con el paquete jurídico de los años 2010 y 2011 con las leyes 1393 de 2010 y 1438 de 2011, que serán la base jurídica de la ley 1608 de 2013, relativa a la proyección de medidas para mejorar la liquidez y el uso de los recursos del sector.

\section{Ley 100 de 1993.}

La reforma al Sistema de Seguridad Social tiene como base jurídica la ley 100 del año 1993, por la cual se creó el Sistema Seguridad Social Integral - SSSI. Será desde allí, que se articularan los diferentes principios, acciones, actores y políticas que darán fundamento al cambio de mentalidad en torno al funcionamiento de la Seguridad Social.

En el caso particular del SGSSS, este se concibe desde la protección individual de los ciudadanos y modifica la idea del subsidio público a la oferta, por la postura del subsidio público a la demanda, bajo tres principios fundamentales que son: Equidad, solidaridad y universalidad. Así se organiza desde el gobierno nacional un modelo donde se vinculan recursos públicos con los privados desde elementos propios del aseguramiento. 
Gráfica 3. SGSSS - Ley 100 de 1993

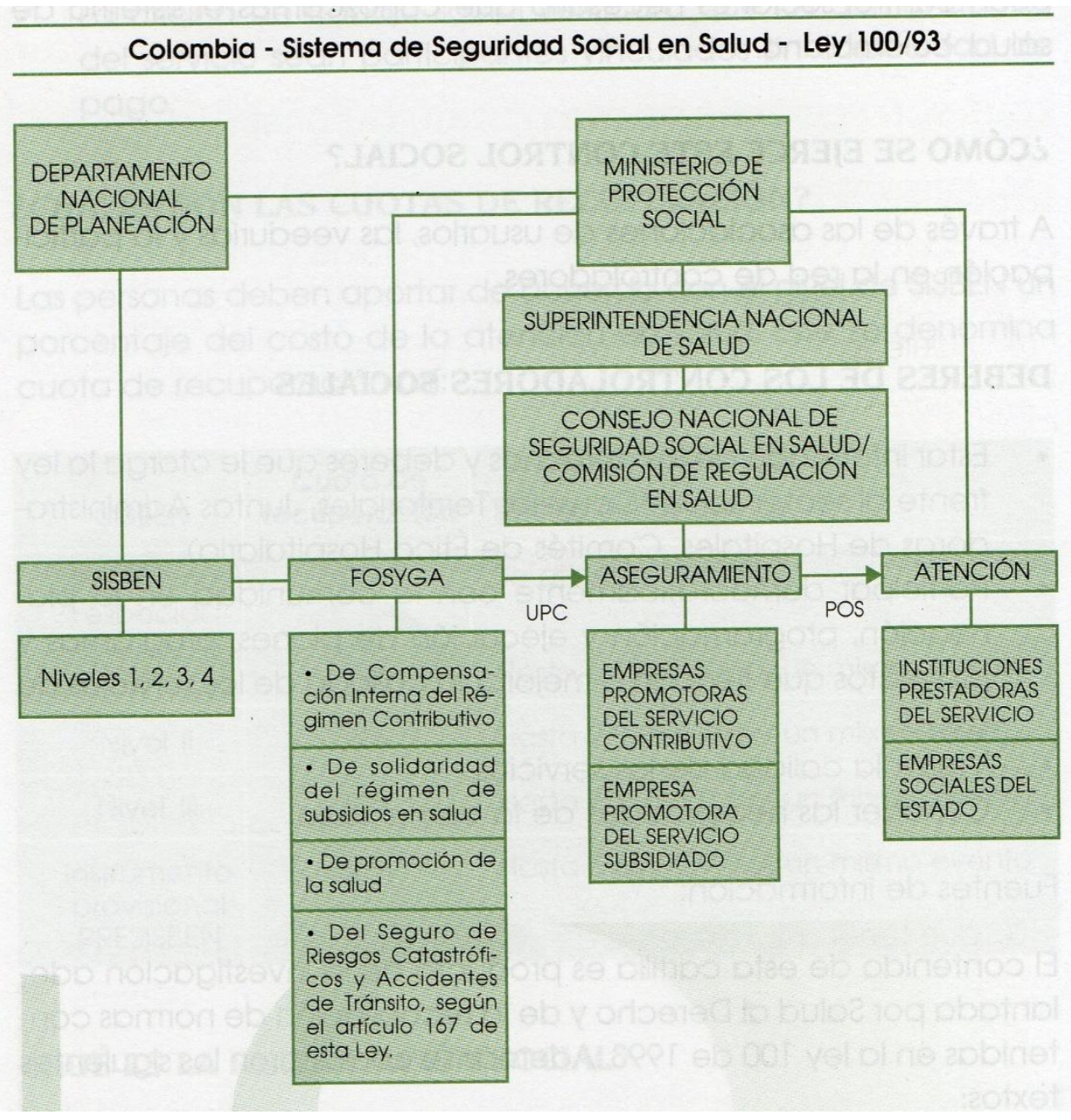

Fuente: (Salud al Derecho, 2009, pág. 46)

La administración y financiación del sistema conforme la ley, se inscribe en los siguientes ejes centrales:

1. Conformación del sistema general de seguridad social en salud. Coexisten articuladamente, para su financiamiento y administración, 
un régimen contributivo de salud y un régimen de subsidios en salud, con vinculaciones mediante el fondo de solidaridad y garantías.

2. Creación y operación del fondo. Una cuenta adscrita al Ministerio de Salud que se manejará por encargo fiduciario, sin personería jurídica ni planta de personal propia, de conformidad con lo establecido en el estatuto general de la contratación de la administración pública de que trata el artículo 150 de la Constitución Política. El consejo nacional de seguridad social en salud determinará los criterios de utilización y distribución de sus recursos.

3. Financiación de los hospitales públicos. Reciben aportes de la Nación y/o de las entidades territoriales. De acuerdo al programa de conversión gradual, las direcciones seccionales, distritales y locales de salud garantizarán la celebración de contratos de compra-venta de servicios con los hospitales para atender la población que se les asigne o con las entidades promotoras de salud, sin perjuicio de lo dispuesto en la Ley 10 de 1990 y en la Ley 60 de 1993. (Ley 100, 1993)

Bajo esta estrategia de aseguramiento la idea de la salud cambia y se inscribe en un modelo de mercado, el cual ha sido duramente criticado frente a lo que se concibe como el derecho a la salud.

"Bajo el principio constitucional del derecho a la seguridad social, la ley 100 de 1993 da fundamentación legal a un proceso de instauración y fortalecimiento del mercado de los servicios de salud, que se presenta desde un lenguaje de participación, donde el tema de la privatización resulta velado tras el énfasis que se le hace a categorías como las de garantización de servicios, estimulación de la participación, ayuda mutua, sana competencia, integralidad en la prestación de los servicios de salud, intervención de la comunidad, entre otros, consolidando en sí 
el concepto de salud como un servicio de compra y venta, que garantiza un bienestar individual antes que colectivo, por lo que queda a la voluntad del cliente, ya no paciente, escoger "libremente" el servicio que más le convenga, desde esta lógica, el que le permita escoger su capacidad económica para alcanzar el objetivo máximo pregonado por la ley de calidad, cobertura y eficiencia." (Naranjo \& Garzón Peña, 2010, pág. 87)

La discusión frente a la sostenibilidad del sistema ha llevado a replantearlo desde todos sus aspectos, y hoy por hoy se discute más que un modelo sostenible, para pensar en la verdadera protección de la salud de los colombianos ante la latente crisis que ha dejado en evidencia hechos tales como:

- El déficit operacional de los hospitales públicos, conforme datos de la Superintendencia Nacional de Salud SNS, alcanzó en 2012 los \$160.591 millones de pesos.

- La cartera de las Instituciones Prestadoras de Servicios de Salud (IPS), para el año 2015 superaba los 12 billones de pesos.

- Se generó en las últimas décadas un "aumento sostenido en las tutelas en salud", pasando de 21.301 en 1999 a 142.957 en 2008. (Guzman Finol, 2014, pág. 1)

- La mayor parte de porcentaje de recursos asignados al servicio de salud han sido gastados en la intermediación, que se consolidará a partir de la ley 100.

- Aunque el gasto público para salud ha incrementado anualmente, (para el año 1993 la inversión equivalía al 4,2\% del producto interno bruto nacional, 4,2 billones de pesos, en 1997 ascendió a 10,1\% y en 2002 a 8,5\% lo que equivalió a 13.9 billones de pesos) la recuperación de costos se ha realizado de forma desigual. (Salud al Derecho, 2007) 
- Por su parte, el gobierno nacional consolidó una serie de estrategias con miras a salvaguardar la sostenibilidad del sistema y garantizar el acceso a los afiliados. Es así como a través de la ley 1450 de 2011, se estableció que para el caso en que las entidades territoriales adeudaran recursos del régimen subsidiado a las Entidades Promotoras de Salud, por contratos realizados hasta marzo 31 de 2011, se procediera a descontar de los recursos asignados a los municipios por el Sistema General de Participaciones de Propósito General de Libre Inversión, Regalías, Por el Fondo de Ahorro y Estabilidad Petrolera (FAEP) u otras fuentes municipales de disposición en el nivel nacional. Esta ley fue reglamentada a su vez, por el Decreto 1080 de 2012.

- Así mismo, la ley 1608 de 2013 autorizó al Ministerio de Salud y Protección, para emplear por una sola vez recursos del FOSYGA hasta un monto de $\$ 150.000$. millones, para que las entidades territoriales del orden municipal (categoría 4,5 y 6) atendieran las deudas reconocidas del Régimen Subsidiado de Salud. Sin embargo, los recursos asignados se deben restituir en un plazo de máximo 10 años, a través del incremento de la cofinanciación del Régimen Subsidiado de Salud. Así el Ministerio procedió a una asignación de $\$ 110.719$ millones a 206 entidades territoriales.

Conforme el Ministerio de Salud a 31 de marzo de 2014, la situación de deudas era la siguiente: 
Tabla 1. Estado de deudas conforme el Minsalud

Tabla 61 . Estado de Deudas

Millones de pesos

\begin{tabular}{|r|r|r|r|l|}
\hline $\begin{array}{l}\text { Deuda } \\
\text { Reconocida } \\
\text { No Pagada* }\end{array}$ & $\begin{array}{l}\text { Recursos de } \\
\text { Asignación } \\
\text { FOSYGA }\end{array}$ & $\begin{array}{l}\text { Desahorro } \\
\text { Del FAEP }\end{array}$ & $\begin{array}{l}\text { Recursos del } \\
\text { SGP libre } \\
\text { inversión } \\
\text { enero- marzo }\end{array}$ & $\begin{array}{l}\text { Deuda } \\
\text { pendiente de } \\
\text { Pago }\end{array}$ \\
\hline 313.315 & 110.719 & 30.680 & 8.460 & 163.456 \\
\hline
\end{tabular}

Fuente: Dirección de Financiamiento Sectorial. Ministerio de Salud y Protección Social.

*Las entidades territoriales han informado un valor pagado de la deuda por un monto de $\$ 7.531$ millones.

Fuente: (Ministerio de Salud y Protección Social, 2014, pág. 116)

Es importante indicar que el SGSSS se financia con recursos fiscales y parafiscales, pero además, en aras de darle salida a la crisis se han implementado diversas formas de financiación, que bajo leyes y decretos ajustan el proceso determinado en la Ley 100.

Tabla 2. Fuentes de recurso del SGSSS

Tabla 68. Fuentes de recursos del SGSSS, 2012-2013

(Millones de pesos constantes, 2013=100)

\begin{tabular}{|l|r|r|}
\hline Fuentes & \multicolumn{1}{|c|}{$\mathbf{2 0 1 2}$} & $\mathbf{2 0 1 3}$ \\
\hline Cotizaciones & 16.593 .468 & 18.932 .048 \\
\hline Otros Ingresos Incluye Rendimientos Financieros & 1.124 .576 & 456.029 \\
\hline Cajas de Compensación Familiar & 361.616 & 561.711 \\
\hline Sistema General de Participaciones & 6.097 .472 & 6.371 .988 \\
\hline Rentas Cedidas y recursos territoriales (Ley 1393 de 2010) & 1.404 .888 & 1.437 .112 \\
\hline Subcuenta ECAT (SOAT) - FOSYGA & 907.687 & 927.636 \\
\hline Subcuenta de Garantías para la Salud (Ley 1438 de 2011) & 131.785 & 292.565 \\
\hline Excedentes Financieros FOSYGA & 2.915 .521 & 4.317 .816 \\
\hline Regalías & 221.442 & - \\
\hline Otros Recursos Territoriales - Régimen Subsidiado & 83.957 & 78.651 \\
\hline Recursos de la Nación (Ley 1393 de 2010) & 918.755 & 792.426 \\
\hline $\begin{array}{l}\text { Aportes de la Nación Sub. Solidaridad FOSYGA - Incluida } \\
\text { Compensación de Regalías }\end{array}$ & 1.533 .807 & 1.279 .622 \\
\hline Total fuentes del SGSSS & $\mathbf{3 2 . 2 9 4 . 9 7 4}$ & $\mathbf{3 5 . 4 4 7 . 6 0 4}$ \\
\hline
\end{tabular}

Fuente: Presupuesto FOSYGA, Presupuesto Dirección Administración de Fondos de la Estadística MSPS, Formulario Único Territorial - FUT

Fuente: (Ministerio de Salud y Protección Social, 2014) 
Si bien se está en el proceso de discusión y reforma del sistema, en el año 2015 se promulgó la Ley Estatutaria 1751, por medio de la cual se reguló el derecho fundamental a la salud, partiendo del objetivo de garantizar el "derecho fundamental a la salud", regularlo y establecer mecanismos de protección. Si bien, esta normativa parte del reconocimiento de la salud como derecho, es importante indicar que principios como el de Sostenibilidad se mantienen intactos tal cual fueron establecidos en la Ley 100 y esto se verifica, cuando en el artículo 6, literal i) se describe:

"El Estado dispondrá, por los medios que la ley estime apropiados, los recursos necesarios y suficientes para asegurar progresivamente el goce efectivo del derecho fundamental a la salud, de conformidad con las normas constitucionales de sostenibilidad fiscal." (Ley Estatutaria 1751, 2015)

Es desde esta panorámica que se revalidan los postulados de la Ley 100 de 1993, teniendo como eje central el modelo de mercado, antes que los derechos, aun así se esté cambiando el lenguaje de servicio público a derecho fundamental.

\section{Acto legislativo 01 de 2005}

En correspondencia con la Ley 100 de 1993, el Acto Legislativo 01 de 2005, procedió a adicionar al artículo 48 de la Constitución los siguientes puntos relativos a la sostenibilidad del Sistema de Seguridad Social, quedando así: 
ARTICULO 48. Se garantiza a todos los habitantes el derecho irrenunciable a la Seguridad Social. El Estado, con la participación de los particulares, ampliará progresivamente la cobertura de la Seguridad Social que comprenderá la prestación de los servicios en la forma que determine la Ley. La Seguridad Social podrá ser prestada por entidades públicas o privadas, de conformidad con la ley. No se podrán destinar ni utilizar los recursos de las instituciones de la Seguridad Social para fines diferentes a ella. La ley definirá los medios para que los recursos destinados a pensiones mantengan su poder adquisitivo constante.

\section{Texto adicionado:}

"El Estado garantizará los derechos, la sostenibilidad financiera del Sistema Pensional, respetará los derechos adquiridos con arreglo a la ley y asumirá el pago de la deuda pensional que de acuerdo con la ley esté a su cargo. Las leyes en materia pensional que se expidan con posterioridad a la entrada en vigencia de este acto legislativo, deberán asegurar la sostenibilidad financiera de lo establecido en ellas (...) La Seguridad Social es un servicio público de carácter obligatorio que se prestará bajo la dirección, coordinación y control del Estado, en sujeción a los principios de eficiencia, universalidad y solidaridad, en los términos que establezca la Ley." (Acto Legislativo 01, 2005)

El Acto Legislativo se convierte en un mandato en torno a la obligación de promover la sostenibilidad financiera del sistema. Si bien se centra en el subsistema de Pensiones, al hacer este parte del gran sistema de seguridad social, se interrelaciona con el de salud, y de allí, que la postura gubernamental sea la de proveer por todos los medios la sostenibilidad del mismo. 


\section{Ley 1393 de 2010}

Mediante la normativa, el gobierno nacional se dio a la tarea de redireccionar recursos, estableciendo rentas de destinación específica para la salud y promoviendo actividades generadoras de recursos, que evitaran la evasión y elusión de aportes a la salud. Para ello se tiene en cuenta los recursos provenientes de la venta de licores, juegos de suerte y azar, cigarrillos y tabacos y el régimen parafiscal.

De forma particular, se destaca en esta ley, la destinación de recursos a los entes territoriales en pro del fortalecimiento de la red pública hospitalaria.

"Artículo 35. Recursos territoriales para el fortalecimiento de la red pública hospitalaria y para otros gastos en salud. Una vez se inicie la implementación del plan de transformación, hasta el 30\% de la totalidad de los recursos de rentas cedidas que por ley se destinan a salud en la respectiva entidad territorial, se aplicarán al saneamiento de las deudas por prestaciones de servicios de salud, registradas en los estados financieros de las entidades territoriales a 31 de diciembre de 2009, no financiadas a la fecha de expedición de la presente ley; para la inversión en infraestructura y renovación tecnológica de la red pública hospitalaria, de acuerdo con el estudio de red de servicios de cada entidad territorial; para programas de salud pública, de acuerdo con el Plan Nacional de Salud Pública; para efectos de cofinanciar la operación de las Empresas Sociales del Estado que por sus condiciones de mercado, constituyan un único oferente de servicios de salud en su área de influencia; y para la unificación del plan obligatorio de salud del Régimen Subsidiado al Contributivo." (Ley 1393 , 2010) 
Este tipo de normas se orientó a la sostenibilidad del sistema desde puntos específicos de intervención del gobierno, en aras de la destinación de recursos.

\section{Ley 1438 de 2011}

La norma en un ejercicio de reforma al SGSSS, promovió el fortalecimiento de este desde la concepción de un modelo de prestación del servicio público en salud que en el marco de la estrategia de Atención Primaria en Salud permitiera la acción coordinada del Estado, las instituciones y la sociedad, bajo parámetros de mejoramiento de la salud y creación de un ambiente sano y saludable, desde un servicio pensado desde con calidad, inclusión y equidad, tomando como centro y objetivo los residentes en el país. (Ley 1438, 2011)

Es así como desde el panorama de la sostenibilidad financiera del sistema y en el marco de la crisis de la red hospitalaria, que se visibilizara en el año 2010, se buscó mediante la Ley establecer un modelo de riesgos y clasificar a quienes debían intervenir. De allí, se definió un estándar de riesgo financiero para los 1050 hospitales que operaban como Empresas sociales del Estado. ${ }^{2}$

"Estas se clasificarán de acuerdo a la reglamentación que expida el Ministerio de la Protección Social en las categorías alto, medio, bajo y sin riesgo. Esta categorización del riesgo de las Empresas Sociales del Estado la realiza el Ministerio teniendo en cuenta sus condiciones de mercado, de equilibrio y viabilidad a partir de sus indicadores

\footnotetext{
${ }^{2}$ Las Empresas Sociales del Estado constituyen una categoría especial de entidad pública, descentralizada, con personería jurídica, patrimonio propio y autonomía administrativa, creadas o reorganizadas por ley o por las asambleas o concejos. El objetivo de las Empresas Sociales del Estado es la prestación de servicio de salud, entendidos como un servicio público a cargo del Estado y como parte integrante del Sistema de Seguridad Social en Salud. (Decreto 1876, 1994)
} 
financieros. Este año el Ministerio reportó 323 Empresas Sociales del Estado del nivel territorial que se encontraban en riesgo alto en 2012 y que continuarán en 2013 con igual categorización, por disposición de la resolución número 2509 de 2012. El departamento con mayores entidades en riesgo alto es Antioquia con 41, seguido de Santander con 34; Bolívar con 32; Cundinamarca 25 y Magdalena 21." (Revista Opinión\&Salud.com, 2013)

El Programa de Fortalecimiento de Hospitales Públicos, desde lo concebido como Empresas Sociales del Estado, partió de la constitución de un fondo con recursos del Presupuesto Nacional que permitiera desarrollar un Plan de Inversiones para fortalecer su capacidad instalada y modernizar su gestión con énfasis en el primero y segundo nivel de atención. Se determinó en el articulado, el trabajo en red y la muestra de "buenos resultados" en torno a indicadores de salud, bajo riesgo fiscal y financiero y documentación de los procesos de calidad, para acceder a créditos condonables y otros estímulos para dotación tecnológica y capacitación del talento humano.

Se plantearon estrategias para saneamiento de cartera, pasivos prestacionales y financiación del servicio en zonas alejadas, así como el saneamiento de aportes patronales. Así mismo, se planteó la determinación del riesgo de las ESE y la obligatoriedad de la adopción de los Programas de Saneamiento Fiscal y Financiero, para aquellas que fueran categorizadas en riesgo medio o alto, con la indicación de quienes no llegaran a cumplirlo se verían intervenidos por la Superintendencia Nacional de Salud. 
Finalmente se establecieron recursos mediante créditos para el rediseño, modernización y reorganización de los hospitales de la red pública para desarrollo de las redes territoriales de prestación de servicios de salud, desde el modelo de créditos condonables.

Esta norma a partir de todas sus estrategias obligó a quienes se determinaron en riesgo medio y alto a iniciar sus procesos de diseño y promoción de los Programas de Saneamiento Fiscal y Financiero, los cuales serían reconcebidos a partir de la ley 1608 de 2013.

\section{Ley 1608 de 2013}

Mediante esta importante normativa se adoptaron las medidas para mejorar la liquidez y el uso de algunos recursos del Sector Salud, para ello se tomó como punto de partida definir las medidas para mejorar el flujo de recursos y la liquidez del sector a través del uso de saldos o excedentes de cuentas maestras del Régimen Subsidiado de Salud, aportes patronales y rentas cedidas, definiendo mecanismos para el financiamiento de las deudas reconocidas del Régimen Subsidiado de Salud por las entidades territoriales en el marco de lo señalado en el artículo 275 de la Ley 1450 de $2011 .^{3}$

Además, se estableció dentro del proceso de saneamiento fiscal y financiero, la figura del programa, entendido este como un proceso "integral, institucional, financiero y administrativo que cubre la Empresa Social del Estado, en aras de

\footnotetext{
${ }^{3}$ Corresponde al Plan Nacional de Desarrollo, 2010-2014.
} 
restablecer su solidez económica y financiera, con el propósito de asegurar la continuidad en la prestación del servicio público de salud.

Este compendio de normativas soportan el proceso de saneamiento del sistema y brindan las herramientas pertinentes para consolidar la figura de los Programas de Saneamiento Fiscal y Financiero desde el orden jurídico nacional.

\subsubsection{Rentabilidad fiscal y Financiera vs. Rentabilidad social}

En el ejercicio del proceso de análisis del PSFF del Hospital de Bosa II Nivel ESE, se hace necesario entender la tensión que existen entre la obligación de mantener una entidad bajo parámetros de rentabilidad fiscal y financiera, y a la vez, cumplir con el papel de entidades garantes de la salud de la población del país. Es por ello que se realizar a continuación una breve parametrización de la situación actual de las entidades de salud, en aras de comprender su complejidad.

El proceso se remonta a las medidas implementadas a partir de la década de 1990, cuando se producen cambios transcendentales tras la incorporación del modelo neoliberal, bajo la perspectiva de la globalización. Bajo esta nueva tendencia, las naciones son entendidas en una nueva forma de relación ligada al "flujo de mercancías, inversiones, producción y tecnología", dejando atrás la idea "reducida" del Estado - Nación, desde una idea de crecimiento económico basado en los flujos internacionales de capital, mercancías y tecnología. (Petras, 2001) Así, se rompe con la idea del bienestar y el Estado cambia sus dinámicas de desarrollo.

Si bien durante la primera mitad del siglo XX, se había construido un modelo de protección, basado en la consolidación de garantías y seguridades para los ciudadanos, lo que daba cuenta de las grandes luchas sociales y laborales del mundo, es a partir de la nueva visión de "aldea global", de aquella interrelación entre 
países, donde el mercado fue más allá de las fronteras, que se inicia un proceso marcado por la influencia de las grandes corporaciones, dejando atrás el antiguo "poderío" del Estado.

Es así, que las políticas y recomendaciones del Fondo Monetario Internacional y los postulados del Consenso de Washington (1989), en concordancia con lo dispuesto por el Banco Mundial y la Organización Mundial del Comercio, determinaran las bases primarias de ese nuevo modelo neoliberal, que marcará el derrotero no solo económico sino político de los llamados países del "tercer mundo".

En cuanto al Consenso de Washington, un decálogo de medidas económicas propuestas para "juzgar la actuación de los países y facilitar la acción de los organismos económicos y financieros internacionales" (Gandarilla Salgado, 2003), se puede desatacar la obligatoriedad de sus políticas, las cuales aplicarían los países, mediante paquetes normativos de carácter obligatorio. Dichos postulados se resumen en:

"Disciplina presupuestaria, cambio de prioridades en el gasto público, reforma fiscal hacia bases imponibles amplias, liberalización financiera, tipos de cambio competitivos, liberalización comercial, apertura a las inversiones extranjeras, privatización de los sectores públicos, desregulación de la economía y garantías al derecho de propiedad." (Petras, 2001, pág. 52)

Todos estos factores afectaron los procesos de salud en el mundo, al ser intervenidos desde una mirada económica y pasar de un enfoque de oferta de la salud, a uno de demanda, donde primó la desigualdad, el capital antes que la vida. 
"En un sistema económico cada vez más globalizado y basado en el mercado, las decisiones de un puñado de instituciones $y$ corporaciones afectan a la vida cotidiana de millones de personas en todo el mundo. Estas decisiones crean estándares laborales, normas de seguridad y de salud laboral y sistemas de protección de los sindicatos, entre muchas otras cosas. Las grandes corporaciones son especialmente relevantes en este proceso en virtud no sólo de su poder y sus recursos crecientes sino también de su enorme influencia en decisiones económicas clave que tienen graves consecuencias en la producción de la salud, la enfermedad y la muerte." (Benach, Muntaner, Solar, Santana, \& Quinlan, 2010, pág. 131)

En Colombia, la respuesta a las políticas impuestas desde Washington se vieron formalizadas mediante una plataforma legal, que parte desde la propia Constitución Política de 1991 y que se puede resumir así:

"Bajo una lógica neoliberal de modernización del Estado, otorga en sus artículos transitorios facultades al Presidente de la República para reducir gastos, suprimir o fusionar empleos, suprimir, fusionar o reestructurar las entidades de la rama ejecutiva, los establecimientos públicos, las empresas industriales y comerciales y las sociedades de economía mixta del orden nacional. "Artículo 20, Transitorio.- (...) es necesario citar puntualmente las siguientes normas expedidas durante la década de 1990, que hacen parte del compendio legal dirigido a consolidar el proceso de reforma laboral y social en Colombia, ellas son: la Ley 10 de 1990, que modificó el antiguo sistema de salud, la Ley 50 de 1990, que reformó el Código Sustantivo del Trabajo, garantizando aspectos como la deslaboralización, satelización de empresas, 
flexibilización laboral y privatizaciones, (...)Esto se suma además, a la aprobación de leyes como la 60 de 1990 (..)Ley 789 de 2002, Ley 776 de 2002, 797 de 2003. (...)Toda esta legislación ha abierto el camino para que lo público pase a lo privado, bajo un discurso que resalta categorías tales como las de modernización, desarrollo, competitividad, cobertura, ocultando una realidad que hizo de la salud una mercancía, encubierta en una imagen de respeto por los derechos." (Naranjo \& Garzón Peña, 2010, págs. 41-44)

Esta situación de enfrentarse a un nuevo modelo enmarcado en la idea de mercado entro en contradicción con las ideas de un Estado Social de Derecho, donde se protegían y garantizaban una serie de aspectos ligados a la calidad de vida de los ciudadanos, el bienestar, la dignidad y el reconocimiento de los derechos.

Bajo esta lógica, se debe entender la contradicción que existe entre la aplicación de normativas, como en el caso particular, de saneamiento fiscal y financiero, frente al respeto de unos derechos garantizados en un Estado que se promulga como Social y de derechos.

\subsection{Conceptualización de los Programas de saneamiento fiscal y financiero}

Conforme el desarrollo normativo y específicamente mediante la ley 1608 de 2013 , estos programas se define como:

"un programa integral, institucional, financiero y administrativo que cubre la Empresa Social del Estado, que tiene por objeto restablecer su solidez económica y financiera de estas Empresas, con el propósito de asegurar la continuidad en la prestación del servicio público de salud." (Ley 1608, 2013) 
Su contenido se estructura en cinco medidas a saber:

1. Reorganización administrativa

2. Racionalización del gasto

3. Restructuración de la deuda

4. Saneamiento de pasivos

5. Fortalecimiento de ingresos

Estas pautas se establecen en aras de permitir una adecuada operación, que garantice el acceso, oportunidad, continuidad y calidad en la prestación de los servicios de salud a la población usuaria. Los resultados del programa son evaluados por el Ministerio de Hacienda y Crédito Público y quienes lo incumplan deberán iniciar ante el Ministerio,

"la promoción de acuerdo de reestructuración de pasivos cuando del análisis de la situación de la Empresa Social del Estado se identifique la capacidad de generar ingresos suficientes para el pago de sus compromisos corrientes y el pago de sus acreencias. La nominación y promoción de los acuerdos de reestructuración de pasivos adelantados por las Empresas Sociales del Estado, estarán a cargo del Ministerio de Hacienda y Crédito Público." (Ley 1608, 2013)

En cuanto a los parámetros generales de contenidos, seguimiento y evaluación de los Programas, estos deben contener los siguientes aspectos:

1. Financieros

2. Administrativos

3. Institucionales

4. jurídicos. 
En la parte metodológica el Ministerio de Hacienda y Crédito Público generó una herramienta para la elaboración de los mismos, donde le garantizan a las ESE un material propicio para consolidar "diagnósticos enmarcados en la realidad institucional y de contexto que conduzcan a la formulación de medidas efectivas y por tanto a programas eficaces que garanticen la permanencia de las Empresas Sociales del Estado y su sostenibilidad financiera en el mediano y largo plazo. (Ministerio de Hacienda Y Crédito Público)

A partir de este documento metodológico se procederá a analizar de manera general el caso de los hospitales de II nivel de Bogotá y de forma particular, el caso del Hospital de Bosa.

\section{CAPITULO 2. PROGRAMAS DE SANEAMIENTO FISCAL Y FINANCIERO EN HOSPITALES DE II NIVEL - ESE - BOGOTA. COMPARACIÓN DE MODELOS PARES (BOSA - MEISSEN - SAN BLAS)}

La crisis de los hospitales en Colombia corresponde a una problemática de orden histórico, que se ha enmarcado en situaciones tan complejas como la deficiencia en la calidad, la corrupción y el hacinamiento. Sin embargo, antes de la entrada en vigencia de la ley 100 de 1993, la población era atendida sin importar su capacidad de pago, toda vez que el sistema se enmarcaba en el subsidio público a la oferta, con la nueva normativa el modelo cambió a un subsidio público a la demanda, basado en parámetros de competencia de mercado que tienen como base la rentabilidad financiera, por encima de la protección y cumplimiento de los derechos. De allí, que a partir de 1993 un gran número de entidades hospitalarias han sido declaradas como inviables financieramente, teniendo que ser reestructuradas o cerradas definitivamente. (Salud al Derecho, 2007, pág. 20) 
El cambio en la relación del sistema - IPS Y ESE- por los procesos de facturación de servicios en aras de consolidar autofinanciación y reducir inversión del Estado, ratificó las condiciones de rentabilidad financiera, eficiencia administrativa y costo beneficio de la atención en salud, pero este hecho llevó a que quienes no fueran competitivos salieran del mercado, lo que a su vez generó, una creación de IPS (de segundo y tercer nivel) de carácter privado que consolidaron estrategias de manejo de recursos desde una sola entidad (integración vertical) ${ }^{4}$, que terminaron convirtiéndose en monopolios de salud que afectaron gravemente el patrón público.

Uno de los temas más difíciles fue el cierre de hospitales y el despido de un sin número de trabajadores a causa del "déficit financiero", en su mayoría producido por que las cuentas de atención a población vinculada no eran canceladas por el Estado, sumado a la demora en los pagos a los hospitales por parte de las aseguradoras, la corrupción y desviación de recursos. De allí, que fuera un reflejo de la crisis los paros en el sector salud, los cierres de hospitales, la reestructuración y fusión, todo referido a la inviabilidad financiera en contradicción con la misión institucional de "brindar atención en salud a quien lo necesite." (Salud al Derecho, 2007, pág. 21)

\footnotetext{
${ }^{4}$ La Corte Constitucional ha planteado sobre la integración vertical que:

"Debido a que las EPS tienen la función principal de garantizar la prestación de los servicios del POS, como producto final a sus afiliados, se ha supuesto que esta firma se enfrenta a la decisión entre entregar directamente los servicios o llevarlos al usuario mediante ciertas transacciones en el mercado, esto es, se plantea que la EPS podría integrarse hacia adelante con la IPS y de este modo controlar directamente la atención a sus afiliados. La amplitud de la integración entre EPS e IPS puede examinarse de dos maneras bien sea en término del rango de servicios o de actividades que hacen parte del POS y que son entregados de manera directa por las EPS, o en término de la población que como una proporción del total de afiliados es servida de esta forma. Por su parte, el grado de integración vertical va a estar referido al porcentaje del gasto en servicios de salud que la EPS realiza a través de sus propias IPS. La forma de la integración se determina por la manera como la EPS establece control sobre la IPS. corresponde a las aseguradoras que contratan con sus propias IPS, en aras de mantener los recursos dentro de sus mismas instituciones." Sentencia C-1041/07
} 
Sobre el particular, el documento Conpes 3204 de 2002 y en los informes del Ministerio de la Protección Social, al realizar una revisión de la "situación financiera de los hospitales públicos", destacaron los procesos de crecimiento del déficit financiero a partir del año 1997. Por su parte, el documento Conpes 3447 de 2006 planteó estrategias de solución a la cartera existente, partiendo de la identificación de los "principales deudores en cada régimen." (Guzman Finol, 2014, pág. 3)

La Superintendencia de Salud en el año 2010, reflejó la relación entre los ingresos reconocidos y los recaudados, dando como resultado que de 997 IPS públicas, 883 presentaban déficit presupuestal en 2009. (Guzman Finol, 2014, pág. 3)

Es así como dentro de un panorama nacional la situación de los hospitales entre los años 1994 a 2007, se enmarcaba en:

- Crisis económica

- Renuncia de personal de la salud

- Solicitud de mejoras salariales

- Demora en citas y cirugías

- Falta de personal especializado

- Atraso en el pago de cuentas por servicios prestados

- Deficit financiero

Es así como mediante la Resolución 2509 de 2012, emitida por el Ministerio de Salud y Protección Social, se generó la metodología para la categorización del riesgo de las Empresas Sociales del Estado del nivel territorial, efectuando además, 
la primera categorización de riesgo para la vigencia 2012. En aquella oportunidad, a nivel de Bogotá, se categorizaron catorce (14) hospitales en riesgo medio y alto y ocho (8) en riesgo bajo. (Secretaria Distrital de Salud, 2012, pág. 3)

Para la vigencia 2013, el Ministerio de Salud y Protección Social mediante la Resolución 1877 de 2013, mantendrá la categorización determinada en el año 2012 y ratificara su responsabilidad de "determinar y comunicar a las direcciones departamentales, municipales y distritales de salud," el correspondiente riesgo de las ESE a nivel territorial, teniendo como base la situación financiera, respondiendo a condiciones de mercado, equilibrio y viabilidad a partir de indicadores financieros, "sin perjuicio de la evaluación por indicadores de salud." Así mismo, destaca el valor de los Programas de Saneamiento Fiscal y Financiero proyectados por la ley 1608 de 2013, como estrategias obligatorias para las ESE que fueron catalogadas en riesgo medio o alto. (Resolución 1877, 2013)

Así, el Ministerio de Salud y Protección Social se dio a la tarea de implementar el Proyecto de Inversión "Mejoramiento, fortalecimiento y ajuste en la gestión de las instituciones de la red pública hospitalaria del país", asignando a los departamentos, mediante la Resolución 4874 de 2013, recursos por valor de $\$ 149.000$ millones, distribuidos por las entidades territoriales entre las empresas sociales del Estado, atendiendo a conceptos de viabilidad de los programas definidos por el Ministerio de Hacienda y Crédito Público." (Ministerio de Salud y Protección Social, 2014, pág. 116) 
Gráfica 4. Categorización de ESE de Bogotá, en riesgo medio y alto, vigencia 2012-2013

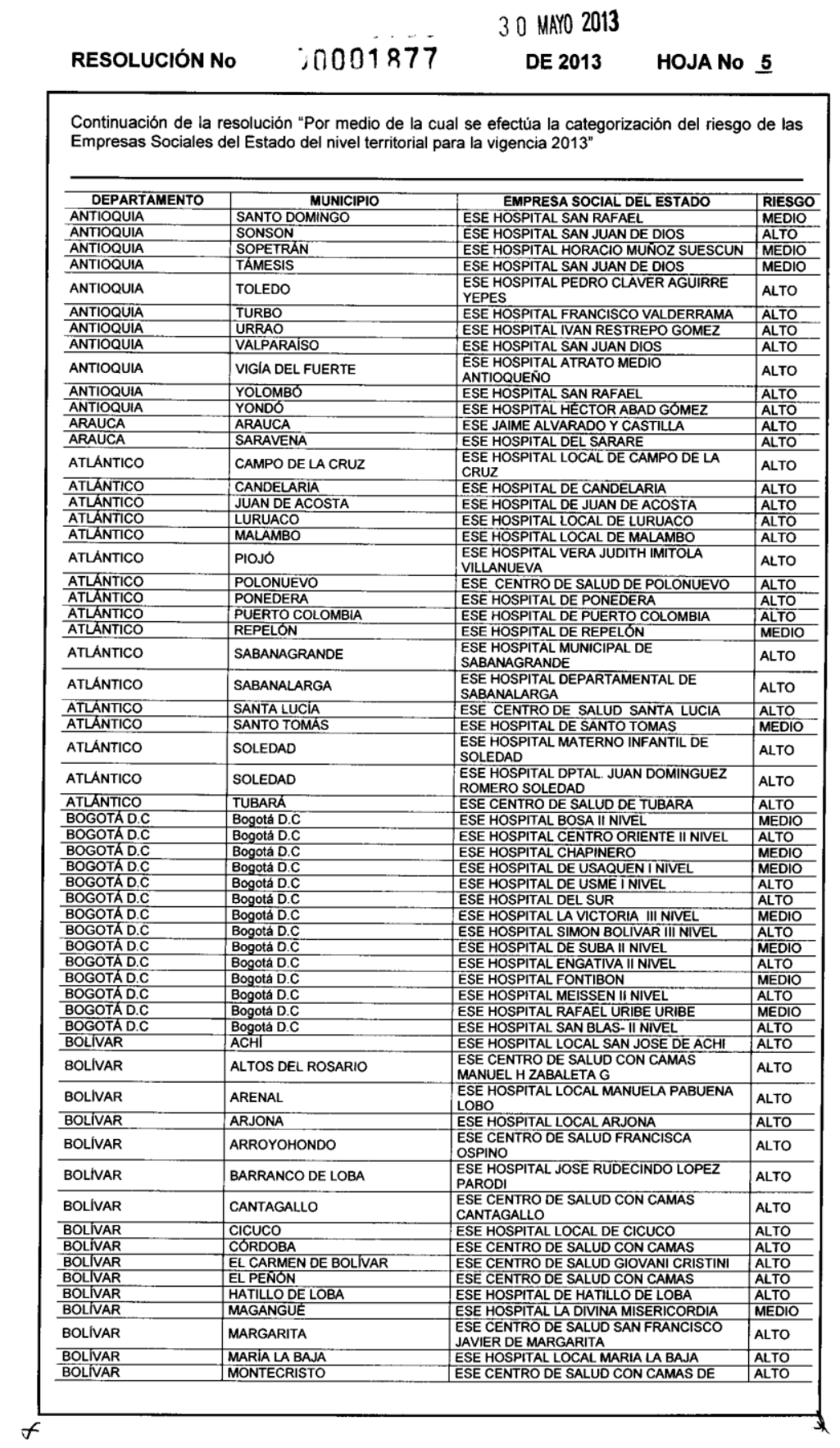

Fuente: (Resolución 1877, 2013) 
En el año 2014, mediante la resolución 2090 de 2014, el Ministerio de Salud y Protección Social, retoma la categorización del riesgo de las ESE, detalla el proceso jurídico mediado por las leyes y resoluciones emitidas y asume la recomendación del Ministerio de Hacienda y Crédito Público, en su "Informe anual de implementación y desarrollo de programas y medidas de saneamiento fiscal y financiero de ESE en riesgo medio y alto", de no aplicar ningún proceso de categorización, hasta tanto no se concretara la situación de "incumplimiento de sus obligaciones legales o se realice la evaluación de la ejecución de su programa de saneamiento fiscal y financiero viabilizado." Razón por la cual se mantiene la categorización del año 2012. (Resolución 2090, 2014)

En el 2015, El Ministerio de Salud y Protección Social, a través de la Resolución 1893 de 2015, basado en los informes emitidos por el Ministerio de Hacienda y Crédito Público y la Superintendencia Nacional de Salud (Informe de Planes de Gestión Integral del Riesgo - PGIR de las Empresas Sociales del Estado en riesgo medio o alto"), procedió a realizar una nueva categorización para la vigencia 2015. Para el caso de Bogotá se determinó un (1) hospital en riesgo alto, un (1) hospital en riesgo medio, un (1) hospital en riesgo bajo y diecinueve (19) hospitales $\sin$ riesgo. (Resolución 1893, 2015) 
Tabla 3. Consolidado de categorización del riesgo de las ESE en Bogotá 20122015

\begin{tabular}{|c|c|c|}
\hline \multicolumn{3}{|c|}{ CONSOLIDADO DE CATEGORIZACIÓN DEL RIESGO DE LAS ESE EN BOGOTÁ } \\
\hline & $2012-2014$ & 2015 \\
\hline \multirow[t]{8}{*}{ ALTO } & Hospital Centro Oriente II Nivel & \multirow[t]{7}{*}{ Hospital Bosa II Nivel } \\
\hline & Hospital de Usme I Nivel & \\
\hline & Hospital del Sur & \\
\hline & Hospital Simón Bolívar III Nivel & \\
\hline & Hospital Engativá II Nivel & \\
\hline & Hospital Meissen II Nivel & \\
\hline & Hospital San Blas II Nivel & \\
\hline & 2012 - 2014 & 2015 \\
\hline \multirow[t]{8}{*}{ MEDIO } & Hospital Bosa II Nivel & \multirow[t]{7}{*}{ Hospital Chapinero } \\
\hline & Hospital Chapinero & \\
\hline & Hospital de Usaquén I Nivel & \\
\hline & Hospital La Victoria III Nivel & \\
\hline & Hospital de Suba II Nivel & \\
\hline & Hospital Fontibón & \\
\hline & Hospital Rafael Uribe Uribe & \\
\hline & $2012-2014$ & 2015 \\
\hline \multirow[t]{8}{*}{ BAJO } & Hospital Occidente de Kennedy III Nivel & \multirow[t]{7}{*}{ Hospital San Blas II Nivel } \\
\hline & Hospital Santa Clara & \\
\hline & Hospital Vista Hermosa I Nivel & \\
\hline & San Cristóbal & \\
\hline & Hospital Nazareth I Nivel & \\
\hline & Hospital Pablo VI Bosa I Nivel de Atención & \\
\hline & Hospital Tunjuelito II Nivel & \\
\hline & $2012-2014$ & 2015 \\
\hline \multirow[t]{11}{*}{ SIN RIESGO } & \multirow[t]{11}{*}{ Hospital El Tunal } & Hospital Centro Oriente II Nivel \\
\hline & & Hospital de Usme I Nivel \\
\hline & & Hospital del Sur \\
\hline & & Hospital Simón Bolívar III Nivel \\
\hline & & Hospital Engativá II Nivel \\
\hline & & Hospital Meissen II Nivel \\
\hline & & Hospital de Usaquén I Nivel \\
\hline & & Hospital La Victoria III Nivel \\
\hline & & Hospital de Suba II Nivel \\
\hline & & Hospital Fontibón \\
\hline & & Hospital Rafael Uribe Uribe \\
\hline
\end{tabular}




\begin{tabular}{|l|l|}
\hline \multirow{n}{*}{} & Hospital Occidente de Kennedy III Nivel \\
& Hospital Santa Clara \\
& Hospital Vista Hermosa I Nivel \\
& San Cristóbal \\
& Hospital Nazareth I Nivel \\
& Hospital Pablo VI Bosa I Nivel de Atención \\
\cline { 2 - 2 } & Hospital Tunjuelito II Nivel \\
\cline { 2 - 2 } & Hospital El Tunal \\
\hline
\end{tabular}

Fuente: Elaboración de las autoras

A nivel nacional, desde el año 2013 el Ministerio ha garantizado:

"asistencia técnica a las direcciones territoriales, para el desarrollo e implementación del Programa Territorial de Reorganización, Rediseño y Modernización de las redes de Empresas Sociales del Estado (PTRRM) ESE. Es de destacar que sin excepción, todos los departamentos y distritos han sido objeto de asistencia técnica, sin embargo, algunas de ellas tienen pendiente la viabilización de su Programa Territorial por parte del Ministerio. Con Corte a 30 de mayo de 2014, se han viabilizado los Programas Territoriales de 22 entidades territoriales departamentales y distritales (Amazonas, Antioquia, Atlántico, Arauca, Bogotá, Bolívar, Boyacá, Caldas, Cauca, Cundinamarca, Casanare, Guainía, Guaviare, Huila, Magdalena, Meta, Norte de Santander, Risaralda, Santander, Santa Marta, Valle del Cauca, Vaupés). Para apoyar la financiación de acciones de reorganización y rediseño de la oferta de prestación de servicios y saneamiento de las IPS públicas que se definan en el marco de la red entre 2012 y 2013, se ejecutaron recursos de la Nación por valor de \$59.916.7millones, en los departamentos de Antioquía, Bolívar, Caldas y Valle del Cauca." (Ministerio de Salud y Protección Social, 2014, pág. 117) 
Valga la pena además hacer referencia a que el Ministerio de Salud en el año 2014, planteó en torno al tema de sostenibilidad del sistema 9 puntos específicos de análisis, partiendo de los fondos y nuevos recursos determinados con miras a salvaguardar el funcionamiento del SGSSS.

1. Gastos por eventos no incluidos en el Plan de Beneficios - Recobros

2. Determinación y pago de deudas: Cuentas maestras y otras fuentes

3. Mejoramiento del flujo de recursos: giro directo

4. Saneamiento y compra de cartera

5. Recursos del sector salud y nuevas fuentes

6. Fondo de Solidaridad y Garantía - FOSYGA

7. Fondo de Salvamento y Garantía para el sector salud - FONSAET

8. Unidad de Pago por Capitación (UPC) y senda de igualación de la UPC

9. Controles a los Precios de Medicamentos (Ministerio de Salud y Protección Social, 2014)

Realizada esta breve parametrización del proceso de categorización del riesgo de las Empresas Sociales del Estado, se procede a presentar una descripción de tres Programas de Saneamiento Fiscal y Financiero del Hospitales pares, ellos son: Hospital Meissen II Nivel, Hospital San Blas II Nivel y el Hospital Bosa II Nivel, con el fin de evidenciar sus problemáticas principales y las medidas para contener el riesgo desde los lineamientos establecidos por el gobierno nacional. 
2.1. Modelos pares. Caracterización de los Programas y medidas de saneamiento fiscal y financiero de Empresas Sociales del Estado - ESE, en riesgo medio y alto

\subsubsection{Caracterización del PSFF hospital de Meissen II nivel ESE}

El hospital de Meissen cuenta con tres (3) sedes que prestan servicios en salud de media y alta complejidad, la sede principal perteneciente a la localidad de ciudad Bolívar se encuentra ubicada en la Calle 60G sur No 18 Bis 09, la sede de consulta externa se encuentra ubicada en la Carrera 18 A Bis $N^{\circ} 60 \mathrm{G} 84$ y en esta se realiza consulta del programa de Plan Canguro y de otras especialidades. Por último se tiene la sede de Laboratorio Clínico ubicada en la Carrera 18A Bis $N^{\circ} 60 \mathrm{G} 20$ sur, donde se realiza toma de muestras y procesamiento de las mismas (Hospital de Meissen ESE, 2013).

De conformidad con la Resolución No. 1877 del 30 de mayo de 2013 por la cual se categorizó el riesgo de las Empresas Sociales del Estado del nivel territorial para la vigencia 2013 y en correspondencia con los artículos 80 y 81 de la ley 1438 de 2011 y el artículo 8 de la Ley 1608 de 2013, se clasificó al Hospital Meissen II Nivel ESE en riesgo alto.

Tabla 4 Portafolio de servicios prestados Hospital de Meissen II Nivel ESE 


\section{Sede Principal}

- Baja Complejidad : Enfermería, fisioterapia, terapia del lenguaje, terapia ocupacional, terapia respiratoria, nutrición, odontología, optometría, medicina alternativa, psicología, actividades de promoción y prevención, higiene oral, planificación familiar, toma de muestras laboratorio, toma de muestras citología cervico uterina, toma e interpretación de radiología oral.

- Mediana complejidad: Hospitalización, unidad de cuidados intermedios neonatales y adultos. En consulta externa: cardiología, pediatría, dermatología, ginecoobstetricia, infectología pediátrica, medicina interna, neurología, oftalmología, ortopedia, otorrinolaringología, pediatría, psiquiatría, urología, cirugía pediátrica, odontopediatría, neuropediatría, ortopedia infantil, neumología pediátrica que son ofertados en horario de lunes a viernes de 8:00 a.m. a 8:00 p.m.; bajo la modalidad de cirugía: cirugía general y cirugía maxilofacial y los servicios de Urgencias y farmacia que se prestan las 24 horas y como servicio de apoyo diagnostico Laboratorio de patología.

-Alta Complejidad: hospitalización general adultos, pediátrica y obstetricia, así como cuidados intensivos neonatal y adultos; como servicio quirúrgico de esta complejidad se realizan procedimientos de cirugía general, obstetricia, ortopédica, oftalmológica, otorrinolaringología, pediátrica, plástica y estética, urológica e implantes y trasplantes

\section{Sede Consulta Externa}

- Enfermería, consulta de medicina general, consulta de psicología, consulta de fonoaudiología y/o terapia de lenguaje, planificación familiar, promoción en salud todos estos servicios a enfocar la trasnversalidad de la ESE.

- Los servicios habilitados de mediana complejidad de consulta externa ofertados son: Consulta de anestesia, consulta de cirugía general, consulta de medicina interna, consulta de psiquiatría y consulta de cirugía plástica. En horario de lunes a viernes de 8:00 a.m. a 8:00 p.m

Sede Laboratorio

- Baja Complejidad: Toma de muestra y servicio transfusional

- Mediana complejidad: laboratorio clínico (procesamiento de muestras), este servicio esta ofertado en dos horarios: toma de muestras de laboratorio para consulta externa de 8:00 a.m. a 8:00 p.m. y procesamiento de muestras para la sede asistencial y servicio transfusional se oferta las 24 horas

Fuente: Tabla elaborada por las autoras.

\section{En cuanto a la planta de personal del Hospital de Meissen II Nivel, los datos reportados en el PSFF evidencian para el 2013 un total de 141 cargos distribuidos de la siguiente forma:}


Tabla 5. Planta de Personal Hospital de Meissen II Nivel Ese

\begin{tabular}{|c|c|r|r|}
\hline PLANTA ACTUAL & TOTAL & \multicolumn{1}{|c|}{ Valor mes } & \multicolumn{1}{c|}{ Valor año } \\
\hline $\begin{array}{c}\text { Activos sin condiciones } \\
\text { especiales }\end{array}$ & 67 & $\$ 452.774 .463,3$ & $\$ 5.433 .293 .560$ \\
\hline Pre y pensionables & 22 & $\$ 56.445 .780,1$ & $\$ 677.349 .361$ \\
\hline Aforados & 2 & $\$ 5.523 .909,0$ & $\$ 66.286 .908$ \\
\hline Trabajadores oficiales & 20 & $\$ 56.439 .347,0$ & $\$ 677.272 .164$ \\
\hline Vacantes & 30 & $\$ 160.439 .071,7$ & $\$ 1.925 .268 .861$ \\
\hline TOTAL & $\mathbf{1 4 1}$ & $\$ \mathbf{7 3 1 . 6 2 2 . 5 7 1 , 1}$ & $\$ 8.779 .470 .854$ \\
\hline
\end{tabular}

Fuente: (Hospital de Meissen ESE, 2013)

Los costos del total de la planta de personal para el año 2013 eran de \$8.779.470.854 valor anual; el número de vacantes correspondía a treinta (30) cuyo valor era de \$1.925.268.861; estas vacantes en su mayoría son cargos asistenciales. Dentro de los costos de personal se evidencia que $83 \%$ son contratistas y solamente un $7 \%$ corresponde a personal de planta (Hospital de Meissen ESE, 2013).

A continuación se presenta la descripción de la situación del Hospital Meissen II Nivel en relación con los aspectos institucionales, administrativos, jurídicos y financieros identificados en el PSFF a los cuales se les atribuye el origen de las problemáticas que generaron la categorización de la entidad en riesgo alto.

\section{Aspectos institucionales}

Al realizar el análisis de los aspectos institucionales que han generado la insostenibilidad financiera del hospital de Meissen se encontró que se señalan aspectos relacionados con desactualización de los procesos institucionales, una alta rotación del recurso humano, inconsistencias en la información que se 
suministra al CIP, una baja utilización de la capacidad instalada física y del recurso humano del programa APH de $86 \%$, por problemas asociados al talento humano, así como problemas de deterioro en la infraestructura y en los equipos con que cuenta el hospital ya que los problemas financieros con los que atraviesa la institución no han permitido que se realicen los mantenimientos correspondientes.

En cuanto a la caída de la producción en el periodo 2011-2012 esta se atribuye según el PSFF la información encontrada en el Hospital de Meissen principalmente a la mala imagen de la institución debido a casos denunciados de corrupción y a la unificación del POS.

\section{Aspectos Administrativos}

En cuanto a los procesos administrativos se encuentra que estos están documentados y también hay un proceso de actualización de los mismos. Los problemas más frecuentes que se identifican en todo los proceso administrativos prioritarios son:

- Problemas de presupuesto que afectan directamente el cumplimiento de algunos estándares como lo es el Sistema Único de Habilitación; disponibilidad presupuestal para el recursos humano.

- Problemas en los sistemas de información debido a procesos recientes de transición entre sistemas, deficiencia en el software actual y en sistemas de información para el cumplimiento de las actividades. No existe un sistema de información integral (definido, fiable y estable). Poca credibilidad en la información de los aplicativos y en el área de sistemas de información. Desconocimiento de la arquitectura y funcionamiento de los aplicativos. 
- La falta de control por parte de los entes territoriales para la referencia de pacientes, autorización de servicios y recaudo de cartera

- Alta rotación del personal para dar continuidad a los procesos. Alta rotación del personal que disminuye adherencia a los procesos.

- No existen procesos obligatorios específicos para evaluación y control para el área de inventarios.

- Falta de continuidad de proveedores y productos por la situación financiera de la institución.

- Demora en la entrega de soportes para pago.

- Falta de oportunidad y fluidez en lo referente al aporte de documentos requeridos para el proceso de contratación.

- Procesos legales pendientes y con problemática de la administración anterior, representando reproceso de información y continua entrega de informes a entes de control.

\section{Aspectos jurídicos}

En cuanto a los aspectos jurídicos se encontró que el Hospital presenta problemas relacionados con la dificultad en el cobro de cartera:

- No hay claridad en los términos jurídicos relacionados con la prescripción y caducidad de las cuentas por cobrar lo cual genera problemas para la conciliación de las deudas.

- Problemáticas en la contratación: Falta de oportunidad y fluidez entre las demás áreas y Jurídica en lo referente al aporte de documentos requeridos para el proceso de contratación. Pendiente la actualización por parte del área jurídica de los procedimientos para la elaboración de los contratos.

- Problemas en la articulación con las otras dependencias: Falta de claridad de las funciones específicas del área jurídica por parte de las demás 
áreas del Hospital, lo cual genera una dinámica más lenta en procesos asignados y que no son propios del área.

- Procesos pendientes, deficientes y con problemática legal de la administración anterior, lo cual representa para el área reproceso de información y continua entrega de informes a entes de control que investigan los antecedentes de las actuaciones judiciales y procesos contractuales anteriores

- Conciliaciones extrajudiciales administrativas: Procesos conciliatorios que buscan reparaciones por fallas directas presentadas en el servicio del hospital, así como el pago de obligaciones pendientes de vigencias anteriores a proveedores y problemas en la contratación de personal que laboró sin soporte contractual y presupuestal. Conciliaciones con ex contratistas vinculados por prestación de servicios, quienes demandan el pago de prestaciones económicas (agotando el requisito de procedibilidad para demandar), aduciendo la existencia de un contrato. El monto aproximado en conciliaciones asciende a la suma de $\$ 4.186 .641 .558$, con fundamento en las siguientes consideraciones.

- Procesos judiciales: De acuerdo a las problemáticas planteadas en el PSFF, actualmente existen en el hospital sesenta y cinco (65) procesos judiciales en la institución, con unas pretensiones de cuantía estimada de \$19.011.882.458 aproximadamente.

\section{Aspectos financieros}

La situación en relación con los aspectos financieros del hospital de Meissen las principales problemáticas que se presentan están relacionadas con:

- Bajos niveles de ingresos provenientes de los recaudos 
- Contratación de abogados externo para la recuperación de cartera de difícil cobro.

- Demora en la implementación de un sistema de información que cumpla con las condiciones para todo el proceso financiero.

- Oportunidad en el pago a proveedores de bienes y servicios

- No se cuenta con recursos financieros para el desplazamiento en el proceso de cobro a las afueras de la ciudad.

- No se cuenta con la totalidad de contratos con los diferentes pagadores.

- Faltan Equipos de mayor capacidad para la realización de actividades diarias.

- Existen diferencias respecto de la información que en su momento se reportó en el Informe Decreto 2193

- La distribución de costos del Hospital, genera que el valor total de uso sea mayor al valor causado por la venta de servicios, es decir que el costo de producir una actividad es mayor al valor cobrado a las diferentes entidades Responsables de Pago.

\section{Acciones propuestas por el hospital de Meissen II Nivel para el saneamiento fiscal y financiero}

\section{Medidas de Reorganización administrativa}

La estrategia que ha definido el hospital para mejorar la producción y aumentar la prestación de servicios está relacionada con el reajuste de las horas de trabajo de los empleados con el fin de optimizar el servicio prestado, esto se debe principalmente a que la producción frente a las horas de talento humano disponibles en la actualidad reflejan una baja productividad, según el diagnóstico, se plantea una reestructuración para optimizar el talento humano basado en concentrar la disponibilidad de este durante las horas de mayor afluencia de pacientes; lo anterior, 
con el fin de poder soportar el incremento en la proyección de la producción (Hospital de Meissen ESE, 2013).

La otra parte de la estrategia propuesta por el hospital de Meissen se fundamenta en optimizar los tiempos de atención al usuario en cada uno de los servicios ofertados en el hospital, este mejoramiento se centra en los siguientes aspectos:

- Disminuir los tiempos de consulta en cada uno de los servicios mejorando los procedimientos que se llevan a cabo.

- Establecimiento de convenios con instituciones de educación superior con el fin de implementar procesos que mejoren los tiempos de atención y ejecución de procedimientos.

- Las medidas de reorganización administrativa están orientadas a fortalecer el sistema único de habilitación enfatizando en la actualización de procesos asistenciales; el sistema de información de la ESE; a través de la generación de reportes por unidad de negocios, documentación de los procesos para la seguridad de la información.

- Contrarrestar el tema de inasistencia a consultas médicas a través del aumento de la programación por hora y la implementación de llamadas recordatorias.

- Aumento de la productividad en los servicios a través de la reasignación del personal médico y la optimización de los servicios que ofrece el hospital.

- Venta de servicios de imagenología al fondo financiero

- Transferencia de servicios a otros hospitales de la red.

- Revisión y ajuste de los procesos de contratación institucional y supervisión de los mismos; para que se logre el impacto positivo en los niveles de recaudo. 


\section{Medidas de fortalecimiento de ingresos}

Con el fin de fortalecer los ingresos el hospital de Meissen busca principalmente adoptar medidas que permita mejorar los servicios facturables y de esta forma canalizar mejor los ingresos (Hospital de Meissen ESE, 2013), dentro del grupo de medidas que busca el hospital se encuentran:

- Incrementar la utilización de la capacidad instalada y el recurso humano de la institución, aumentando la producción con los servicios cedidos por la Red al Hospital específicamente en el servicio obstétrico y perinatal.

- Mejorar las relaciones comerciales con las principales EPS del Distrito brindándoles tarifas preferenciales qué permitan una mayor remisión de pacientes y una prestación de servicios facturables.

- Incrementos en la facturación del régimen subsidiado debido a la ampliación de la cobertura del POS.

- Fortalecimiento del equipo de auditoría médica, con el fin de realizar conciliaciones en masa con los diferentes entes de control y pagadores generando a su vez, una respuesta de cobro más rápida y eficiente de los valores que le deben al Hospital.

- Garantizar el proceso de radicación de cobros a los distintos pagadores con el fin de que el ara de cartera generar una rápida acción en el cobro de los valores adeudados de la vigencia.

- Implementación del proceso de cobro Coactivo, con el fin de realizar acciones jurídicas en los eventos del no reconocimiento de los servicios prestados a los diferentes pagadores.

- Contratación de abogados externos, con el compromiso de reactivar los pagos por parte del FOSYGA, entidad que no paga oportunamente al hospital. 


\section{Medidas de saneamiento de pasivos}

Es este aspecto el hospital busca usar el flujo de caja para dar prioridad a las obligaciones contraídas en los periodos corrientes y el remanente del excedente financiero, también se busca lograr a través de convenios nuevos recursos direccionados a cubrir las pasivos de vigencias anteriores.

Aunque el flujo corriente arroja un balance positivo a partir del año 2015 el hospital arrastra de vigencias anteriores $\$ 24.101$ millones de cuentas por pagar, las cuales no son posibles de financiar con la operación corriente. Por esta razón el programa establece que estas cuentas deberán ser financiadas con los recursos liberados para oferta por la Ley 1608 de 2013 SGP sin situación de fondos por $\$ 1.623$ millones para el año 2013, \$1.607 millones para el año 2014 y convenios firmados con el FFDS para el pago de pasivos año 2013 por $\$ 25.331$ millones de los cuales $\$ 11.395$ millones serán recaudados en la vigencia 2014 (Hospital de Meissen ESE, 2013).

\section{Medidas de racionalización del gasto}

Con el fin de tomar medidas de racionalización del gasto se plantea una disminución del gasto corriente de $\$ 3.421$ millones, pasando de $\$ 63.251$ millones en 2013 a \$59.830 millones en 2017 (Hospital de Meissen ESE, 2013), para ello el hospital plantea medidas administrativas como lo son:

- Eliminar costos adicionales en activos improductivos

- Eliminar material médico quirúrgico obsoleto

- Ajustar y redistribuir el personal en las diferentes áreas asistenciales como administrativo

- Realizar compras conjuntas de medicamentos e insumos por la Subred sur con el fin de obtener mejores precios

- Establecer controles efectivos en los costos institucionales. 
Situación de la ESE (Relación entre costos de funcionamiento - ingresos por facturación y costos de la planta de personal)

\section{Costos de funcionamiento}

De acuerdo a lo encontrado en el PSFF para el hospital de Meissen se encuentra que en el año 2012 se presenta una disminución en los gastos de funcionamiento, debido principalmente a la reducción del personal administrativo y asistencial del hospital. En las gráficas 5 y 6 se presenta el consolidado de los elementos del costo para el periodo 2008 -2012, en ellas se puede evidenciar un aumento de los costos totales que para el año 2009 ascienden a un $28 \%$, un $17 \%$ para el 2010 , y un $2 \%$ para el año 2011, los ajustes realizados por el hospital en términos de reducción de personal lograran mostrar un decrecimiento del -3\% en el año 2012 (Hospital de Meissen ESE, 2013).

Gráfica 5 Variación de los costos totales de funcionamiento Hospital de Meissen periodo 2008-2012

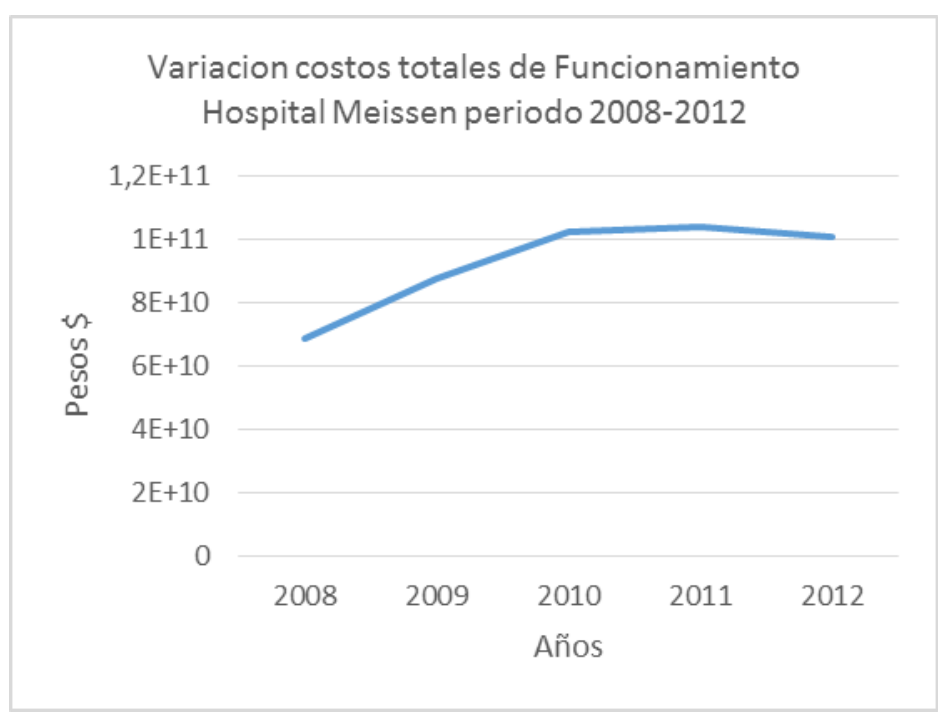

Fuente: (Hospital de Meissen ESE, 2013) 
Gráfica 6 Variación de los costos de funcionamiento Hospital de Meissen periodo 2008-2012.

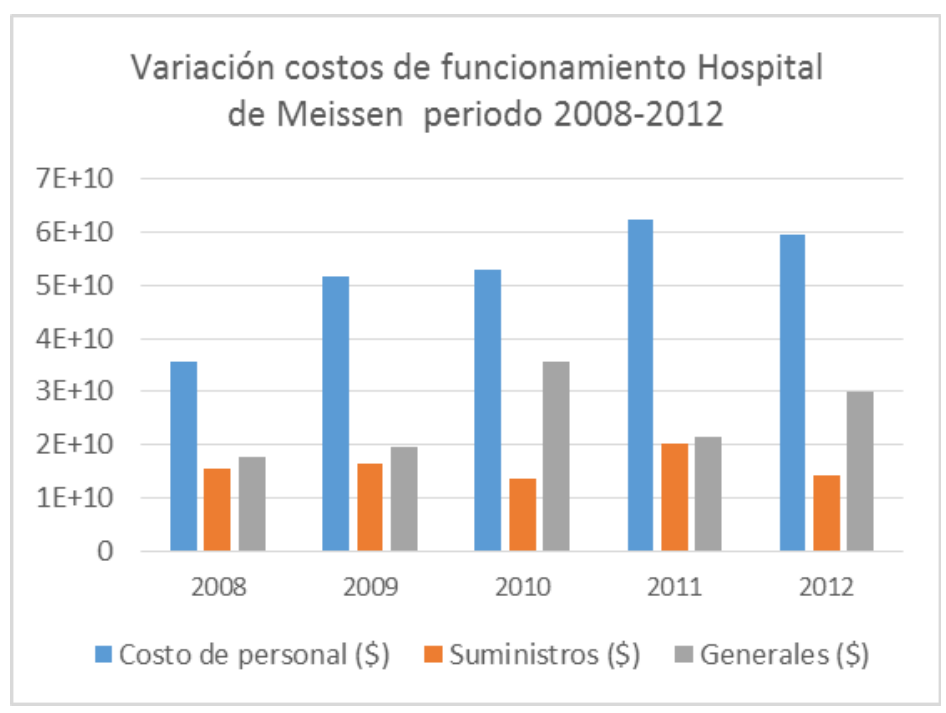

Fuente: (Hospital de Meissen ESE, 2013)

\section{Costo de personal}

En cuanto a los costos generados por la contratación de personal en el hospital de Meissen durante el periodo 2008-2012 se encuentra que más del 95\% corresponde a contratos de prestación de servicios por contratación directa del hospital, estos contratos tienen un peso muy importante en el componente de costos por honorarios y remuneraciones de los funcionarios asistenciales, Existían especialistas de alto costo en servicios en donde la producción era baja.

Otro factor que aumentaba los costos de personal en el periodo 2008 al 2012 fueron los contratos por concepto de honorarios para el proceso de acreditación a través de firmas especializadas con alto costo para la institución. Otros aspecto que incremento los cotos de funcionamiento fueron las compras desmedidas y los altos costos generados por la compra de suministros generales. Desde mayo de 2012 se 
realizaron ajustes significativos disminuyendo la cantidad y el costo del personal administrativo y asistencial, a través de análisis de las necesidades de la institución y ajustando el personal necesario para la atención a los usuarios y soporte administrativo.

En la siguiente tabla se presenta el consolidado de los elementos del costo para el periodo 2008 -2012, donde se puede evidenciar el creciente aumento de los costos totales que aumentan un $28 \%$ para el año 2009, un 17\% al 2010, un 2\% al año 2011 y debido a los ajustes mencionados logra decrecer un -3\% en el año 2012 (Hospital de Meissen ESE, 2013).

Tabla 6. Costos de personal vigencia 2008-2012

\begin{tabular}{|r|r|c|c|r|}
\hline \multicolumn{1}{|c|}{ Año } & Costo de personal $(\$)$ & Suministros $(\$)$ & Generales $(\$)$ & \multicolumn{1}{c|}{ Costos Totales $(\$)$} \\
\hline 2008 & $\$ 35.649 .281 .113$ & $\$ 15.339 .353 .544$ & $\$ 17.617 .324 .278$ & $\$ 68.605 .958 .935$ \\
\hline 2009 & $\$ 51.659 .923 .390$ & $\$ 16.284 .307 .134$ & $\$ 19.671 .033 .583$ & $\$ 87.615 .264 .107$ \\
\hline 2010 & $\$ 53.062 .943 .296$ & $\$ 13.611 .887 .701$ & $\$ 35.571 .395 .396$ & $\$ 102.246 .226 .393$ \\
\hline 2011 & $\$ 62.355 .987 .909$ & $\$ 20.062 .366 .566$ & $\$ 21.430 .901 .626$ & $\$ 103.849 .256 .101$ \\
\hline 2012 & $\$ 59.569 .845 .239$ & $\$ 14.356 .623 .000$ & $\$ 29.936 .206 .177$ & $\$ 103.862 .674 .416$ \\
\hline
\end{tabular}

Fuente (Hospital de Meissen ESE, 2013)

\section{Ingresos por facturación}

Al analizar el comportamiento histórico de la facturación para el periodo 2008 a 2012 se refleja un comportamiento creciente hasta la vigencia 2010 (figura 7), en el cual es importante resaltar que la facturación con cargo al Régimen Subsidiado, tanto por la modalidad de cápita como de evento fueron los que mayor impacto generaron en este crecimiento; siendo la modalidad de cápita la que brindo un flujo efectivo de recursos para el hospital en el corto plazo; no obstante el resultado de estas dos modalidades de contratación y venta de servicios no generaron resultados positivos de ingreso frente a gasto. En la vigencia 2012 el déficit se incrementa 
significativamente por cuanto entra en vigencia el acuerdo 032 de la CRES que homologa totalmente POS subsidiado y contributivo, por lo cual la facturación con cargo al Fondo Financiero Distrital de Salud cae en un 54\%, desaparecen los ingresos por concepto de los convenios del hemocentro, el Fondo de Desarrollo Local y el recaudo por concepto de cuotas de recuperación (Hospital de Meissen ESE, 2013)

Gráfica 7 Ingresos por facturación Hospital de Meissen 2008-2012

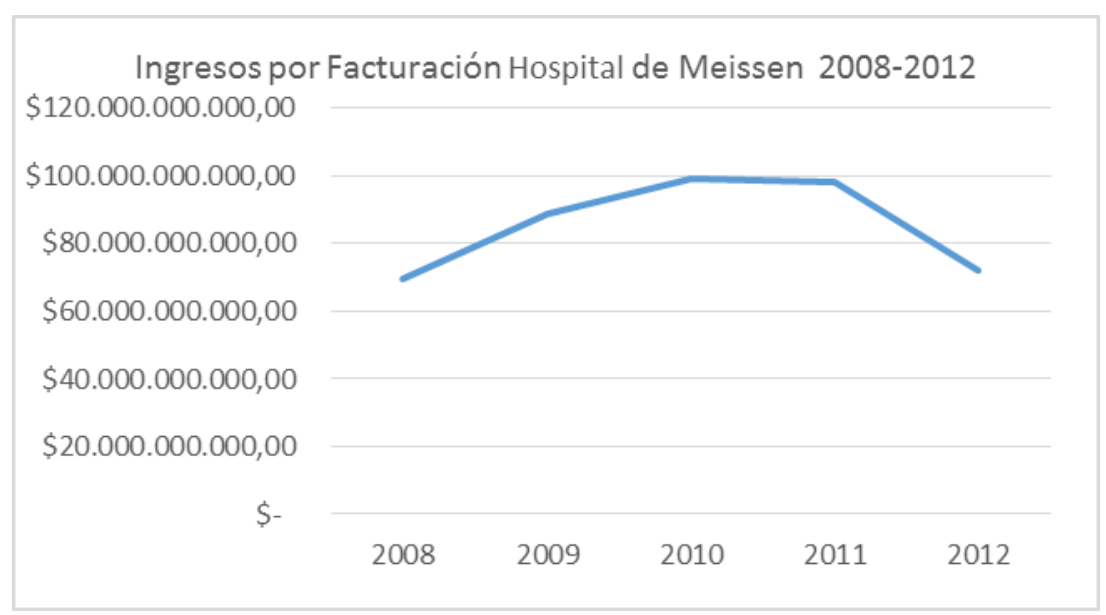

Fuente: (Hospital de Meissen ESE, 2013)

\subsubsection{Caracterización del PSFF hospital de San Blas II nivel ESE}

El hospital de San Blas II Nivel presta sus servicios principalmente en la localidad de San Cristóbal principalmente ofreciendo servicios de alta complejidad, este hospital fue categorizada en riesgo alto por el Ministerio de Hacienda y Crédito Público y actualmente pertenece a la Red Centro oriente que está compuesta por seis (6) hospitales, lo cual ha permitido efectuar una reorganización de los servicios de tal manera que algunos de ellos se fortalezcan en un hospital o sean reubicados en otros (Hospital San Blas II Nlvel, 2013). 
Los servicios ofertados por el Hospital de San Blas II Nivel son los siguientes:

Tabla 7. Servicios prestados por el Hospital San Blas II Nivel ESE

\begin{tabular}{|c|c|c|c|}
\hline $\begin{array}{l}\text { General adultos } \\
\text { General pediátrica } \\
\text { Psiquiatría o unidad } \\
\text { de salud mental } \\
\text { Farmacodependencia } \\
\text { Cuidado intermedio } \\
\text { neonatal } \\
\text { Cuidado intermedio } \\
\text { adultos } \\
\text { Obstetricia }\end{array}$ & $\begin{array}{l}\text { Cirugía general } \\
\text { Cirugía ginecológica } \\
\text { Cirugía maxilofacial } \\
\text { Cirugía ortopédica } \\
\text { Cirugía oftalmológica } \\
\text { Cirugía } \\
\text { otorrinolaringología } \\
\text { Cirugía pediátrica } \\
\text { Cirugía plástica y } \\
\text { estética } \\
\text { Cirugía urológica }\end{array}$ & $\begin{array}{l}\text { Anestesia } \\
\text { Cardiología } \\
\text { Cirugía general } \\
\text { Cirugía pediátrica } \\
\text { Endocrinología } \\
\text { Enfermería } \\
\text { Fisioterapia } \\
\text { Fonoaudiología y/o } \\
\text { terapia de lenguaje } \\
\text { Gastroenterología } \\
\text { Ginecobstetricia }\end{array}$ & $\begin{array}{l}\text { Medicina física y } \\
\text { rehabilitación } \\
\text { Medicina interna } \\
\text { Nefrología } \\
\text { Neurología } \\
\text { Nutrición y dietética } \\
\text { Oftalmología } \\
\text { Optometría } \\
\text { Ortodoncia } \\
\text { Ortopedia y/o } \\
\text { traumatología } \\
\text { Otorrinolaringología }\end{array}$ \\
\hline $\begin{array}{l}\text { Pediatría } \\
\text { Psicología } \\
\text { Psiquiatría } \\
\text { Terapia ocupacional } \\
\text { Terapia respiratoria } \\
\text { Urología } \\
\text { Cirugía plástica y } \\
\text { estética } \\
\text { Servicio de urgencias } \\
\text { Urgencias en salud } \\
\text { mental o psiquiatría }\end{array}$ & $\begin{array}{l}\text { Transporte asistencial } \\
\text { básico } \\
\text { Transporte asistencial } \\
\text { medicalizado } \\
\text { Endoscopia digestiva } \\
\text { Laboratorio clínico } \\
\text { Radiología e } \\
\text { imágenes diagnostico } \\
\text { Toma de muestras de } \\
\text { laboratorio clínico } \\
\text { Transfusión } \\
\text { sanguínea } \\
\text { Servicio farmacéutico }\end{array}$ & $\begin{array}{l}\text { Laboratorio de } \\
\text { patología } \\
\text { Ultrasonido } \\
\text { Lactario - } \\
\text { alimentación } \\
\text { Esterilización } \\
\text { Urología } \\
\text { procedimiento } \\
\text { Electrodiagnóstico } \\
\text { Laboratorio de } \\
\text { histotecnología }\end{array}$ & $\begin{array}{l}\text { Ecocardiografía } \\
\text { Centro atención en } \\
\text { drogadicción } \\
\text { residencial } \\
\text { Sala de enfermedades } \\
\text { respiratorias agudas - } \\
\text { ERA } \\
\text { Sala de yeso } \\
\text { Sala de reanimación } \\
\text { Sala general de } \\
\text { procedimientos } \\
\text { menores }\end{array}$ \\
\hline
\end{tabular}

Fuente: Tabla elaborada por las autoras.

Para la vigencia 2013, la planta de personal del Hospital San Blas II Nivel ESE estaba conformada por 365 cargos distribuida entre empleados públicos y prestaciones de servicio, 12 trabajadores oficiales y 64 vacantes de las cuales 49 son definitivas y 15 temporales.

Tabla 8. Planta de personal del Hospital de San Blas II Nivel ESE 


\begin{tabular}{|c|c|c|c|c|c|c|}
\hline \multirow{2}{*}{ PLANTA ACTUAL } & \multicolumn{2}{|c|}{$\begin{array}{c}\text { SUBTOTAL } \\
\text { ADMINISTRATIVOS }\end{array}$} & \multicolumn{2}{|c|}{$\begin{array}{c}\text { SUBTOTAL PRESTACIÓN } \\
\text { DE SERVICIOS }\end{array}$} & \multicolumn{2}{|r|}{ TOTAL } \\
\hline & Núm. & Valor mes & Núm. & Valor mes & Núm. & Valor mes \\
\hline $\begin{array}{l}\text { Activos sin } \\
\text { condiciones }\end{array}$ & 10 & 663.187 .788 & 199 & 13.190 .249 .130 & 209 & 13.853.436.918 \\
\hline Pre y pensionables & 36 & 1.104 .633 .955 & 41 & 2.362.153.699 & 77 & 3.466 .787 .654 \\
\hline Aforados & 0 & - & 3 & 140.613 .990 & 3 & 140.613 .990 \\
\hline Trabajadores oficiales & 3 & 104.727 .595 & 9 & 342.946 .295 & 12 & 447.673 .890 \\
\hline Vacantes & 17 & 501.914 .402 & 47 & 1.667 .671 .983 & 64 & 2.169 .586 .385 \\
\hline TOTAL & 66 & 2.374 .463 .740 & 299 & 17.703 .635 .097 & 365 & 20.078 .098 .837 \\
\hline
\end{tabular}

Fuente: (Hospital San Blas II NIvel, 2013)

En cuanto a la distribución de los empleos del Hospital San Blas- ESE, la mayoría corresponde a cargos asistenciales y del área de apoyo, en segundo lugar se encuentran los de nivel profesional y en tercer lugar los técnicos. Los datos encontrados muestran en los dos niveles anteriores son mayoría los del área operativa. En cuanto al total de cargos (365), el $13.42 \%$ corresponde al área administrativa mientras que el $86.57 \%$ son empleos del área asistencial.

\section{Aspectos institucionales}

En cuanto a los aspectos institucionales del Hospital San Blas II Nivel se encontró que también presenta al igual que le hospital de Bosa y el Hospital de Meissen una baja productividad en servicios atribuida a la entrada en vigencia de la unificación del POS y el aseguramiento Universal de la Población del D.C. Otros de los aspectos encontrados están relacionados con la no generación de rentabilidad en la prestación de servicios particularmente el de ginecología debido al alto gasto del personal de planta. Dentro de las problemáticas institucionales identificadas en el Plan de Saneamiento Fiscal y Financiero del Hospital San Blas se encuentran: 
- Baja rentabilidad de los servicios relacionados con ginecología debido a los altos costos del personal de planta y la disminución de los niveles de producción por competencia con otros hospitales que se han especializado y han generado estrategias exitosas.

- Existencia del centro de drogadicción CAD Despertar, de baja rentabilidad económica pero de alta rentabilidad social.

- Alta rotación de personal dificulta la difusión, implementación y adherencia de las guías clínicas y protocolos de atención, para la consolidación de una cultura de servicio orientada hacia la calidad.

- Baja capacidad instalada en el servicio de hospitalización como son ginecoobstetricia, pediatría, recién nacidos y cuidados intermedios neonatales.

- Largos tiempo de espera (inoportunidad del servicio) en la prestación se servicio principalmente los de medicina interna en consulta externa y endocrinología. Largos tiempos de espera para asignación de citas.

- Estancia prolongada de usuarios por abandono por abandono social lo cual ha generado incremento de infecciones nosocomiales.

\section{Aspectos administrativos}

Al revisar los aspectos administrativos concernientes al Hospital San Blas se encontraron problemáticas relacionadas con la falta de adherencia a los diferentes procesos relacionados con la contratación, la evaluación de proveedores y la adquisición de bienes y servicios. Las principales problemáticas administrativas encontradas en el hospital y a las cuales se les atribuye la calificación del mismo en riesgo alto son:

- Dificultades en la utilización del paquete contable del hospital, ya que presenta falencias en el cargue de la información y no permite integrar con 
facilidad las distintas áreas de la institución por medio de interfaces, esto puede traer como consecuencia que dejen de registrar partidas importantes que afectan la cuenta de deudores, la falta de conciliación con los pagadores.

- Falencias en la planeación del presupuesto, lo cual ocasiona un desequilibrio presupuestal.

- Obsolescencia en los equipos médicos utilizados debido al cumplimiento de su vida útil y los altos costos de mantenimiento de los mismos. No se cuenta aún con un estudio de gestión de tecnología para la selección, adquisición, mantenimiento de los equipos biomédicos que garanticen una atención segura y con calidad para los usuarios.

- Problemas en la infraestructura física del hospital lo cual lo hace vulnerable desde el punto de vista sísmico. La Infraestructura física en general, es insuficiente por lo que se presenta hacinamiento en algunos procesos como por ejemplo, facturación, en los que las condiciones de iluminación y ventilación afectan el desarrollo de las tareas.

- El sistema de información es obsoleto y precario y no integra los procesos administrativos y asistenciales, esto no garantiza niveles óptimos de disponibilidad, oportunidad, confiabilidad y seguridad.

- No se cuenta con equipamiento biomédico propio para prestar servicios especializados de mediana y alta complejidad, lo que obliga a la contratación de los servicios con operadores externos que presten sus servicios incluyendo el equipamiento necesario.

\section{Aspectos jurídicos}

En relación con los aspectos jurídicos encontrados en el hospital se identificaron en el PSFF las siguiente problemáticas:

- No se tiene acceso a las nuevas tecnologías

- El área de jurídica no cuenta con personal de planta. 
- Deficiencias en los procesos en los cuales el hospital debe defenderse por falta de claridad en la letra con la cual se diligencian las historias clínicas por parte del personal asistencial. Las historias clínicas no son claras y esto pone en desventaja al hospital en una situación de litigio.

- La Oficina Jurídica no tiene información anterior confiable de los procesos y procedimientos realizados para corregir deficiencias repetitivas tanto administrativas como operativas.

- No se ha logrado la aplicación del Manual de contratación de forma completa por insuficiencia presupuestal.

\section{Aspectos financieros}

En relación con los aspectos financieros y las problemáticas encontradas en el PSFF del hospital San Blas, se enfatiza principalmente en la falta de un sistema de información que articule distintos procesos y que favorezca el cobro de cartera. Las problemáticas identificadas con los aspectos financieros del hospital son:

- Carencia de una herramienta de administración de la información de manera integrada que articule datos de financiera, administrativa y asistencial, como soporte básico de gestión, direccionamiento y control.

- Información de Cartera no depurada.

- Ausencia y / o desactualización de procesos y procedimientos, implementados para el área financiera.

- Desconocimiento de los procesos, procedimientos y normatividad aplicable.

- Falta de manual de cartera y procedimiento para el cobro jurídico de cartera.

- El Hospital San Blas en el Programa de saneamiento fiscal y financiero ha formulado acciones integrales, enfocadas en lo institucional, financiero y administrativo, con las cuales se pretende operar integral y coordinadamente en condiciones de viabilidad empresarial, técnica y financiera, para 
restablecer su solidez económica y financiera, con el propósito de asegurar la continuidad en la prestación del servicio público de salud

\section{Acciones propuestas por el Hospital San Blas II Nivel para el saneamiento fiscal y financiero}

El conjunto de acciones propuestas por el Hospital para el sostenimiento fiscal y financiero comprende medidas de reorganización administrativa, racionalización del gasto, fortalecimiento de ingresos y saneamiento de pasivos de acuerdo a lo planteado por la guía Metodológica propuesta por el ministerio de Hacienda y Crédito Público. (Ministerio de Hacienda y Crédito Público)

\section{Medidas de Reorganización administrativa}

En cuanto a las medidas de reorganización administrativa el Hospital de San Blas plantea principalmente adelantar procesos de reestructuración de personal principalmente en el servicio de Ginecología y Pediatría, así como generar procesos de autoevaluación con el fin de lograr la acreditación en salud. Para ello proponen las siguientes acciones:

- Reordenamiento del personal auxiliar asistencial del servicio de ginecoobstetricia hacia otros servicios, según necesidad. Preliminarmente debe darse el Proceso de reestructuración del personal especialista.(ginecología y pediatría)

- Realizar la ruta crítica de Acreditación, articulada con el PAMEC, a través de las siguientes actividades: Preparación previa a la autoevaluación, de los estándares de acreditación, priorización de procesos a mejorar, el análisis causal y elaboración de planes de mejoramiento. El incremento sería del 20\% anual. 
- En cuanto a la problemática generada por la obsolescencia de los equipos biomédicos se plantea implementar un programa para el mejoramiento del proceso de evaluación y adquisición de tecnología biomédica. También se busca contar con un sistema de información de tecnología moderna, gráfica, amigable, robusta en funcionalidad y eficiente, que apoye los procesos y se adapte a las necesidades exigencias del sector salud. Para ello se debe gestionar la adquisición de recursos.

\section{Medidas de Racionalización del gasto}

En cuanto a la racionalización del gasto se proponen un conjunto de medidas tendientes a disminuir los costos de funcionamiento del hospital y promover el ahorro y la buena utilización de los recursos, para ello se proponen las siguientes acciones:

- Cierre del servicio de Centro de Atención en Drogadicción Despertar por pérdida de la función social para el cual fue creado.

- Fortalecimiento del recurso humano del Hospital San Blas, adecuándolo a los servicios propuestos de acuerdo al plan de saneamiento, sin incurrir en gastos que estén por fuera de la proyección financiera.

- No cubrir las vacantes existentes, ni las generadas por los funcionarios que van renunciando por cumplir requisitos para pensión de acuerdo a la proyección estimada para los años 2014-2017. A continuación se presenta esta proyección: 
Tabla 9. Proyección de Vacantes 2014-2017. Hospital San Blas II Nivel ESE

\begin{tabular}{|c|c|c|c|}
\hline AÑO & $\begin{array}{c}\text { NO. DE } \\
\text { VACANTES }\end{array}$ & $\begin{array}{c}\text { VALOR } \\
\text { ACUMULADAS }\end{array}$ & $\begin{array}{c}\text { ACUMULADO EN } \\
\text { PESOS (\$) DE LAS } \\
\text { VACANTES }\end{array}$ \\
\hline 2013 & & 64 & \\
\hline 2014 & 14 & 78 & 1.094 .532 .563 \\
\hline 2015 & 5 & 83 & 1.448 .438 .144 \\
\hline 2016 & 16 & 99 & 2.563 .372 .579 \\
\hline 2017 & 20 & 119 & 3.866 .099 .191 \\
\hline Total & 55 & 119 & 3.866 .099 .191 \\
\hline
\end{tabular}

Fuente: (Hospital San Blas II NIvel, 2013)

- Ahorrar en cuanto al consumo de pedidos que dispensa el Almacén.

- Ahorrar en las compras de medicamentos el $20 \%$ a partir de las compras conjuntas de excelente calidad y de la misma manera en la compra de dispositivos médicos en un $40 \%$.

- Ahorrar el consumo de papel.

- Reducción del valor de las pólizas de amparo por cambio de compañía de seguros con un ahorro.

- Implementar la UNIDOSIS para dispensación de medicamentos en el Hospital.

- La Reestructuración del personal especialista del servicio de Ginecología, pediatría y servicios conexos (Recién Nacido, Cuidados intermedios neonatales, Sala de partos). Igualmente reordenamiento de camas en ginecología y medicina interna.

- Supresión y reducción del número de camas en servicios como ginecología, medicina interna y pediatría. 
- Fortalecimiento de la oferta de consulta de medicina interna y endocrinología, con el fin de disminuir el tiempo de espera para asignación de citas.

- Disminuir el costo de la consulta de endocrino y medicina interna.

\section{Medidas de Saneamiento de pasivos}

Para el saneamiento de pasivos el PSFF el hospital San Blas plantea principalmente la depuración de deudas, para ello se platean las siguientes medidas:

- Definir saldos consistentes en las cuentas del pasivo de las cuales no se tiene aún certeza esto con el fin de que sean depuradas.

- Depurar de la cuenta por pagar reintegros y anticipos por pagar a pacientes.

- Depurar de la cuenta recaudos por reclasificar. Esta cuenta agrupa los valores consignados a favor de la ESE y que no se ha identificado su pagador.

\section{Medidas de Fortalecimiento de los ingresos}

En este aspecto se centran la mayor cantidad de medidas propuestas por el hospital San Blas en su PSFF, esto con el fin de generar la sostenibilidad financiera. EI conjunto de medidas planteadas para el fortalecimiento de los ingresos son:

- Ajustar el portafolio de servicios con el fin de adecuarlo a las necesidades de los usuarios en función del diseño de la red de prestación de servicios definida por la Dirección Distrital de Salud y en el marco del trabajo en Red (Hospital San Blas II NIvel, 2013). Lo cual implica la apertura de nuevos servicios como lo son aquellos relacionados con la atención integral de la diabetes, consulta para el dolor y cuidados paliativos y el servicio de apoyo diagnostico - tomografía axial computarizada TAC

- Especializar y fortalecer los servicios en los cuales el Hospital San Blas tiene una demanda superior al $80 \%$ de su utilización. 
- Fortalecer la oferta de consulta de medicina interna y endocrinología, con el fin de disminuir el tiempo de espera para la asignación de citas.

- Gestionar la reubicación de usuarios por abandono social con Trabajo social, para evitar estancias prolongadas para ellos se debe realizar un trabajo articulado la secretaria de integración social, SDS y contar con la vigilancia de los demás entes de control.

- Mejorar las condiciones de contratación actuales del Hospital de San Blas con las Empresas responsables de pago en el régimen contributivo y subsidiado. Mejorar condiciones de negociación de tarifas con CAPITAL SALUD TARIFA SOAT.

- Establecer y cumplir metas mínimas de recaudo y disminución de cartera, de acuerdo con la facturación radicada. Para ello se propone metas de recaudo con base en: a) facturación radicada, b) cuentas por cobrar vigencias anteriores, c) rezago de facturación no pagada, correspondiente a cartera corriente y no corriente así como suministrar a la oficina jurídica de la ESE, los soportes documentales requeridos para efectos de proceder con cobro coactivo de cartera.

- Ejercer control sobre el proceso de facturación de los servicios de salud que presta el Hospital San Blas de manera tal que se posibilite la facturación de los servicios prestados en el periodo.

- Mejorar el proceso de recepción, trámite y respuesta de glosa.

- Elaborar plan de saneamiento de cartera de difícil cobro e irrecuperable para la depuración de los estados financieros.

- Elaborar y ejecutar un plan de recuperación de cartera superior a 180 días. 
Situación de la ESE (Relación entre costos de funcionamiento - ingresos por facturación y costos de la planta de personal)

\section{Costos de funcionamiento}

En relación con los costos de funcionamiento se analizan los Gastos distribuidos en Gastos por Servicios Personales (Directos e Indirectos), Gastos Generales y Adquisición de Bienes y Servicios. Los gastos totales en el periodo analizado de 2008 ( $\$ 41.290$ millones a precios constantes) ascendieron a $\$ 44.391$ en el 2013 , es decir que en los 5 años analizados se presenta un incremento del 7.5\%. En el 2013, la participación mayor la tiene Servicios Personales que asciende al 46\%( \$20.262 millones), seguido por la adquisición de Bienes y Servicios con un participación del $27 \%$.

Gráfica 8 Composición de gastos Hospital San Blas 2008-2013 Fuente (Hospital San Blas II NIvel, 2013)

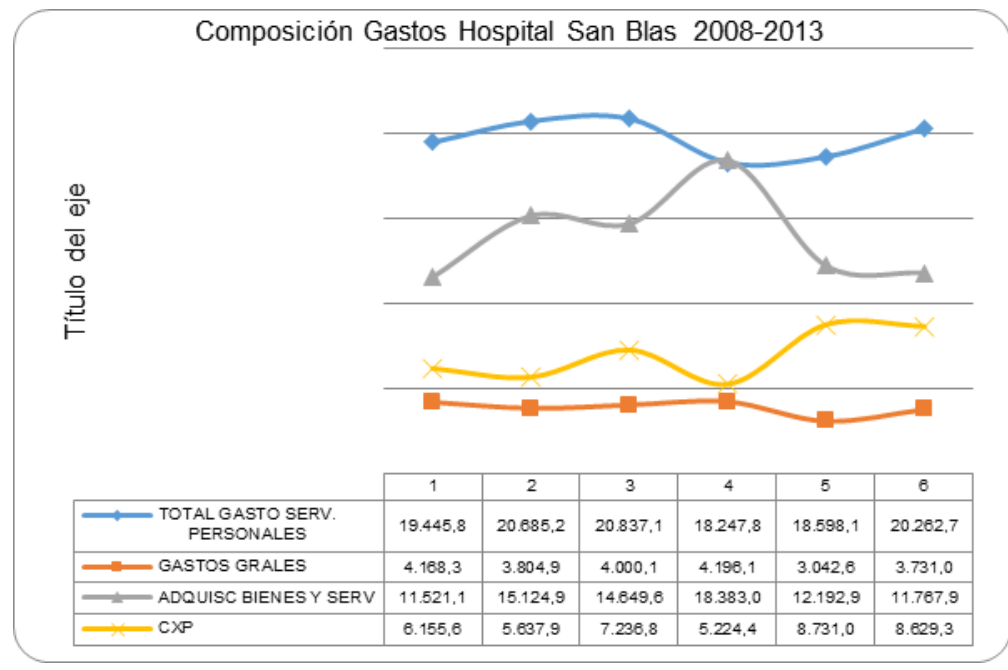

Fuente: (Hospital San Blas II Nlvel, 2013) 
Gráfica 9 Costos generados por servicios Hospital San Blas periodo 2008-2013

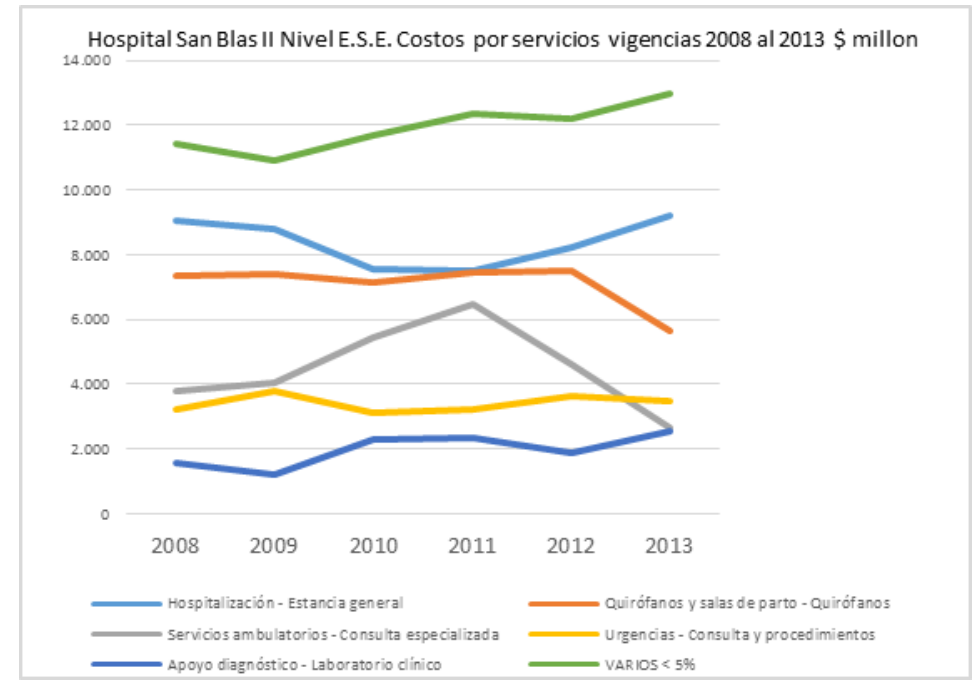

Fuente: (Hospital San Blas II NIvel, 2013)

\section{Costo de Personal}

En relación con los costos de la Planta de Personal, se observa que en las vigencias 2011- 2012, existen las mayores variaciones en Servicios personales asociados a la Nómina ( $\$ 899,4$ millones $=9.3 \%$ de incremento en comparación con el 2011), que incluye sueldos, horas extras, recargos y primas; esta variación se debe al incremento en al año 2012 del 5.5\% de la asignación básica y a sus implicaciones del personal de régimen retroactivo. Lo anterior produjo el incremento en las contribuciones inherentes a la nómina, que en el nivel privado fue de $\$ 444,6$ millones, correspondiente al $22.5 \%$ de incremento en comparación al 2011. Adicionalmente, el incremento es producido por la liquidación de personal directivo 
perteneciente a la administración anterior del Hospital, a los retirados por pensión (16 pensionados) y a la provisión de 29 vacantes y 7 encargos (Hospital San Blas II NIvel, 2013). De acuerdo al PSFF los altos costos en materia prestacional no se encuentran relacionados con el número de funcionarios sino con la antigüedad de su vinculación con el Hospital lo que hace que exista una serie de prebendas que generan dichos costos.

Gráfica 10 Valores mensuales de los costos de personal Hospital San Blas

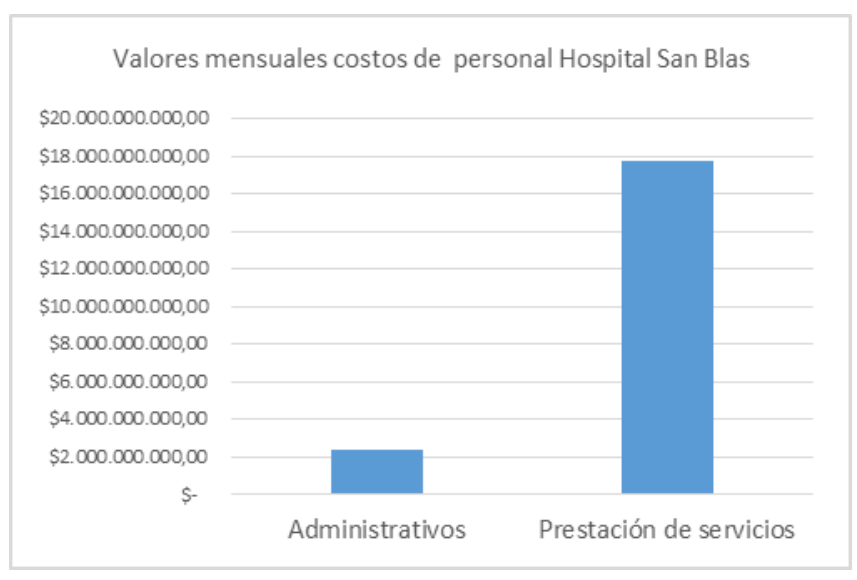

Fuente: (Hospital San Blas II NIvel, 2013)

Gráfica 11 Variación en los gastos de personal Hospital San Blas periodo 20102012.

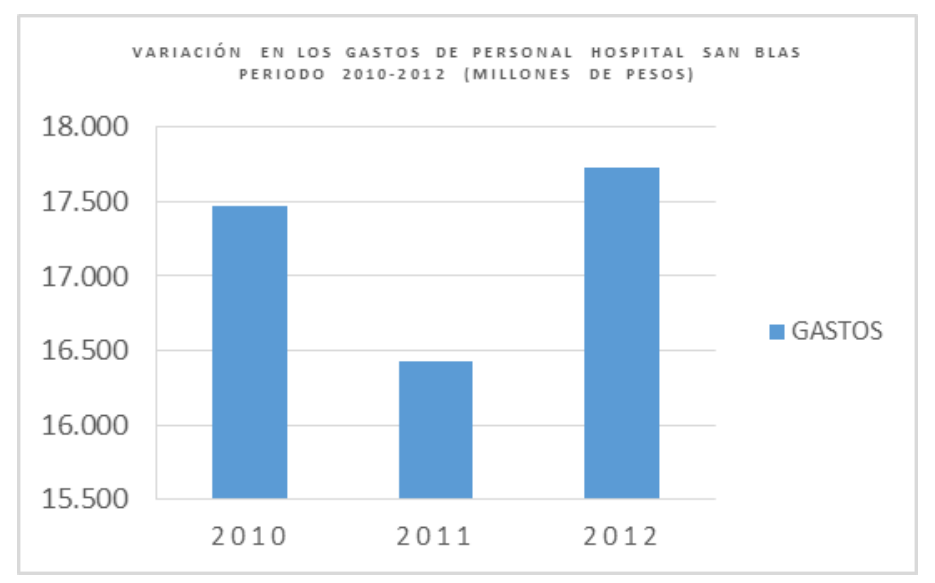

Fuente: (Hospital San Blas II Nlvel, 2013) 


\section{Ingresos por Facturación}

En relación con los ingresos del Hospital San Blas, estos están dados por la facturación de venta de servicios de salud a las diferentes entidades con las cuales el hospital ha celebrado contratos por evento, servicios agrupados en paquetes y por los copagos realizados por los usuarios beneficiados. Los ingresos del 2008 fueron de $\$ 32.893 .015$ y con otros ingresos representan al $20 \%$ del total de los años en estudio, el comportamiento de los ingresos fue uniforme en los años 2008, 2009 y 2010 , en el 2011 se presentó un incremento en la venta de servicios del $2 \%$, esta recuperación se perdió en el año 2012 y adicionalmente se presentó una disminución del $3 \%$.

Del período en estudio, el principal pagador fue el Fondo financiero, seguido por las EPS-S, aseguradoras y entidades regionales. El Fondo financiero Distrital fue disminuyendo la contratación hasta que el mes de junio de 2012 con la unificación del Plan Obligatorio de Salud, fueron las EPS Las entidades con las cuales el Hospital San Blas inicio el proceso de la nueva negociación, bajando notablemente los ingresos. (Hospital San Blas II NIvel, 2013)

Gráfica 12 Ingresos por facturación Hospital de Meissen periodo 2008-2013

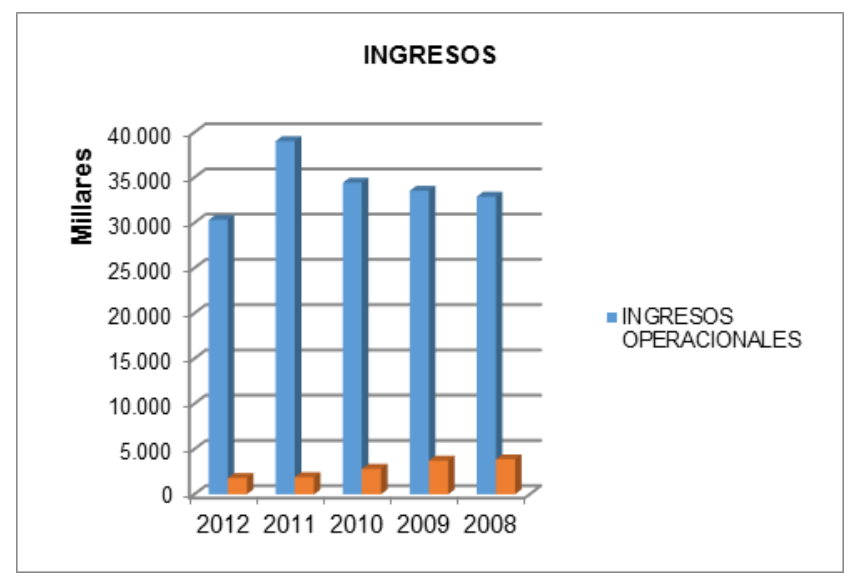

Fuente: (Hospital San Blas II NIvel, 2013) 


\subsubsection{Caracterización del PSFF hospital de Bosa II nivel ESE}

El Hospital Bosa II Nivel, ESE, es una Empresa Social del Estado creada mediante el acuerdo 17 de 1997, con autonomía administrativa, patrimonio propio, Junta Directiva y estructura organizacional definida, actualmente integra la subred Suroccidental de hospitales públicos distritales junto con otros hospitales como el Hospital Occidente de Kennedy, el Hospital Fontibón, el Hospital del Sur y el Hospital Pablo VI de Bosa.

Este hospital presta sus servicios en salud en la ciudad de Bogotá, y se encuentra ubicado en la Localidad de Bosa, en la Calle 65D Sur No. 79C 90. Está conformado por tres sedes que son: hospitalaria, consulta externa y una sede en la terminal satelital de transporte del sur, las cuales se encuentran habilitadas bajo los estándares de la Resolución No. 1043 de 2006, y actualmente se adelanta el proceso de renovación de su certificación por parte de la Secretaría Distrital de Salud. (Hospital Bosa II Nivel ESE, 2013) 
Tabla 10. Oferta de servicios Hospital de Bosa II Nivel ESE

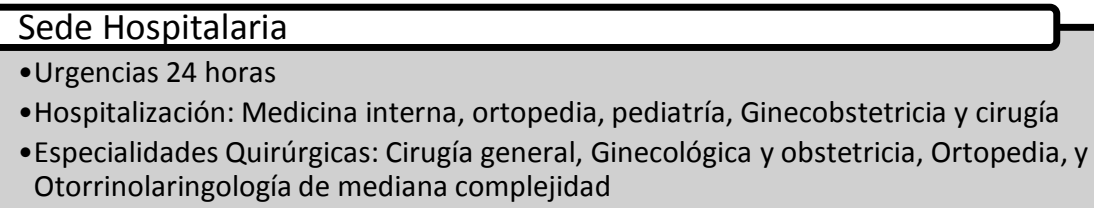

Sede Consulta Externa

- Presta servicios de fisioterapia de baja complejidad, consulta externa especializada de cirugía general, Ginecobstetricia, Medicina interna, ortopedia, pediatría, otorrinolaringología y las sub especialidades de: cardiología, y neumología pediátrica de mediana complejidad.

Sede Satelite del sur

- apoyo pre hospitalario al interior del Terminal de Transportes del Sur

Fuente: Elaborada por las autoras

A partir de la Resolución 2509 de 2012, la ESE fue categorizada como un hospital "en riesgo medio". A continuación se presenta una breve caracterización de la situación del Hospital con relación a los aspectos institucionales, administrativos, jurídicos y financieros identificados a través del PSFF a los cuales se les atribuye el origen del riesgo.

\section{Aspectos institucionales}

De acuerdo con la información que se encuentra en el PFSS está categorización del hospital en riesgo medio es el resultado de las condiciones financieras de la vigencia 2012 y las acumuladas de las vigencias anteriores, las cuales fueron afectadas por la baja en la venta de servicios, como consecuencia de la implementación de las medidas que llevaron a la unificación del Plan Obligatorio de Salud POS, así como la disminución en el recaudo de cartera, especialmente del régimen subsidiado por el incumplimiento en el pago de las Entidades Promotoras de Salud EPS y la estructura de costos en la prestación de servicios con escasas posibilidades de disminución. 
Otro de los aspectos identificados como problemáticos es la reducción en la producción del hospital debido a la disminución en la prestación de servicios y a las dificultades en la contratación de personal especializado por las problemáticas propias del contexto en el cual se ubica el hospital ( ubicación del hospital, difícil acceso, inseguridad, etc...).

Gráfica 13. Población atendida por el Hospital de Bosa II Nivel ESE. 2008-2012

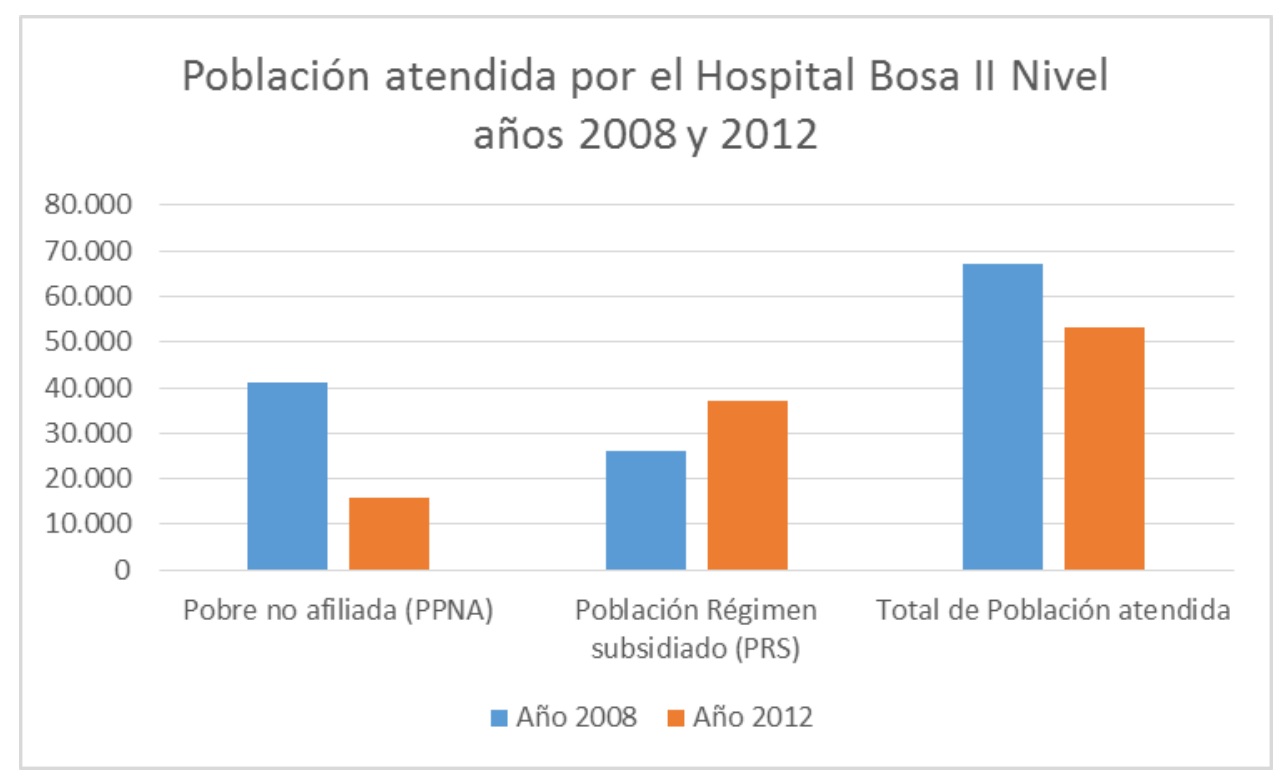

Fuente: Elaborado por las autoras

La reducción en la producción se ha originado principalmente por cambios en el tipo de población que demanda los servicios del hospital, ya que se pasó de la atención de población pobre no afiliada (PPNA) a la atención de población perteneciente al régimen subsidiado, esto generó una disminución significativa en la demanda de servicios por parte de la población PPNA que no logró ser compensada por la demanda de atención de la población perteneciente al régimen subsidiado, otro 
aspecto al cual se atribuye esta reducción, es la disminución en la demanda de servicios asistenciales como consulta especializada y cirugía, cuya reducción se atribuye a que la atención a la población pobre no afiliada que accedía a estos servicios en mayor medida, fue asumida por las EPS quienes cuentan con redes privadas cuyos costos son más competitivos en comparación con los costos de la red pública de hospitales. (Hospital Bosa II Nivel ESE, 2013)

\section{Aspectos administrativos}

En cuanto a los aspectos administrativos estos corresponde a aquellos relacionados con las actividades de soporte y complementarias que permiten el desarrollo del objeto social de la ESE y que se concretan en procedimientos que respaldan la entidad.

Al realizar la revisión del PSFF se encontró que el hospital presenta dificultades en relación con el cumplimiento de los estándares obligatorios mínimos de prestación de servicio exigidos por la ley, debido a limitaciones presupuestales, también se plantea que el sistema de información utilizado para el apoyo de las funciones misionales esta desactualizado, es obsoleto y carece del soporte adecuado lo cual limita la calidad en la prestación del servicio (HOSPITAL DE BOSA II NIVEL ESE, 2012).

Esto ha ocasionado una inoportuna e insuficiente consolidación, análisis y generación de reportes, en la ausencia de una historia clínica sistematizada que reúna los requisitos de integralidad, seguridad y confidencialidad, el sistema de procesamiento en lotes y la exigencia de reproceso y procesos paralelos para validar la información por las cargas administrativas que generan. Es importante 
resaltar que la falta de un adecuado sistema integrado de información no permite a la institución realizar un completo seguimiento tanto a la gestión clínica como administrativa y financiera. (Hospital Bosa II Nivel ESE, 2013).

Una problemática que se manifiesta en el Programa es la alta carga prestacional generada por la antigüedad en el servicio de gran parte del personal que labora en el hospital, otro facto problemático se le atribuye a la pertenencia de funcionarios al régimen de cesantías retroactivas, así como el fuerte impacto que tienen sobre las finanzas del hospital algunos factores salariales como lo son la prima de antigüedad creada por el Concejo Distrital en los acuerdos No. 8 de 1985 y No. 6 de 1986.

Por otra parte, el Hospital cuenta con una alta programación de turnos nocturnos y dominicales en el personal de planta, lo cual trae como consecuencia incrementos en el valor de la nómina, sumado a que los acuerdos convencionales ${ }^{5}$ impiden aplicar algunas acciones de reducción en esos gastos de los rubros de nómina.

\section{Aspectos jurídicos}

En relación con los aspectos jurídicos se encontró que el hospital presenta un alto volumen de pasivos contingentes judiciales, ocasionados por la baja adherencia de los funcionarios a las guías de práctica clínica, lo cual ha ocasionado demandas en contra de la entidad por falla en los procedimientos médicos.

\footnotetext{
${ }^{5}$ Corresponde a la Convención Colectiva de los Trabajadores Oficiales de la Red Pública de Hospitales del Distrito Capital. 2012-2016.
} 


\section{Aspectos financieros}

El análisis conjunto de los informes financieros individuales de costos, ingresos, gastos, pasivos, cartera, presupuesto y estados financieros, permite identificar una serie de problemas detectados, sus causas, las debilidades, las amenazas, las fortalezas y las oportunidades para fortalecer la formulación de medidas de saneamiento fiscal y financiero. Ya en la primera parte del análisis comparativo de los estados de actividad económica y social y del balance general de los últimos cinco años y evaluando el comportamiento de los indicadores, las cifras y sus variaciones, se identificaron algunos factores que generan riesgo financiero a la ESE, los cuales son:

1. No se dispone de un sistema de información integrado para el procesamiento de información de cartera y el sistema que soporta los demás procesos financieros es obsoleto.

2. La información de cartera procesada en las actuales condiciones genera atrasos que impactan la confiabilidad y oportunidad, por lo que las cifras están desactualizadas, carecen de conciliaciones oportunas, tanto internas como externas, acumulan datos de cuentas incobrables y requieren un proceso de depuración inmediato.

3. La estructura de costos del hospital constituye una debilidad que, lejos de permitir aplicar correctivos, tiende generar situaciones permanentes de desequilibrio que eclipsan las acciones de mejora desarrolladas en otras áreas para alcanzar el punto de equilibrio.

4. El proceso de atención, respuesta y conciliación de glosas se afecta en oportunidad por la falta de un sistema de información que incorpore este elemento tan importante para agilizar el recaudo. 
En las anteriores vigencias las transferencias del nivel central corrigieron el déficit presentado. Para este año el insuficiente presupuesto asignado genera dificultades a todos los procesos que requieren oportuna y suficientemente la asignación de recursos humanos y técnicos. Los tramites que se requieren para superar esta amenaza, deben adelantarse con mucha frecuencia durante el año, afectado a todos los procesos. (Hospital Bosa II Nivel ESE, 2013)

Los resultados deficitarios de vigencias anteriores han generado altos niveles de pasivos que están siendo superados con el apoyo financiero del ente territorial. El sistema de información de costos hospitalarios es incipiente y no cuenta con herramientas de software adecuado que permita hacer uso del mismo para el análisis y toma de decisiones.

\section{Acciones propuestas por el Hospital de Bosa II nivel para el saneamiento fiscal y financiero}

En relación con del Plan de Saneamiento Fiscal y Financiero el PSFF del Hospital Bosa II Nivel, el artículo 8 de la Ley 1608 de 2013, determina que este plan debe contener medidas que permitan una adecuada operación de las Entidades sociales del estado garantizando el acceso, oportunidad, continuidad y calidad en la prestación de los servicios de salud a la población usuaria. (Ministerio de Hacienda y Crédito Público).

Para ello propone que los planes contengan medidas centradas en cinco componentes los cuales son: Reorganización administrativa; Racionalización del gasto; Reestructuración de la deuda; Saneamiento de pasivos, y Fortalecimiento de 
los ingresos de las ESE; es a partir de estos ejes que se analiza la propuesta planteada por el hospital para mejorar sus finanzas:

\section{Medidas de Reorganización Administrativa}

Las medidas de reorganización administrativa tomadas por el hospital se centran en los siguientes Aspectos:

1. Socialización, actualización y evaluación de las adherencias a los procedimientos:

2. Consolidación de la información de actividades facturadas mensualmente, registradas en los Registros Individuales de Prestación de Servicios (RIPS) en el período $2008-2013$

\section{Medidas de Racionalización del Gasto:}

1. Negociación y compra conjunta en Red, a través de cooperativas u otros mecanismos para medicamentos e insumos medico quirúrgicos, y otros elementos o servicios para las 5 ESE de la Red Sur Occidente

2. Disposición de un valor mensual de liquidez (efectivo), que permitan a la ESE poder efectuar pagos oportunos y obtener descuentos por pronto pago

3. Reorganización del trabajo asistencial nocturno del personal de planta y contratista

4. Lograr concientizar a los prepensionados para que realicen sus trámites de pensión

En el marco de las Redes Integradas de Servicios de Salud (RISS), se realiza reorganización de servicios para las cinco E.S.E de la Subred sur occidente, de acuerdo a nivel de complejidad, capacidad instalada y experiencia acumulada en la operación de sus servicios. 


\section{Medidas de saneamiento de pasivos:}

5. Mantener depuradas y conciliadas las cuentas por pagar

\section{Medidas de Fortalecimiento de los ingresos de la ESE}

1. Fortalecer central de cuentas, que facilite el mejoramiento del proceso de facturación con pre auditoría a la atención en salud y generación de facturas

2. Incrementar los volúmenes de recaudo de cartera de la vigencia que financien la operación con la abogacía del Ministerio de Salud y SDS

3. Mejorar la producción del servicio de Ginecoobstetricia, Pediatría y urgencias

4. Depuración y conciliación de la cartera para obtener su reconocimiento

5. Financiamiento parcial del gasto generado por la operación de los Trabajadores oficiales con recursos del Programa de Saneamiento Fiscal y Financiero. 


\section{CAPITULO 3. PROGRAMA DE SANEAMIENTO FISCAL Y FINANCIERO DEL HOSPITAL DE BOSA II NIVEL - ESE: DESDE SU VIABILIDAD E IMPACTO FRENTE A LAS OBLIGACIONES CONVENCIONALES Y CARGAS LABORALES}

\subsection{Programa de Saneamiento Fiscal y Financiero 2013-2017 - Hospital de Bosa II Nivel ESE}

Conforme los parámetros gubernamentales establecidos, el Hospital de Bosa II Nivel ESE, viene implementando su "Programa de Saneamiento Fiscal y Financiero 2013-2017', razón por la cual se ha visto en la necesidad de replantear una serie de acciones tendientes al logro de dicho objetivo, bajo los presupuestos económicos de restablecer la solidez financiera de la entidad. (Hospital de Bosa II Nivel - ESE)

Esta situación ha planteado una fuerte tensión entre lo que se considera una entidad garante del derecho a la salud, frente a una institución que debe dar continuidad, como afirma la ley, en la prestación del servicio público de salud desde una adecuada operación que será monitoreada y evaluada por el propio Ministerio de Hacienda y Crédito Público. De allí, que se obsérvese a la ESE desde su caracterización como garante social, pero a la vez, como una entidad rentable desde lo económico.

El Hospital enmarca su accionar conforme lo planteado en las políticas Públicas Distritales, "Programa Territorios Saludables y Red de Salud para la Vida desde la Diversidad," desde los siguientes postulados, 
"Asegurar el goce efectivo del derecho fundamental a la salud a través de un modelo de salud humanizado, participativo, integral e incluyente, que basado en la Atención Primaria en Salud (APS) y en la organización de los servicios estatales en red, permita de manera muy precisa modificar las condiciones que determinan la calidad de vida y la salud de la población del Distrito Capital, incluyendo la superación de todas aquellas situaciones problemáticas inherentes al modelo de seguridad social en salud prevaleciente en la ciudad y en el país, favoreciendo con su operación la atención integral y oportuna, en coordinación y con el apoyo de la comunidad y los demás sectores y entidades de la administración, bajo la perspectiva del enfoque diferencial en la atención en cuanto a género, edad, ciclo vital, etnia, territorio, grupo y condición social, junto con la incorporación de once enfoques diferenciales para la atención integral a víctimas del conflicto armado y el reconocimiento de prácticas de los grupos étnicos." (Secretaria Distrital de Salud, 2012)

Es desde estos parámetros, que la visión - misión de la entidad corresponde a su participación en la Red Territorial Sur Occidente, en el marco de una "Gestión Socialmente Responsable", que contribuya al mejoramiento de la calidad de vida y salud de las comunidades, a partir de la prestación de servicios de salud "con calidad científica, centrada en la seguridad del paciente, con un equipo humano competente que genera confianza y satisfacción en sus usuarios", cumpliendo con una "atención oportuna, cálida y segura, que genere rentabilidad social." (Hospital Bosa II Nivel ESE, 2013) 
De esta forma se presenta a una entidad prestadora de servicios de salud, con un doble compromiso, por una parte, garantizar el goce efectivo del derecho fundamental a la salud desde un modelo humanizado y por otra, lograr rentabilidad, solidez económica y financiera.

Como se evidenció en el capítulo anterior, en el PSFF del hospital de Bosa se logró identificar las dificultades presentadas en torno a: I) reorganización administrativa, II) racionalización del gasto, III) saneamiento de pasivos y IV) fortalecimiento de los ingresos. Desde estos parámetros se formularon una serie de medidas en pro de lograr el saneamiento y fortalecer la institución. El grueso de las medidas se dirigió a racionalización del gasto y fortalecimiento de los ingresos, tomándolos como aspectos ejes del programa con el objetivo de lograr el equilibrio financiero de la entidad. (Hospital de Bosa II Nivel ESE, 2014) 


\section{Tabla 11. Medidas planteadas en el programa de saneamiento fiscal y financiero}

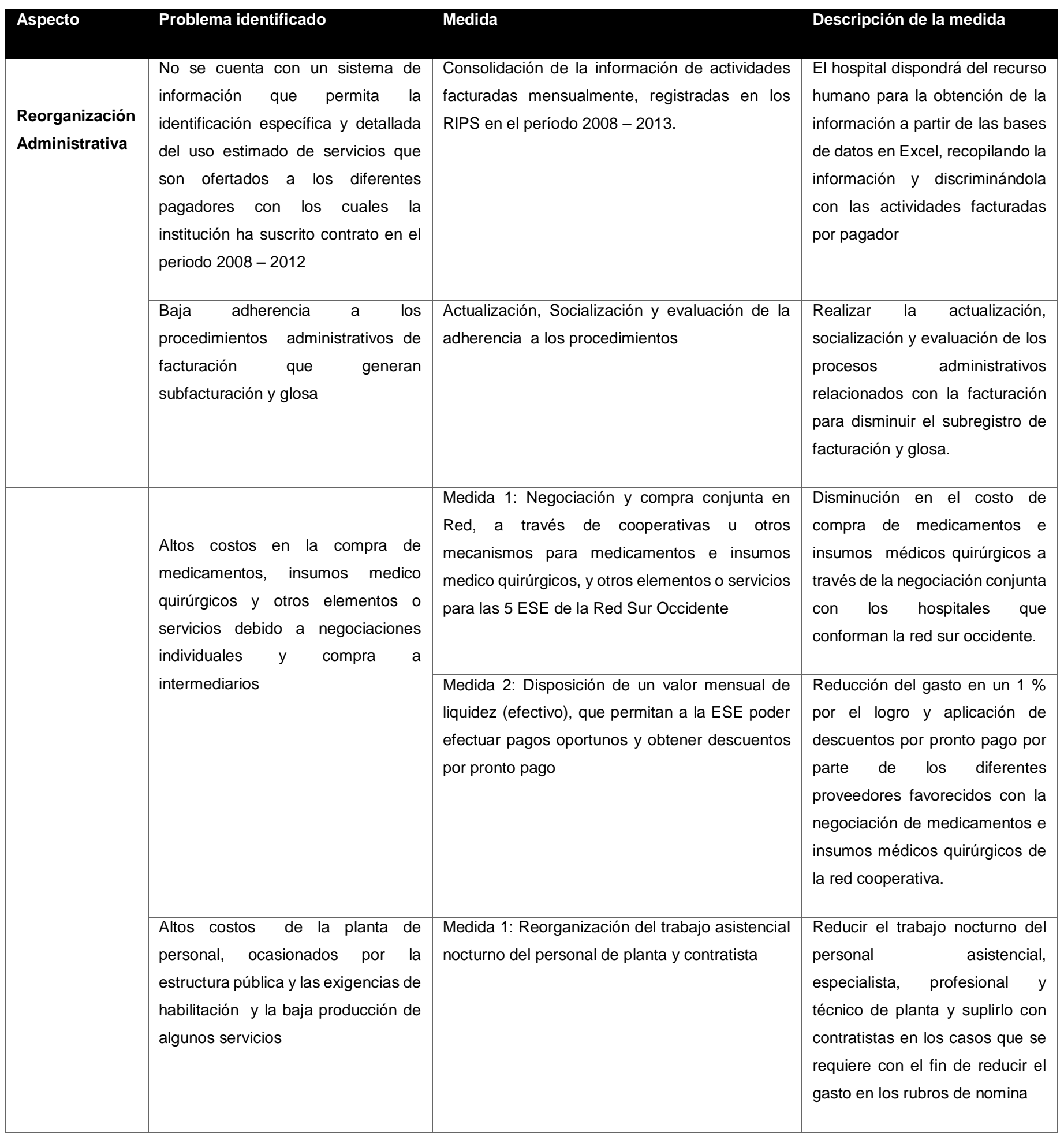




\begin{tabular}{|c|c|c|c|}
\hline \multirow[t]{3}{*}{$\begin{array}{l}\text { Racionalizació } \\
\text { n del gasto }\end{array}$} & & $\begin{array}{l}\text { Medida 2: En el marco de las RISS, se realiza } \\
\text { reorganización de servicios para las cinco E.S.E } \\
\text { de la Subred sur occidente, de acuerdo a nivel de } \\
\text { complejidad, capacidad instalada y experiencia } \\
\text { acumulada en la operación de sus servicios. }\end{array}$ & $\begin{array}{l}\text { Las ESE de la sub red sur } \\
\text { occidente, implementaran la } \\
\text { medida a través de un plan de } \\
\text { acción que integre: estrategias } \\
\text { de sistema de referencia y contra } \\
\text { referencia, sistemas de } \\
\text { información, unificación de } \\
\text { tarifas- Manual tarifario en Red, } \\
\text { portafolio de servicios ajustados, } \\
\text { venta de servicios en red, que } \\
\text { contribuyan al equilibrio, } \\
\text { sostenibilidad y perdurabilidad } \\
\text { financiera de las ESE que } \\
\text { integran esta subred }\end{array}$ \\
\hline & $\begin{array}{l}\text { Alto costo de la carga prestacional } \\
\text { generada por el régimen de } \\
\text { cesantías y otros beneficios }\end{array}$ & $\begin{array}{l}\text { Medida: Lograr concientizar a los } \\
\text { prepensionados para que realicen sus trámites } \\
\text { de pensión }\end{array}$ & $\begin{array}{l}\text { Apoyar programa de } \\
\text { prepensionados con un } \\
\text { profesional en sicología y uno en } \\
\text { derecho que desarrollen } \\
\text { acciones tendientes a lograr que } \\
\text { los prepensionados inicien y } \\
\text { culminen sus trámites de pensión }\end{array}$ \\
\hline & $\begin{array}{l}\text { Altos costos en el mantenimiento del } \\
\text { área de imagenología y esterilización }\end{array}$ & $\begin{array}{l}\text { Altos costos en el mantenimiento de los equipos } \\
\text { de } R X \text { y Esterilización y arriendo de la } \\
\text { procesadora de placas }\end{array}$ & $\begin{array}{l}\text { Cero pesos en mantenimiento } \\
\text { correctivo de equipos de rayos } X \\
\text { y esterilización y arriendo de } \\
\text { procesadora de placas }\end{array}$ \\
\hline $\begin{array}{l}\text { Saneamiento } \\
\text { de Pasivos }\end{array}$ & $\begin{array}{l}\text { Desfinanciación de las cuentas por } \\
\text { pagar }\end{array}$ & $\begin{array}{l}\text { Mantener depuradas y conciliadas las cuentas } \\
\text { por pagar }\end{array}$ & $\begin{array}{l}\text { Realizar conciliación y } \\
\text { depuración de pasivos }\end{array}$ \\
\hline \multirow{3}{*}{$\begin{array}{l}\text { Fortalecimiento } \\
\text { de los ingresos } \\
\text { de la ESE }\end{array}$} & $\begin{array}{l}\text { Bajo nivel de recaudo por } \\
\text { deficiencias en el proceso de } \\
\text { facturación }\end{array}$ & $\begin{array}{l}\text { Fortalecer central de cuentas, que facilite el } \\
\text { mejoramiento del proceso de facturación con } \\
\text { preauditoría a la atención en salud y generación } \\
\text { de facturas }\end{array}$ & $\begin{array}{l}\text { Reducir los porcentajes de glosa } \\
\text { parcial y devolución de facturas, } \\
\text { mediante la pre auditoría de } \\
\text { cuentas }\end{array}$ \\
\hline & & $\begin{array}{l}\text { Incrementar los volúmenes de recaudo de cartera } \\
\text { de la vigencia que financien la operación con la } \\
\text { abogacía del Ministerio de Salud y SDS }\end{array}$ & $\begin{array}{l}\text { Incrementar el porcentaje de } \\
\text { recaudo de la vigencia con } \\
\text { acciones efectivas de cobro pre } \\
\text { jurídico y jurídico }\end{array}$ \\
\hline & $\begin{array}{l}\text { Baja utilización de la capacidad } \\
\text { instalada y baja producción en los } \\
\text { diferentes niveles de servicios } \\
\text { asistenciales causada por }\end{array}$ & $\begin{array}{l}\text { Mejorar la producción del servicio de } \\
\text { Ginecoobstetricia. }\end{array}$ & $\begin{array}{l}\text { Contar con la resolución de la } \\
\text { SIC que apruebe el acuerdo de } \\
\text { voluntades entre los hospitales } \\
\text { de la Subred suroccidente para } \\
\text { estandarizar tarifas de ventas de }\end{array}$ \\
\hline
\end{tabular}




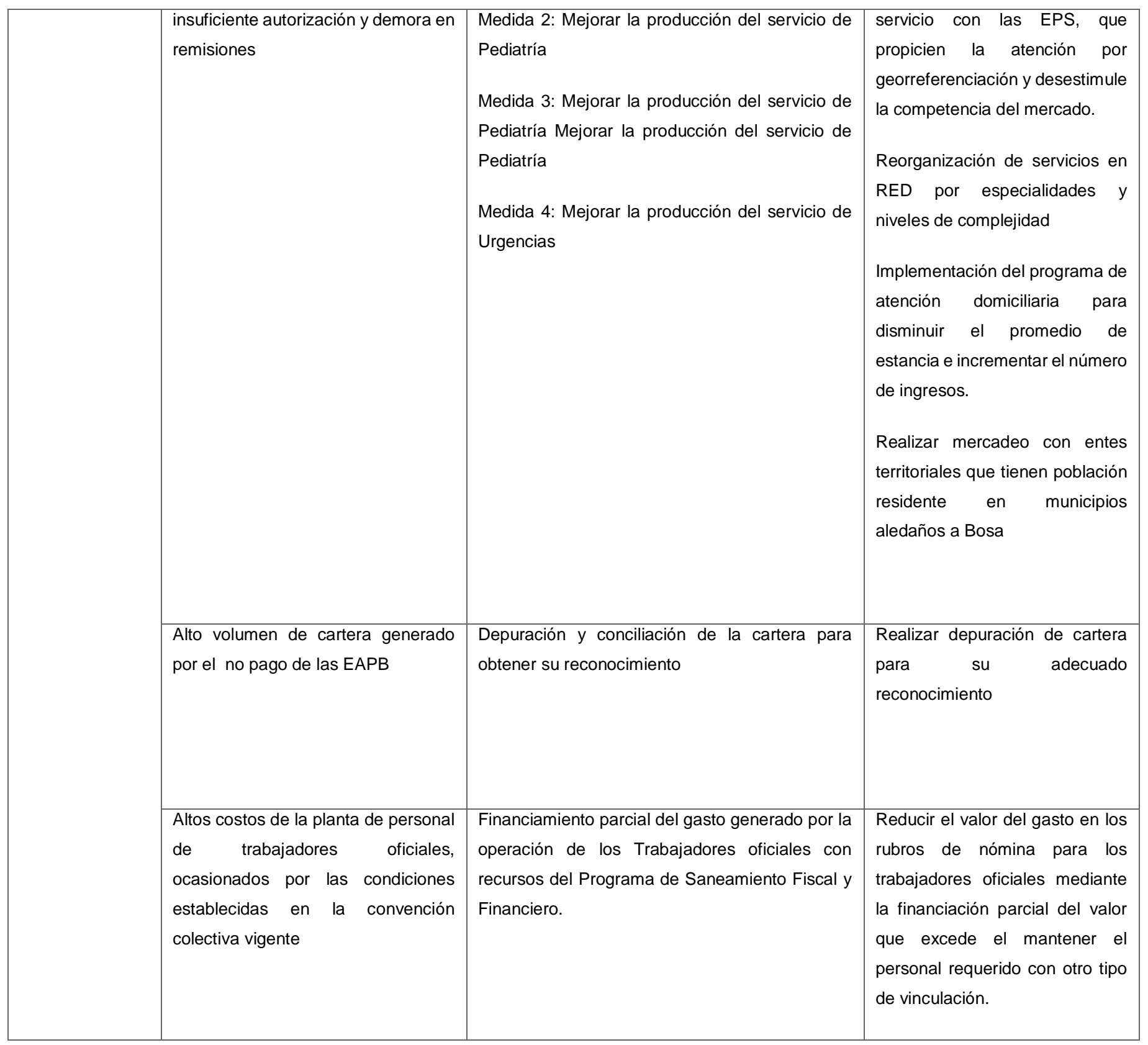

Fuente: Tabla elaborado por las autoras.

Del estudio inicial del Programa se verifica el cumplimiento de todos los aspectos definidos por la Ley 1608 de 2013 y su disposición al proceso de seguimiento y evaluación a cargo del Ministerio de Hacienda y Crédito Público, es así como en el 
Monitoreo que realiza la ESE del cumplimiento de las medidas con corte a III trimestre de 2015 se tiene el siguiente análisis:

\section{CATEGORÍA: RACIONALIZACIÓN DEL GASTO ${ }^{6}$}

\section{Medida 1: Reorganización del trabajo asistencial nocturno del personal de planta y contratista.}

La medida se proyectó para el año 2015, sin embargo el Hospital inició su implementación en el año 2014. Esta medida fue planteada en el Plan de Saneamiento Fiscal y Financiero, como una reducción de $2.9 \%$ frente a la línea base del año 2013 , que era de $\$ 610.950 .978$ en el rubro de trabajo nocturno.

La reducción de horas nocturnas del personal profesional y especialista de planta del Hospital se logró con la optimización de la capacidad instalada en recurso humano del Hospital, aprovechándola al máximo y realizando redistribución del recurso humano de planta y adicionalmente, en los casos requeridos, se suplieron esas horas nocturnas con personal contratista sin afectar la calidad y oportunidad en la prestación de los servicios, dado que los profesionales de planta y contrato tienen los mismos perfiles y competencias para desarrollar las actividades del correspondiente servicio.

Es así como para el tercer trimestre del año 2015, se generó una disminución en el gasto en los rubros de horas extras, dominicales y festivos 2013 vs 2015 equivalente a $\$ 8.224 .588$ de conformidad con las ejecuciones presupuestales correspondientes a los mismos años a 3 trimestre.

\footnotetext{
${ }^{6}$ Para la elaboración del presente acápite se toma como fuente el documento Monitoreo III Trimestre 2015, elaborado por los profesionales del Hospital de Bosa. (Hospital de Bosa II Nivel - ESE, 2015)
} 
Medida 2: En el marco de las RISS, se realiza reorganización de servicios para las cinco E.S.E de la Subred sur occidente, de acuerdo a nivel de complejidad, capacidad instalada y experiencia acumulada en la operación de sus servicios.

No se avanzó en la implementación de la medida, debido a limitantes con la comunidad usuaria de servicios de salud de las diferentes localidades.

\section{Medida 3: Lograr concientizar a los prepensionados para que realicen sus trámites de pensión.}

El hospital logro la reducción anticipada del gasto en los rubros de nómina, debido al apoyo que prestó a los prepensionados en aspectos legales y psicológicos y la aplicación del programa de prepensionados del hospital. Es importante observar, que además de la reducción anticipada del gasto en los rubros de nómina, para el año 2015 tercer trimestre, se calcula a la fecha una reducción por valor de \$262.264.656 debido al retiro por obtención de pensión de 8 funcionarios proyectados para 2015 y 1 funcionario que había sido proyectado para 2016. Sumado a esto, la ESE definió la no provisión de los cargos que resultan vacantes por cuenta del logro del reconocimiento de la pensión por vejez de estos funcionarios

Medida 4: Altos costos en el mantenimiento de los equipos de RX y Esterilización y arriendo de la procesadora de placas.

Solo hasta finales del mes de marzo se pudo contar con el equipo de rayos $\mathrm{X}$ con digitalizador de imágenes en funcionamiento y por ende el ahorro planteado en esta medida solo empezó a evidenciarse a partir del 1 de abril del año 2015, en donde a la fecha se ha generado un ahorro equivalente a seis meses de arrendamiento de 
la procesadora de las antiguas placas radiográficas, por $\$ 2.150 .000$ en el rubro de arriendos.

\section{CATEGORÍA: FORTALECIMIENTO DE LOS INGRESOS DE LAS ESE}

5: Fortalecer central de cuentas, que facilite el mejoramiento del proceso de facturación con preauditoría a la atención en salud y generación de facturas.

Para este subproceso, fundamental en la generación de ingresos y recaudo, se mantiene el proceso de mejoramiento mediante la aplicación de técnicas de análisis y solución de problemas, que conlleva la actualización del manual de procesos y procedimientos y el Manual de Autorizaciones. Estos documentos actualizados están siendo socializados, evaluados y medido el impacto en el mejoramiento de los niveles de facturación y prevención de objeciones por parte de las empresas responsables de pago. Se complementa el fortalecimiento con capacitación y entrenamiento permanente al personal involucrado.

El mejoramiento de los procesos de facturación está orientado a prevenir la ocurrencia de objeciones sobre las facturas por venta de servicios de salud, de manera que se logren reducir los porcentajes de glosa parcial y devolución de facturas, con acompañamiento de acciones de preauditoria de las cuentas.

\section{Medida 6: Incrementar los volúmenes de recaudo de cartera de la vigencia que financien la operación con la abogacía del Ministerio de Salud y SDS.}

Se consiguió mejorar el recaudo de la facturación de la vigencia frente al año anterior en un $2,7 \%$, de acuerdo con los siguientes resultados: 
Tabla 12. Recaudo de facturación

\begin{tabular}{|l|r|r|r|c|}
\hline & 2014 & 2015 & $\begin{array}{r}\text { VARIACION } \\
\text { ABSOLUTA }\end{array}$ & $\begin{array}{c}\text { VARIACION } \\
\text { RELATIVA }\end{array}$ \\
\hline FACTURADO & 12.312 .275 .072 & 12.229 .093 .236 & $(83.181 .835)$ & $-0,7 \%$ \\
\hline RECAUDO VIGENCIA & 8.058 .292 .741 & 8.274 .761 .623 & 216.468 .882 & $2,7 \%$ \\
\hline $\begin{array}{l}\text { RECAUDO CUENTAS POR } \\
\text { COBRAR }\end{array}$ & 2.285 .926 .776 & 3.417 .541 .870 & 1.131 .615 .094 & $49,5 \%$ \\
\hline $\begin{array}{l}\text { TOTAL RECAUDO VENTA } \\
\text { DE SERVICIOS }\end{array}$ & 10.344 .219 .517 & 11.692 .303 .493 & 1.348 .083 .976 & $13,0 \%$ \\
\hline $\begin{array}{l}\text { PORCENTAJE DE LA } \\
\text { VIGENCIA }\end{array}$ & $\mathbf{6 5 \%}$ & $\mathbf{6 8 \%}$ & $\mathbf{2} \%$ & \\
\hline
\end{tabular}

Fuente: (Hospital de Bosa II Nivel - ESE, 2015)

Si bien el resultado del incremento en el total del recaudo fue del $13 \%$, el porcentaje de recaudo de la vigencia muestra un nivel que lo hace insuficiente para el cumplimiento de la programación para atenuar el déficit fiscal, debido a tan solo se alcanza un $68 \%$ en los primeros nueve meses. Lo anterior a todas las estrategias de cobro y de gestión persuasiva y coactiva al mismo.

Medida 7: Mejorar la producción del servicio de Ginecoobstetricia.

Medida 8: Mejorar la producción del área Quirúrgica.

Medida 9: Mejorar la producción del servicio de Pediatría.

Medida 10: Mejorar la producción del servicio de Urgencias

En el caso del servicio de ginecobstetricia no se dió el cumplimento en la meta de producción, debido principalmente a que en el marco de las RISS lo se logró la reorganización de servicios para las cinco E.S.E de la subred sur occidente. 
En el servicio de cirugía, el cumplimiento de la meta de producción para fortalecer los ingresos alcanzo para el periodo evaluado el $79 \%$. A pesar de las practica dilatorias de las EPS para que los usuarios accedan a los servicios ambulatorios, donde media una autorización para condicionar la prestación del servicio, la ESE realizo múltiples gestiones a fin de evitar que este servicio disminuyera la producción.

El servicio de urgencias presentó al tercer trimestre del 2015 un cumplimiento de meta en consulta del $76 \%$ Este resultado corresponde a la demanda espontanea que tiene el servicio en la localidad y la interconsulta corresponde a la demanda de las diferentes especialidades que presenta el servicio de urgencias.

\section{Medida 11: Depuración y conciliación de la cartera para obtener su reconocimiento}

Se presentó cumplimiento en dos de las estrategias planteadas para el cumplimiento de la medida. En la primera, se estableció un cronograma interno para la radicación oportuna y su cumplimiento es satisfactorio, garantizando que el $91 \%$ de la facturación se radica según el citado cronograma interno y el 100\% dentro de los plazos establecidos por la norma, para facilitar su recaudo. Sin embargo la cartera se incrementó con las EPS, aseguradoras del SOAT y el FOSYGA, especialmente la cartera mayor a 360 días, debido a la falta de resolución de deudas para las que las aseguradoras aducen prescripción.

\section{Medida 12: Apalancamiento del costo de los trabajadores oficiales con subsidio mediante convenio con el Ente Territorial}

El Hospital, planteó esta medida desde el año 2013, el ente territorial emitió certificación de aporte ordinario a esta medida, y Secretaria Distrital de Salud mediante acto administrativo asignó los recursos correspondientes al año 2015. 
Del análisis inicial del Programa se verifica el cumplimiento de todos los aspectos definidos por la Ley 1608 de 2013 y su disposición al proceso de seguimiento y evaluación a cargo del Ministerio de Hacienda y Crédito Público, más sin embargo para el interés de la investigación y tras continuar el hospital en la categorización de "en riesgo" (medio- alto) se toma como eje de estudio un ítem de gran importancia que se relaciona directamente con el tema del derecho colectivo y su interpretación, pero además, tiene que ver con la garantía de las condiciones de trabajo frente a lo que implica un modelo financiero. Esto corresponde a la medida propuesta por el hospital de: "Financiamiento parcial del gasto generado por la operación de los Trabajadores oficiales con recursos del Programa de Saneamiento Fiscal $y$ Financiero." Propuesta que es considerada por la ESE tras "los altos costos de la planta de personal de trabajadores oficiales, ocasionados por las condiciones establecidas en la convención colectiva vigente." (Hospital Bosa II Nivel ESE, 2013)

Bajo esta perspectiva surge la pregunta de si $i$ es posible implementar el Programa de Saneamiento Fiscal y Financiero 2013-2017 del Hospital Bosa II Nivel ESE y al mismo tiempo cumplir con las cargas pactadas en la Convención Colectiva vigente?

Este planteamiento se hace relevante ante la necesidad de la ESE de fortalecer sus ingresos como parte del proceso de restablecimiento de solidez económica y financiera, en aras de dar continuidad a la prestación del servicio público de salud. Pero también, ante la responsabilidad social que tienen de respetar y cumplir con los acuerdos convencionales establecidos entre "las entidades descentralizadas adscritas técnica, científica y administrativamente a la Secretaría Distrital de Salud, comprendidos los Hospitales I, II y III Niveles de Atención y sus Trabajadores 
Oficiales." (ESE - SINTRASALUD - AGRECONDUCTORES - SINDISTRITALES, 1995 - 2016)

A continuación se procederá a revisar el proceso de acuerdos convencionales frente a la implicación de promover el financiamiento parcial del gasto generado por la operación de los Trabajadores Oficiales con recursos del Programa de Saneamiento Fiscal y Financiero. (Hospital Bosa II Nivel ESE, 2013)

\subsection{Los trabajadores Oficiales en el Programa de Saneamiento del Hospital de Bosa II Nivel - ESE}

La Convención Colectiva, conforme el Código Sustantivo del Trabajo se define como:

"La que se celebra entre uno o varios empleadores o asociaciones patronales, por una parte, y uno o varios sindicatos o federaciones sindicales de trabajadores, por la otra, para fijar las condiciones que regirán los contratos de trabajo durante su vigencia. (...) Además de las estipulaciones que las partes acuerden en relación con las condiciones generales de trabajo, en la convención colectiva se indicarán la empresa o establecimiento, industria y oficios que comprenda, el lugar o lugares donde ha de regir, la fecha en que entrará en vigor, el plazo de duración y las causas y modalidades de su prórroga, su desahucio o denuncia, y la responsabilidad que su incumplimiento entrañe." (Congreso de la República de Colombia, 150) 
Es importante reconocer que los acuerdos convencionales son obligación para las partes, hecho que ha sido ratificado por la Corte Constitucional en la Sentencia C902 del año 2003, exaltando sus componentes normativo y obligacional, como acto jurídico de forzoso cumplimiento entre quienes lo suscriben. Únicamente en la medida en que las partes vinculadas tengan el legítimo propósito y actúen en consecuencia de respetar los acuerdos pactados, es posible asegurar que las relaciones entre empresarios y trabajadores constituyan el entorno de cooperación para el mantenimiento de paz laboral. Desde esta perspectiva, la Convención Colectiva se entiende como un acuerdo bilateral, donde existen elementos de intercambio - quid pro quo - y se establecen las reglas que regulan, siendo ésta el elemento obligatorio o aspecto obligacional, que está conformado por aquellas cláusulas que señalan deberes u obligaciones para las partes. (Sentencia C-902, 2003)

Sumado a ello valga la pena resaltar, el efecto jurídico de la Convención que recae en la regulación de las relaciones de trabajo individual, es decir, los contratos individuales de trabajo. Destacándose, las medidas de orden económico, que atañen las cargas monetarias para las empresas frente a los trabajadores en particular o ante la organización sindical. (Sentencia C-902, 2003) Para efectos de la técnica de casación laboral se ha aceptado reiteradamente que la norma convencional equivale a la ley sustantiva o sustancial, aunque para su consideración como ley sustancial sea necesario que se cite en su apoyo la norma legal de la cual deriva su carácter obligatorio (C.S.T, art. 467) y su aplicabilidad al caso concreto, cuando en esta se discute (C.S.T Artículo 470 - 471). Sin embargo, se puede afirmar que la Convención adquiere la calidad de "norma sobre trabajo". (Sentencia C-009, 1994) 
La Convención se equipara a un "pacto de paz" entre las partes por el cual se da finalización al conflicto laboral, beneficiando de manera recíproca a empleador y trabajadores, aunque con un claro fin protector del sector trabajador en un ejercicio de correlación de fuerzas. Así mismo, se puede considerar como a) instrumento de regulación de la oferta de trabajo y de protección de los trabajadores ante las presiones que sobre ellos puedan presentarse, b) forma de definición de las condiciones generales del trabajo, c) herramienta de cooperación entre las partes asociadas. d) Código industrial o método de regular los salarios y otras condiciones del empleo. (Sentencia C-1050, 2001)

Las garantías convencionales se circunscriben a periodos de tiempo, lo que permite la adaptación a las necesidades variables en las relaciones laborales, concibiéndose la posibilidad de las prórrogas o de la renegociación, a partir de la denuncia de la convención que se debe realizar dentro de los sesenta (60) días inmediatamente anteriores a la expiración de su término. (Ospina, 2013, pág. 279)

El valor de los acuerdos convencionales tiene además un criterio internacional, basado en los Convenios promulgados por la Organización Internacional del Trabajo - OIT. Sobre el particular, Colombia ha ratificado el Convenio 087 - Sobre la libertad sindical y la protección del derecho de sindicación, 1948, como también, el Convenio 098 - Sobre el derecho de sindicación y de negociación colectiva, 1949, Convenio 151 - Sobre las relaciones de trabajo en la administración pública, 1978, Convenio 154 - Sobre la negociación colectiva, 1981.

Es así, que la Convención Colectiva adquiere un importante lugar en el ejercicio del derecho de negociación, el cual es consustancial con el derecho de asociación sindical; tal como plantea la Corte Constitucional Colombiana, 
"su ejercicio potencializa y vivifica la actividad de la organización sindical, en cuanto le permite a ésta cumplir la misión que le es propia de representar y defender los intereses económicos comunes de sus afiliados, y hacer posible, real y efectivo el principio de igualdad, si se tiene en cuenta, que dicha organización, por su peso específico, queda colocada en un plano de igualdad frente al patrono. Se busca cumplir así la finalidad de 'lograr la justicia en las relaciones que surgen entre patronos y trabajadores, dentro de un espíritu de coordinación económica y equilibrio social"'. (Sentencia C-009, 1994)

Para el caso específico del hospital de Bosa II Nivel ESE y todas las demás ESE adscritas a la Secretaria Distrital de Salud de Bogotá - SDS-, las relaciones individuales y colectivas de trabajo con los Trabajadores Oficiales $^{7}$, se rigen mediante la Convención Colectiva, que se suscribiera desde el 1 de enero de 2012 hasta el 31 de diciembre de 2016.

Esta Convención garantizó a dichos Trabajadores Oficiales, además de las condiciones que regirán los contratos de trabajo, beneficios en torno a la jornada de trabajo (de 44 horas semanales), la calidad de trabajador oficial, la reclasificación y nivelación de cargos, ascensos, incrementos salariales, subsidios y primas extralegales (subsidio de alimentación, auxilio de transporte, quinquenios, prima de antigüedad, pago por trabajo en zonas rurales, prima de servicios por 40 días de

\footnotetext{
${ }^{7}$ Conforme el Decreto 1848 DE 1969, se consideran Trabajadores oficiales a todos aquellos que prestan sus servicios a los ministerios, departamentos administrativos, superintendencias, establecimientos públicos, unidades administrativas especiales, empresas industriales o comerciales de tipo oficial y sociedades de economía mixta, "en la construcción y sostenimiento de las obras públicas, con excepción del personal directivo y de confianza que labore en dichas obras"; y los que prestan sus servicios en establecimientos públicos organizados con carácter comercial o industrial, en las empresas industriales o comerciales del Estado y sociedades de economía mixta. (Decreto 1848, 1969)
} 
salario, prima de vacaciones, prima de navidad), bienestar social (capacitación y estímulos para la educación), entre otras.

Es necesario tener presente que las negociaciones tras los conflictos colectivos suscitados entre las ESE (Hospitales) adscritos a la Secretaría Distrital de Salud de Bogotá y sus Trabajadores Oficiales se han promovido desde el año 1995, para finalmente recopilar todo el proceso de negociación en la última Convención con vigencia hasta el 31 de diciembre de 2016.

Desde los parámetros del derecho colectivo y del reconocimiento de los derechos de negociación colectiva y asociación sindical, el desarrollo de esta Convención es el reflejo del pacto entre la Secretaría Distrital de Salud, las ESE que conforman la Red Pública del Distrito Capital y los Trabajadores Oficiales, en un compromiso por las buenas relaciones laborales, en un sector tan importante como el de la salud al servicio de los habitantes de Bogotá, en el marco del proceso de asegurar el goce efectivo del derecho fundamental a la salud a través de un modelo de salud humanizado, participativo, integral e incluyente.

La siguiente tabla representa distribución del plan de cargos del Hospital Bosa II Nivel con corte al último trimestre del año 2015. 
Tabla 13. Plan cargos 2015. Hospital Bosa II Nivel - ESE

\begin{tabular}{|c|c|c|c|c|}
\hline $\begin{array}{c}N^{\circ} \text { DE } \\
\text { CARGOS }\end{array}$ & DENOMINACIÓN DEL EMPLEO & JORNADA & VACANTES & ACTIVOS \\
\hline & \multicolumn{4}{|l|}{ NIVEL DIRECTIVO } \\
\hline 1 & Gerente Empresa Social del Estado & 8 & 0 & 1 \\
\hline 3 & Subgerente & 8 & 0 & 3 \\
\hline \multirow[t]{3}{*}{2} & Jefe de Oficina & 8 & 0 & 2 \\
\hline & TOTAL & & 0 & 6 \\
\hline & \multicolumn{4}{|l|}{ NIVEL ASESOR } \\
\hline \multirow[t]{3}{*}{1} & Asesor & 8 & 0 & 1 \\
\hline & TOTAL & & 0 & 1 \\
\hline & \multicolumn{4}{|l|}{ NIVEL PROFESIONAL } \\
\hline 25 & Médico Especialista & 4 & 13 & 12 \\
\hline 9 & Médico Especialista & 8 & 2 & 7 \\
\hline 15 & Médico General & 4 & 6 & 9 \\
\hline 4 & Médico General & 8 & 0 & 4 \\
\hline 5 & $\begin{array}{l}\text { Profesional Universitario Área Salud } \\
\text { (Bacteriólogas) }\end{array}$ & 8 & 2 & 3 \\
\hline 11 & Enfermero & 8 & 3 & 8 \\
\hline 1 & Profesional Especializado, VAC TEM & 8 & 1 & 0 \\
\hline 1 & Profesional Universitario & 8 & 0 & 1 \\
\hline 1 & Tesorero General & 8 & 0 & 1 \\
\hline 5 & Profesional Universitario & 8 & 0 & 5 \\
\hline 1 & Profesional Universitario & 8 & 0 & 1 \\
\hline \multirow[t]{3}{*}{1} & $\begin{array}{l}\text { Profesional Universitario Área Salud, } \\
\text { Nutricionista }\end{array}$ & 8 & 0 & 1 \\
\hline & TOTAL & & 27 & 52 \\
\hline & \multicolumn{4}{|l|}{ NIVEL TÉCNICO } \\
\hline 2 & Técnico Operativo, Nómina y Costos & 8 & 1 & 1 \\
\hline 1 & Técnico Operativo & 8 & 0 & 1 \\
\hline 1 & Técnico Operativo & 8 & 0 & 1 \\
\hline 1 & Técnico Operativo & 8 & 1 & 0 \\
\hline 1 & Técnico Administrativo & 8 & 0 & 1 \\
\hline 1 & Técnico Operativo & 8 & 0 & 1 \\
\hline \multirow[t]{3}{*}{4} & Técnico área Salud, Instrumentadoras & 8 & 1 & 3 \\
\hline & TOTAL & & 3 & 8 \\
\hline & \multicolumn{4}{|l|}{ NIVEL ASISTENCIAL } \\
\hline 1 & Secretario Ejecutivo & 8 & 0 & 1 \\
\hline 4 & Secretario, 1 vacante temporal & 8 & 1 & 3 \\
\hline 1 & Auxiliar Administrativo & 8 & 0 & 1 \\
\hline
\end{tabular}




\begin{tabular}{|c|c|c|c|c|}
\hline 4 & Auxiliar Administrativo & 8 & 1 & 3 \\
\hline 1 & Auxiliar Administrativo & 8 & 0 & 1 \\
\hline 4 & Auxiliar Administrativo, Radio & 8 & 0 & 4 \\
\hline 1 & Auxiliar Administrativo & 8 & 0 & 1 \\
\hline 4 & Auxiliar Área Salud, Estadística & 8 & 2 & 2 \\
\hline 1 & Auxiliar Área Salud & 8 & 1 & 0 \\
\hline 4 & Auxiliar Área Salud, Farmacia & 8 & 2 & 2 \\
\hline 2 & Auxiliar Área Salud, Aux. Laboratorio & 8 & 1 & 1 \\
\hline \multirow[t]{3}{*}{48} & $\begin{array}{l}\text { Auxiliar Área Salud, Aux. Enfermería, } \\
\text { en las vacantes va incluida } 1 \text { vac temp, }\end{array}$ & 8 & 22 & 26 \\
\hline & TOTAL & & 30 & 45 \\
\hline & \multicolumn{4}{|l|}{ TRABAJADORES OFICIALES } \\
\hline 11 & Conductor & 8 & 4 & 7 \\
\hline 15 & Operario Servicios Generales & 8 & 8 & 7 \\
\hline 1 & Operario Servicios Generales & 8 & 0 & 1 \\
\hline \multirow[t]{2}{*}{7} & Camillero & 8 & 3 & 4 \\
\hline & TOTAL & & 15 & 19 \\
\hline 206 & GRAN TOTAL & & 75 & 131 \\
\hline
\end{tabular}

Fuente: Oficina jurídica. Hospital de Bosa II Nivel ESE. 2015

Es así como el talento humano del Hospital se encuentra dividido en porcentajes de $17 \%$ área administrativa y $83 \%$ área asistencial, dentro de esta última se cuenta con 34 cargos de trabajadores oficiales -TO-, de los cuales sólo 23 se tienen provistos, correspondiendo todos al nivel jerárquico asistencial.

Los perfiles de los 23 TO están divididos en siete (7) conductores, cinco (5) camilleros y once (11) operarios de servicios generales, la disyuntiva entre la correcta aplicación del PSFF y la consecuente reforma de la planta de personal nace del resguardo que poseen estos 23 trabajadores por estar amparados por los acuerdos convencionales, esto sugiere, efectivamente, que ellos cuentan con 
condiciones laborales especiales frente a las de los empleados públicos, permitiéndoles acceder a factores salariales y prestaciones sociales adicionales 0 en valor superior con respecto a las de un empleado público. (Hospital de Bosa II Nivel ESE, 2014)

Por todo lo anterior, el Hospital Bosa II Nivel ESE consideró que dentro de su PSFF debían contemplarse medidas que disminuyeran los " altos costos de la planta de personal" debido a las condiciones establecidas en la Convención Colectiva de Trabajo, en los empleados con régimen de cesantías retroactivas y la programación de trabajo nocturna del personal asistencial del Hospital.

Concretamente, en lo atinente a los trabajadores oficiales se contempló como una medida de fortalecimiento de los ingresos dentro del PSFF, el "apalancamiento ${ }^{8}$ con subsidio mediante convenio", del valor en nómina de estos perfiles de trabajadores oficiales, lo que implica generar un convenio interadministrativo o cualquier otro acto administrativo proferido por la Secretaria Distrital de Salud que apalanque el financiamiento parcial del valor en nómina de estos trabajadores por un periodo de dos años, bajo los siguientes parámetros:

- Subsidio Total: Valor requerido para el pago correspondiente a 7 perfiles de trabajadores oficiales que el hospital no requiere para el correcto funcionamiento de los servicios.

\footnotetext{
${ }^{8}$ Término económico que hace referencia a la acción y efecto de apalancar. El apalancamiento, multiplicador de recursos o leverage es la expresión del efecto que produce un hecho concreto sobre el riesgo y el grado de variabilidad de los resultados de una empresa. Hay cuatro tipos de apalancamientos. Dos de ellos, el financiero -ligado a la estructura capital-, y el operativo - condicionado por estructura de costes o relación entre costes variables y costes fijos-, se consideran estructurales. Por el contrario, el de producción y el de marketing -relacionados con el crecimiento del hospital-, se consideran dinámicos. (Varo, 1994)
} 
- Subsidio parcial: Valor solicitado para el pago correspondiente a los 16 perfiles de trabajadores oficiales que contribuyen con las funciones de carácter misional de la entidad (Camilleros, Conductores y Auxiliares de Lactario y Nutrición). Vale anotar, que el Hospital, para estos 16 perfiles asumiría el valor equivalente al que tendría el mismo perfil si desempeñara sus actividades a través de otra modalidad de vinculación y para el excedente del valor en nómina solicitaría subsidio en atención a que son perfiles indispensables para el adecuado funcionamiento de los servicios de la ESE. " (Hospital de Bosa II Nivel ESE, 2014)

Según la ESE, los recursos provendrían del Programa de Saneamiento Fiscal y Financiero, que estarían inscritos en el convenio interadministrativo u otro acto administrativo, por "la suma total de $\$ 1.312 .852 .332$ que serían aplicados a las vigencias 2015 y 2016 y que permitirian financiar los gastos de nómina de trabajadores oficiales por el mismo valor. La aplicación de esta medida, permitiría que el hospital, para el año 2015 financiara en alguna medida su déficit corriente y para el año 2016 lograra cerrar la operación con un equilibrio financiero sólido." (Hospital de Bosa II Nivel ESE, 2014)

e allí que la ESE al obtener el "Financiamiento parcial del gasto generado por la operación de los Trabajadores Oficiales con Recursos del Programa de Saneamiento Fiscal y Financiero", protegiera los acuerdos pactados en la Convención (artículo 89) manteniendo su obligación de dar "estricto e inmediato cumplimiento a lo pactado". (ESE - SINTRASALUD - AGRECONDUCTORES SINDISTRITALES, 1995 - 2016) 
en $\mathrm{Si}$ bien se mantienen las condiciones garantistas de la Convención, que son además una obligación, la ESE soportaría financieramente las dificultades de orden económico, mientras generaba nuevas condiciones de solidez. A su vez, podría plantear a los TO la posibilidad de una nueva negociación, tras la terminación de la vigencia de la Convención, que expira el 31 de diciembre de 2016, lo que permitiría presentar la denuncia de la convención en aras de generar un nuevo conflicto colectivo, que permitiera negociar las mejores condiciones de trabajo, conforme la situación real de la entidad.

Sin embargo en la revisión del documento monitoreo correspondiente al III trimestre de 2015 se evidencia que:

"La calificación del riesgo del hospital obedece a una situación generalizada de déficit operacional, que en los años anteriores requirió la participación del ente territorial en su financiación a través de convenios. Los resultados fiscales históricos, con el seguimiento de la vigencia 2015 en cuanto a los ingresos por venta de servicios, como en el déficit generado y los montos recibidos por convenios" (Hospital de Bosa II Nivel - ESE, 2015)

Tabla 14 Déficit histórico generado en la operación corriente (en millones de pesos)

\begin{tabular}{|c|c|c|c|c|c|c|c|c|}
\hline & \multicolumn{7}{|c|}{ DEFICIT HISTORICO GENERADO EN LA OPERACIÓN CORIENTE (En millones de pesOs) } \\
\hline & $\mathbf{2 0 0 8}$ & $\mathbf{2 0 0 9}$ & $\mathbf{2 0 1 0}$ & $\mathbf{2 0 1 1}$ & $\mathbf{2 0 1 2}$ & $\mathbf{2 0 1 3}$ & $\mathbf{2 0 1 4}$ & $\mathbf{2 0 1 5}$ a sept \\
\hline $\begin{array}{c}\text { RECAUDO VENTA DE } \\
\text { LA VIGENCIA }\end{array}$ & 13.340 & 12.968 & 15.119 & 12.262 & 9.622 & 10.787 & 10.994 & 9.890 \\
\hline DEFICIT GENERADO & -2.327 & 1.127 & 3.525 & -4.630 & -5.098 & -4.103 & -1.236 & -1.994 \\
\hline $\begin{array}{c}\text { FINANCIACION POR } \\
\text { CONVENIOS }\end{array}$ & 2.700 & 7.635 & 7.736 & 4.286 & 6.599 & 7.178 & 2.212 & 0 \\
\hline
\end{tabular}

Fuente: (Hospital de Bosa II Nivel - ESE, 2015) 
En las vigencias anteriores, a pesar de contar con recursos de convenios, se generó déficit. A partir del año 2011 se presentó una baja significativa en la venta de servicios por la unificación del POS que incrementó el déficit en las vigencias siguientes. En la vigencia 2014 el valor de convenios se limita a la financiación de los aportes a través del Sistema General de Participaciones, sin embargo el déficit se redujo en un $70 \%$ en comparación con el año 2013 , vigencia en la cual ya se había reducido el déficit en un 19.5\% frente al 2012. Para el tercer trimestre de 2015 se presenta un déficit de $\$ 1.994$ millones, ocasionado por la dinámica de venta de servicios a crédito y compromiso anticipado en el gasto.

Como resultado del análisis se destaca la dificultad presentada para alcanzar las metas de recaudo de la vigencia.

En cuanto a los gastos se presenta un mayor valor de compromiso frente a lo programado en gastos variables de funcionamiento y de operación, por efecto de mayores valores en gastos no previstos y que no están financiados dentro del PSFF, por ajuste en el valor del contrato de especialistas, profesionales asistenciales y administrativos, servicios técnicos y auxiliares, cuyos valores de contrato se encontraban por fuera los valores de mercado y adicionalmente la administración contaba con múltiples solicitudes efectuadas por los contratistas quienes requerían el aumento argumentando llevar muchos años sin ajuste alguno en sus honorarios y anunciaban su retiro masivo de la prestación de servicios en el hospital, a lo anterior también se sumó el incremento salarial aprobado para empleados públicos equivalente a un $5,16 \%$ porcentaje superior al estimado en el PSFF que fue del $3 \%$.

Al cierre de septiembre de 2015 los resultados del recaudo de la venta de servicios de la vigencia presenta un nivel insuficiente para alcanzar los niveles previstos en cuanto al equilibrio y sostenibilidad, sobre todo teniendo en cuenta que no se alcanza la efectividad de las medidas para la disminución de los costos y gastos, el 
mejoramiento de los niveles de producción y por consiguiente de los montos de facturación. Se alcanzó un nivel de recaudo de la vigencia del $82 \%$, que no es suficiente para financiar los compromisos del gasto. En Población Pobre no Asegurada, el FFDS ha generado recursos por encima de la facturación que van a generar un nuevo pasivo al cierre de la vigencia y afectan el indicador total de recaudo por venta de servicios.

La situación de dificultades para el recaudo, originadas en las prácticas de la EAPB que atrasan significativamente el cumplimiento de las metas, ocasionan que el déficit sea mayor al proyectado en el programa. Aun cuando el equilibrio está programado que se alcance en el año 4 del Programa, se ha solicitado al ente territorial la orientación para efectuar ajustes al Programa de Saneamiento viabilizado, para las vigencias 2015 y subsiguientes, particularmente con relación a las estrategias diseñadas con los demás hospitales de la Subred, el cumplimiento y estabilidad de los acuerdos con los pagadores y la ocurrencia de gastos no previstos, como sentencias judiciales, incrementos en los costos mayores a las estimaciones, como es el caso de los gastos de nómina, quinquenios y otros gastos generados por el cumplimiento de normas como la implementación de Normas Internacionales de Información Financiera, Normas de Calidad y avance en la Acreditación, de seguridad del paciente, entre otras. (Hospital de Bosa II Nivel ESE, 2015)

Desde esta perspectiva y ante la situación del Hospital de Bosa II Nivel ESE, de categorización "en riesgo" (medio-alto), es deber tanto de la entidad como de sus trabajadores, buscar las mejores alternativas de solución que permitan que la entidad asegure la continuidad en la prestación del servicio público de salud, teniendo en cuenta que el principio de sostenibilidad, enmarcado en un modelo de demanda propio de la idea de mercado, entra en contradicción con los postulados 
al derecho a la salud, donde debe primar por sobre todo el ser humano y la vida, pero que en la actualidad, por las disposiciones legales y las políticas económicas puede terminar intervenido y en liquidación afectando no solamente al sector trabajador, sino a los usuarios y población más vulnerable.

Lo anterior, observando que a pesar del apalancamiento para el año 2015, del valor del gasto en nómina de este grupo minoritario objeto de nuestro análisis y de la implementación de las demás medidas planteadas por la ESE en el PSFF, el cumplimiento de metas de las mismas no se ha logrado en un porcentaje suficiente que lleve al Hospital a obtener la sostenibilidad financiera debido a la desarticulación de los demás actores del sistema y el cumplimiento de sus obligaciones normativas como son el pago oportuno de las EPS por los servicios que le presta el Hospital a sus afiliados, situación que lleva a la inviabilidad del programa de saneamiento fiscal y financiero planteado inicialmente por el Hospital Bosa II Nivel ESE.

La situación de sostenibilidad financiera del Hospital Bosa II Nivel ESE no está determinada por las condiciones especiales de las cuales gozan los trabajadores oficiales sino que ésta inviabilidad se circunscribe a los factores externos de incumplimiento de norma que en la actualidad son insuperables hasta tanto no se de una reforma estructural al Sistema de Salud que conmine a las EPS a reconocer los servicios prestados por los Hospitales y a cumplir con sus compromisos sin mayores dilaciones permitiendo de esta forma un flujo de caja constante y con tarifas acordes a los costos de la prestación de una IPS pública. 


\section{CONCLUSIONES}

La crisis del Sistema General de Seguridad Social en Salud - SGSSS, se ha convertido en un problema de orden social de gran envergadura que involucra a muchos actores, instituciones y entidades en pro de formular alternativas de solución que promuevan realmente el respeto por el derecho a la salud, desde parámetros no solamente económicos, sino desde el reconocimiento de un modelo en pro de la vida desde la humanización.

Por esta razón, resulta importante la intervención gubernamental que a través de un variado y prolífico paquete de normas, busque garantizar la continuidad de los procesos y el sostenimiento del sistema. De allí, que normativas como la de categorización del riesgo de las Empresas Sociales del Estado, puedan extenderse con tal rigurosidad a los demás actores del SGSSS y así se conviertan en una oportunidad para revisar de fondo las entidades y promulgar nuevos procesos enmarcados en lo financiero pero a su vez, en los criterios sociales que han mantenido vigentes los hospitales públicos, como entidades emblemáticas en la prestación del servicio de salud en la ciudad capital.

En el caso del Hospital de Bosa II Nivel ESE y los demás hospitales de la red, se observa un valioso esfuerzo por lograr su sostenibilidad y cumplir a cabalidad con las exigencias legales y los parámetros de seguimiento y evaluación de entidades como el Ministerio de Hacienda y Crédito Público y la Superintendencia Nacional de Salud. Si bien las medidas o estrategias se enmarcan en lineamientos económicos, también es posible visibilizar en los PSFF los aspectos de carácter social que promulgan por la prestación de un servicio bajo un "modelo de salud humanizado, 
participativo, integral e incluyente", que basado en la organización de los servicios estatales en red, permita de manera muy precisa modificar las condiciones que determinan la calidad de vida y la salud de la población del Distrito Capital. (Secretaria Distrital de Salud, 2012)

De esta forma, aunque se evidencie la tensión estructural que posee el sistema de salud actual, bajo la premisa del mercado en un enfoque de demanda, se logra a partir del análisis de los PSFF, visibilizar las alternativas de solución desde parámetros de equilibrio.

Para el caso en estudio del PSFF del Hospital de Bosa II Nivel - ESE, la implementación de su paquete de medidas es una muestra clara de la intención de la entidad de promover un proceso de mejoramiento continuo y de estudiar a fondo la realidad misma de la institución. El Programa, permitió analizar la situación real a nivel social, económico y político de relación de la ESE con su personal de Trabajadores Oficiales, hasta el punto de reconocer su importancia y valor, al ser el grupo de trabajadores beneficiado por la Convención Colectiva vigente. Una Convención que da cuenta de un serio proceso de negociación y que exige el reconocimiento del ejercicio mismo del derecho de sindicalización y negociación colectiva, conforme los postulados internacionales, convenios y normativas nacionales.

Sin embargo, la realidad presenta una situación difícil frente a la categorización de la ESE de Bosa, como hospital "en riesgo" (medio-alto) lo que afecta de manera directa no solamente a la entidad como tal, sino a su personal. Porque de ser intervenido o liquidado el hospital, los más seriamente lesionados son los trabajadores y a la vez, los usuarios. Por esta razón, pensar en una medida de 
"Financiamiento parcial del gasto generado por la operación de los Trabajadores Oficiales con recursos del Programa de Saneamiento Fiscal y Financiero", se convierte en una estrategia valida, donde la ESE en convenio interinstitucional con la Secretaria de Salud, de manera coordinada podrán hacer más llevadera la carga y beneficios que les corresponde cumplir con los Trabajadores Oficiales.

Pero a la vez, esta situación lleva a replantear la necesidad de llegar a acuerdos con los trabajadores, pensando en la expiración de la vigencia de la Convención Colectiva, el 31 de diciembre de 2016, lo que permitiría generar una nueva negociación partiendo de ajustar las relaciones laborales del trabajo a las necesidades actuales desde acuerdos y concertaciones basadas en un dialogo social, que de forma articulada entre las ESE, la Secretaria de Salud del Distrito y los Trabajadores Oficiales permita reconocer y garantizar los derechos de las partes.

Finalmente, frente al principio de sostenibilidad este está planteado desde el año 1993, hoy 23 años después, la normativa en torno al tema de la salud en Colombia ratifica dicho postulado, y mantiene en la realidad el modelo de mercado, de costobeneficio, en contraposición de la garantía del derecho. Bajo la lógica de servicio público esencial, de viabilidad financiera, los hospitales debieron adaptarse, para poder subsistir y muchos de ellos lo lograron a costa de recortar servicios que significaban altos costos de atención, circunstancia que llevan a entender que el "ajuste" de las entidades está estrechamente relacionado con la capacidad de vincularse y responder a los retos de la competitividad, antes que a la protección del derecho a la salud. 
Esto lleva a plantear que un proceso de continuidad de las ESE, bajo el modelo actual, se debe circunscribir a una serie de criterios donde primará lo financiero por encima del derecho. Subsiste la ESE, pero su misión y su objetivo principal, que consiste en brindar salud a quien lo necesita resultan limitado.

Por ello resulta importante indicar que en definitiva se requiere la intervención de la rama legislativa a fin de lograr una reforma de fondo que propenda por la garantía para los Hospitales Públicos de una prestación de servicios adecuada y oportunamente compensada, de tal suerte que se permita a las ESE concentrarse en su objeto misional mientras las condiciones de sostenibilidad financiera estén garantizadas por el Estado a través de una seguridad jurídica eficiente. 


\section{BIBLIOGRAFÍA}

Benach, J., Muntaner, C., Solar, O., Santana, V., \& Quinlan, M. (2010). Empleo, trabajo y desigualdades en salud: Una visión global. España: Herder Editorial S.A.

ESE - SINTRASALUD - AGRECONDUCTORES - SINDISTRITALES. (1995 - 2016). CONVENCIÓN COLECTIVA DE TRABAJO. Bogotá, Colombia.

Gandarilla Salgado, J. (2003). Globalización, totalidad e historia. Argentina: Ediciones Herramienta.

Garzón, E. (2014). Estudios sobre investigaciones en salud en Colombia. Bogotá: Universidad La Gran Colombia.

Guzman Finol, K. (2014). Radiografía de la oferta de servicios de saluda en Colombia. Documentos de Trabajo sobre Economía Regional.

Hospital Bosa II Nivel ESE. (2013). Programa de Saneamiento Fiscal y Financiero y de Fortalecimiento Institucional 2013-2017. Bogotá.

Hospital de Bosa II Nivel - ESE. (2015). Monitoreo III Trimestre 2015. Bogotá.

Hospital de Bosa II Nivel ESE. (2012). Programa de Saneamiento Fiscal y Financiero y de Fortalecimiento Institucional 2013 -2017. Bogotá.

Hospital de Bosa II Nivel ESE. (2014). Documento Técnico. Medida de apalancamiento con subsidio mediante convenio. Bogotá.

Hospital de Meissen ESE. (2013). Programa de Saneamiento Fiscal y Financiero. Bogotá.

Hospital San Blas II NIvel. (2013). Programa de Saneamiento Fiscal y Financiero Hospital San Blas II Nivel. Bogotá.

Legis. (2013). Cartilla de seguridad social y pensiones 2013. Bogotá: Legis.

Ministerio de Hacienda Y Crédito Público. (s.f.). Guía metodológica para la elaboración del programa de saneamiento fiscal y financiero y de fortalecimiento institucional de las Empresas Sociales del Estado. Bogotá: Imprenta Nacional.

Ministerio de Salud y Protección Social. (2014). Informe Informe al Honorable Congreso de la República 2010-2014 y 2013-2014 Sector administrativo de salud y protección social. Bogotá: Ministerio de Salud y Protección Social. 
Naranjo, L. D., \& Garzón Peña, E. (2010). La Salud en Colombia. Análisis sociojurídico del proceso privatizador. Bogotá: Ediciones Ciencia y Derecho.

Núñez, J., Zapata, J., Castañeda, C., Fonseca , M., \& Ramírez, J. (2012). La sostenibilidad financiera del Sistema de Salud Colombiano. Dinámica del gasto y principales retos de cara al futuro. Bogotá: FEDESARROLLO.

Ospina, E. (2013). Derecho Colectivo del Trabajo. Bogotá: Panamericana Formas e Impresos S.A.

Petras, J. (2001). Imperialismo y Barbarie Global. Bogotá: Ediciones Pensamiento Crítico.

Salud al Derecho. (2007). La salud en Colombia después de la Ley 100 de 1993. Impacto del tratado de libre comercio Colombia-Estados Unidos en la salud de las y los colombianos. Material seriado. Bogotá, Colombia: EDITORIAL CÓDICE LTDA.

Salud al Derecho. (2009). El derecho a la salud en Colombia y el Sistema General de Seguridad Social en Salud - SGSSS- Ley 100 de 1993. Bogotá: Asociación Colombiana para la Exigibilidad del Derecho a la Salud y la Seguridad Social.

Varo, J. (1994). Gestión estratégica de la calidad en los servicios sanitarios: Un modelo de gestión hospitalaria. Madrid - España: Editorial Díaz de Santos. S.A.

\section{Leyes}

Acto Legislativo 01, 01 de 2005 (Presidencia de la República de Colombia 2005).

Decreto 1848, 1848 (Ministerio del Trabajo y la Seguridad Social 1969).

Decreto 1876, 1876 (Presidente de la República de Colombia 1994).

Ley 100, 100 de 1993 (Congreso de la República de Colombia 1993).

Ley 1393 , 1393 de 2010 (Congreso de la República de Colombia 2010).

Ley 1438, 1438 (Congreso de la República de Colombia 2011).

Ley 1608, 1608 (Congreso de la República de Colombia 2013).

Ley Estatutaria 1751, 1751 (Congreso de la República de Colombia 2015). 


\section{Resoluciones}

Resolución 1877, 1877 (Ministerio de Salud y Protección Social 2013).

Resolución 1893, 1893 de 2015 (Ministerio de Salud y Protección Social 2015).

Resolución 2090, 2090 (Ministerio de Salud y Protección Social 2014).

\section{Jurisprudencia}

Sentencia C-009, 009 (Corte Constitucional 20 de Enero de 1994).

Sentencia C-1050, 1050 (Corte Constitucional Colombiana 4 de Octubre de 2001).

Sentencia C-902, 902 (Corte Constitucional Colombiana 7 de Octubre de 2003).

\section{Cibergrafia}

Banco Interamericano de Desarrollo. (2015). http://idbdocs.iadb.org/. Obtenido de Apoyo a la reforma del sistema general de seguridad social en salud: http://idbdocs.iadb.org/wsdocs/getdocument.aspx?docnum=37834608

Ministerio de Hacienda y Crédito Público. (s.f.). Guia metodologíca para la elaboración del programa de saneamiento fiscal y financiero y de fortalecimiento institucional de las Empresas Sociales del Estado. Bogotá.

Ministerio de Hacienda Y Crédito Público. (s.f.). Guía metodológica para la elaboración del programa de saneamiento fiscal y financiero y de fortalecimiento institucional de las Empresas Sociales del Estado. Bogotá: Imprenta Nacional.

Ministerio de Salud y Protección Social. (2014). Informe Informe al Honorable Congreso de la República 2010-2014 y 2013-2014 Sector administrativo de salud y protección social. Bogotá: Ministerio de Salud y Protección Social. 
Naranjo, L. D., \& Garzón Peña, E. (2010). La Salud en Colombia. Análisis sociojurídico del proceso privatizador. Bogotá: Ediciones Ciencia y Derecho.

Núñez, J., Zapata, J., Castañeda, C., Fonseca , M., \& Ramírez, J. (2012). La sostenibilidad financiera del Sistema de Salud Colombiano. Dinámica del gasto y principales retos de cara al futuro. Bogotá: FEDESARROLLO.

ORGANIZACIÓN INTERNACIONAL DEL TRABAJO - OIT. (2015). ilo.org. Obtenido de http://www.ilo.org/

Organización Internacional del Trabajo OIT. (2015). http://www.ilo.org. Obtenido de http://www.ilo.org/public/spanish/index.htm

Revista Opinión\&Salud.com. (22 de julio de 2013). http://www.opinionysalud.com/destacados/item/7056-la-critica-saludfinanciera-de-los-hospitales-publicos. Obtenido de http://www.opinionysalud.com

Revista Razón y Palabra. (Abril de 2011). www.razonypalabra.org.mx. Obtenido de Revista Electrónica en América Latina Especializada en Comunicación. Libros Básicos en la historia del Campo Iberoamericano de Estudios en Comunicación: www.razonypalabra.org.mx

Secretaria Distrital de Salud. (2012). Saludcapital.gov.co. Obtenido de ndición\%20de\%20Cuentas\%202012/EJE\%201\%20PLAN\%20DE\%20DESA RROLLO\%20BOGOTÁ\%20HUMANA.pdf 